University of Louisville

ThinkIR: The University of Louisville's Institutional Repository

Electronic Theses and Dissertations

$5-2021$

\title{
Principal mentoring as a retention and effectiveness strategy in comprehensive improvement schools.
}

\author{
Robert Fulk \\ University of Louisville
}

Follow this and additional works at: https://ir.library.louisville.edu/etd

Part of the Elementary and Middle and Secondary Education Administration Commons

\section{Recommended Citation}

Fulk, Robert, "Principal mentoring as a retention and effectiveness strategy in comprehensive improvement schools." (2021). Electronic Theses and Dissertations. Paper 3587.

https://doi.org/10.18297/etd/3587

This Doctoral Dissertation is brought to you for free and open access by ThinkIR: The University of Louisville's Institutional Repository. It has been accepted for inclusion in Electronic Theses and Dissertations by an authorized administrator of ThinkIR: The University of Louisville's Institutional Repository. This title appears here courtesy of the author, who has retained all other copyrights. For more information, please contact thinkir@louisville.edu. 


\title{
PRINCIPAL MENTORING AS A RETENTION AND EFFECTIVENESS STRATEGY IN COMPREHENSIVE IMPROVEMENT SCHOOLS
}

\author{
Robert Fulk \\ B.A, University of Louisville, 2003 \\ M.Ed., University of Louisville 2006 \\ Ed.S., University of Louisville 2010
}

\begin{abstract}
A Dissertation
Submitted to the Faculty of the College of Education and Human Development of the University of Louisville in Partial Fulfillment of the Requirements

for the Degree of
\end{abstract}

Doctor of Education in Educational Leadership and Organizational Development

\author{
Department of Educational Leadership, Evaluation, \\ and Organizational Development \\ University of Louisville \\ Louisville, Kentucky
}

May 2021 
Copyright 2019 by Robert Stephen Fulk

All rights reserved 

PRINCIPAL MENTORING EFFECTS ON RETENTION OF COMPREHENSIVE IMPROVEMENT SCHOOLS PRINCIPALS

By

Robert Stephen Fulk

B.A, University of Louisville, 2003

M.Ed., University of Louisville 2006

Ed.S., University of Louisville 2010

University of Louisville

A Dissertation Approved on

December 17, 2020

by the following Dissertation Committee:

Dr. Mary Brydon-Miller

Dissertation Director

Dr. Keith Davis

Second Committee Member

Dr. Harrie Lynn Buecker

Third Committee Member

Dr. Paige Hartstern

Fourth Committee Member 


\section{DEDICATION}

To my wife Natalie who has put up with far too much schooling over the years and given me ample space to complete this work; thank you and I love you more than words can adequately convey.

To my daughters Brigid and Eleanor, and my son Atticus, you are so much to me. I am so proud of you all, now and for what you will become. You are in a book!

To my mother Suzanne, my father Stephen; thank you for giving me the foundation to better myself. To Jane and Jimmy, thank you for your years of kindness.

To Amon Amarth for hours of grinding metal to push this thing to completion.

To Leigh, Justin, Josh, Gavin, Dave, Karl, Jimmy, Joe, Jad, Matt, Erica, Heather, Jacqui, Jason, Eddie, and Craig; you all made it in, brothers and sisters.

Lastly, to Dr. Toetta Taul, Nicole Fields, and Dr. Jason Detre, thank you for standing with me all these years. 


\section{ACKNOWLEDGEMENTS}

I would like to thank the following professionals for their support and help with this dissertation, and professionally over the years. To Dr. Hartstern, Dr. Davis, and Dr. Buecker; thank you for your mentorship and friendship through the years. All three of you have served as fine examples of the educator I want to become. Dr. Hartstern for your exceptional poise, Dr. Davis for your acerbic approach to the work, and Dr. Buecker for your unflappable kindness.

To the \#Block20 cohort I am truly in your debt for the camaraderie, assistance, and motivation during this doctoral journey.

To Dr. Meyer, Ms. Rogers, Ms. Morales, Ms. Hosch, Dr. Hogue, Ms. Johnson, Ms. McDowell, Dr. Coleman, Mr. Perkins, Dr. Jury, Dr. Shearon, Dr. Hitchings, Ms. Morris Hunt, Mr. Courtney, Ms. Gregory, Ms. Gibbs, and Ms. Stroud- all of you have impacted my work and growth and made me a better educator. Thank you sincerely for all the support.

To Erica McClure, colleague of the highest order.

Lastly to Dr. Brydon-Miller; you held my hand through the process and I will always be in your debt. You are the epitome of a critical thinker, and a truly remarkable person. 


\title{
ABSTRACT \\ PRINCIPAL MENTORING AS A RETENTION AND EFFECTIVENESS STRATEGY IN COMPREHENSIVE IMPROVEMENT SCHOOLS
}

\author{
Robert Fulk
}

December 17, 2020

This qualitative study examines Comprehensive Improvement Schools (CSI) principals' experiences with mentoring programs and their perceptions of how such programs may mitigate administrative attrition. Semi-structured interviews were conducted with eight practicing CSI principals and the study utilized the pragmatic framework. The interviews captured principal's experiences with being a principal mentee during their first year of CSI principalship, and what actions or activities in their mentorships aided their retention in the position. The analysis suggested several recommendations for practice in principal mentoring programs to increase school leader retention.

At the heart of these recommendations was an emphasis on the importance of the trustbased relationship between the mentor and mentee and ample time for on- demand support from the mentor. Further nuanced recommendations were developed from the principals' experience and the body of literature regarding principal mentorship. These recommendations can be utilized by local school districts and state education departments to construct model principal mentoring programs. 


\section{TABLE OF CONTENTS}

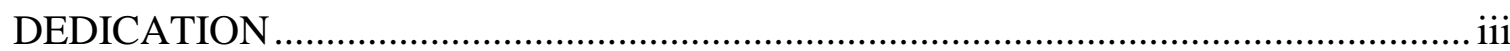

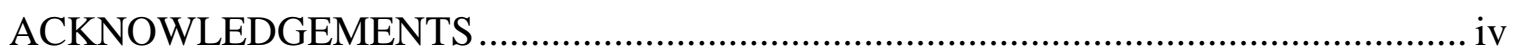

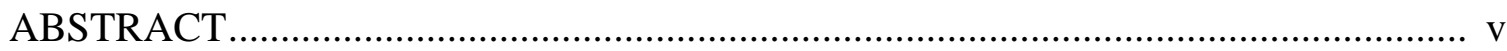

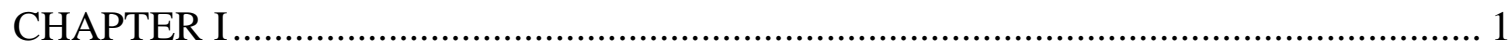

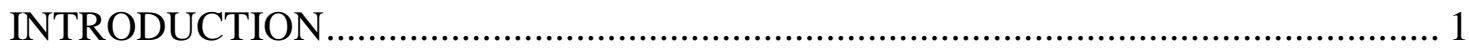

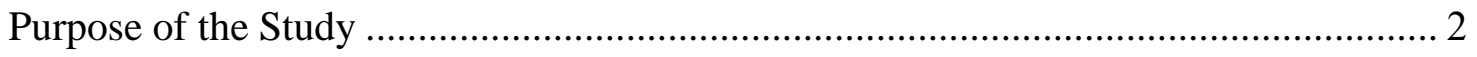

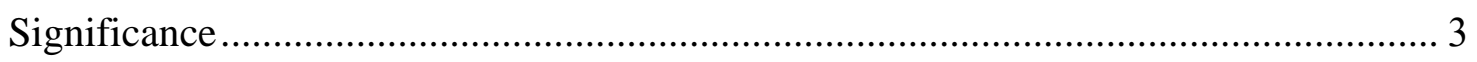

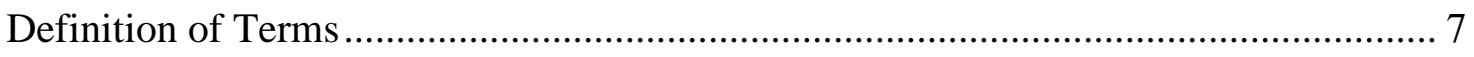

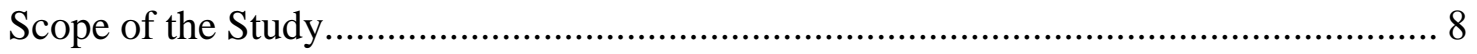

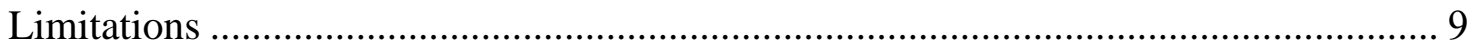

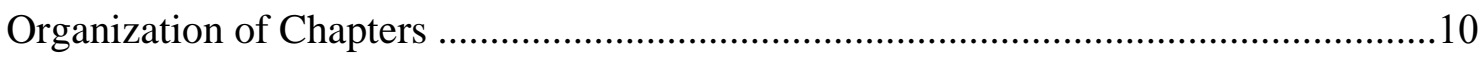

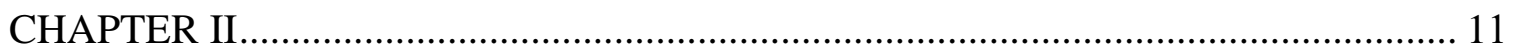

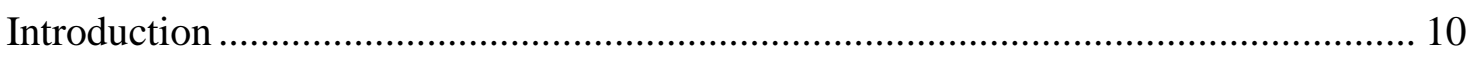

Functional definition of mentoring ................................................................ 19

Teacher mentoring effectiveness leading to principal mentoring practices .................. 20

History of principal mentoring ............................................................................... 23

Attributes of effective principal mentoring programs ................................................. 30

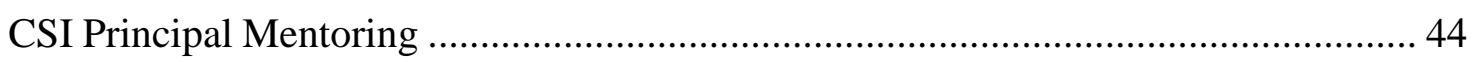

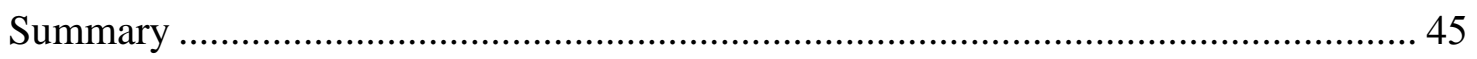

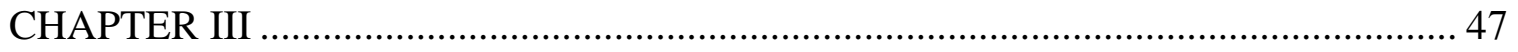

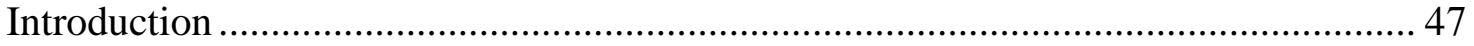

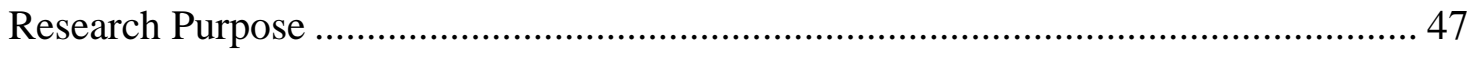

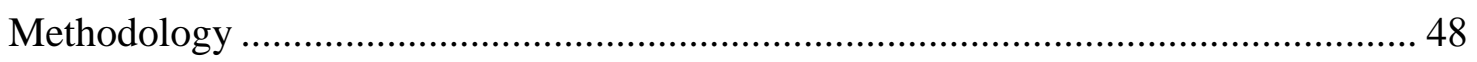

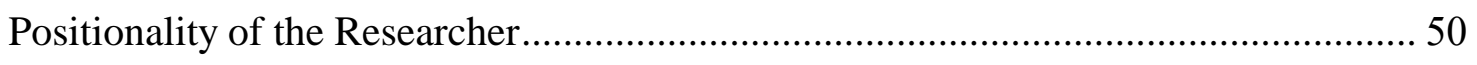

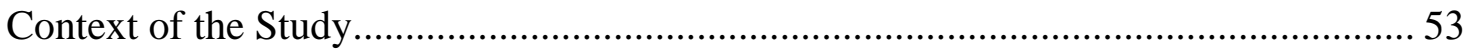

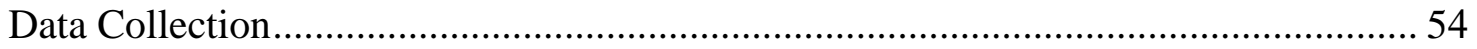

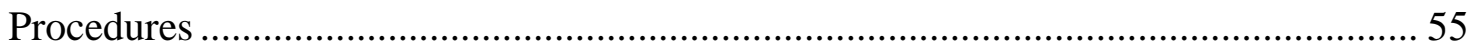




\section{TABLE OF CONTENTS CONTINUED}

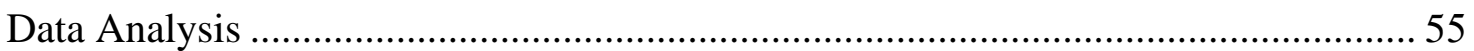

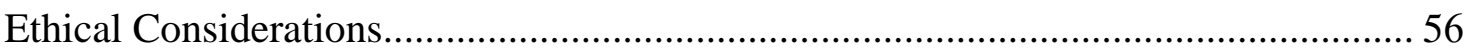

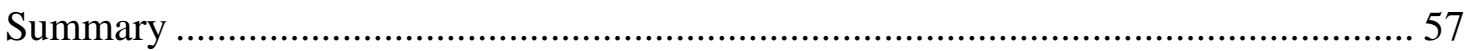

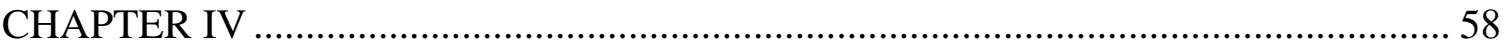

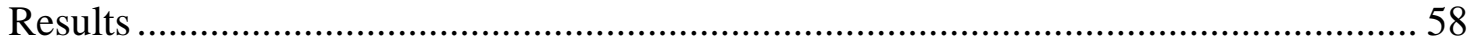

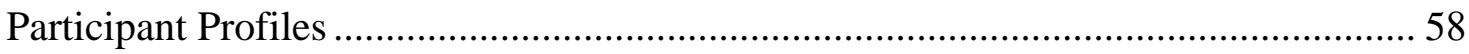

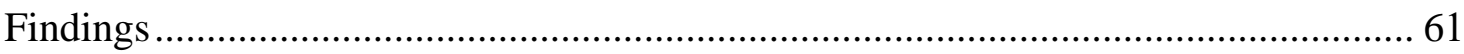

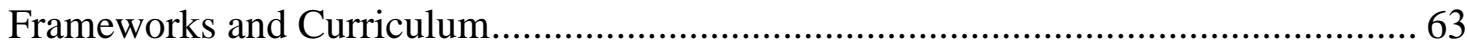

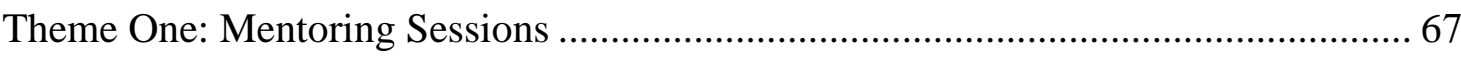

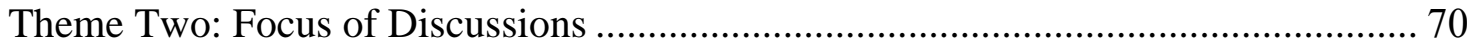

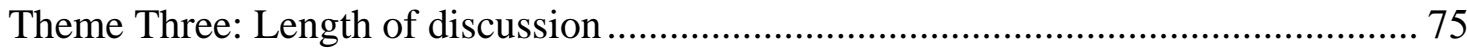

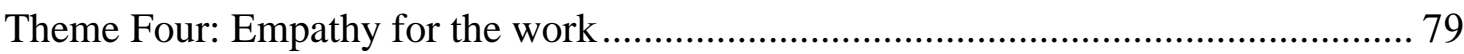

Theme Five: Clarification of roles and responsibilities ....................................... 82

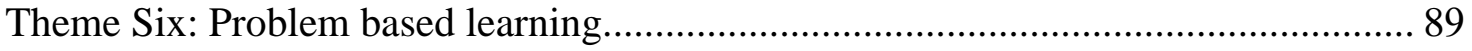

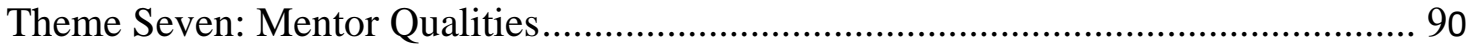

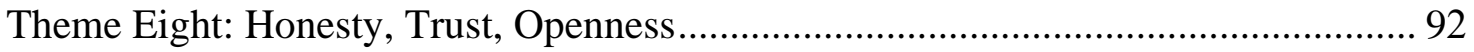

Theme Nine: Perceived and Demonstrated Effectiveness of the Mentor ................... 96

Theme Ten: Social position of the mentor in the district ....................................... 99

Theme Eleven: Disagreements with the mentor ................................................. 103

Theme Twelve: Contribution to success as a CSI principal................................... 106

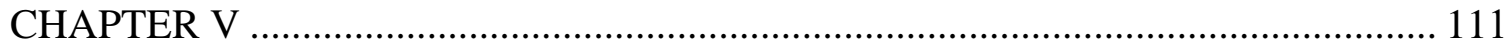

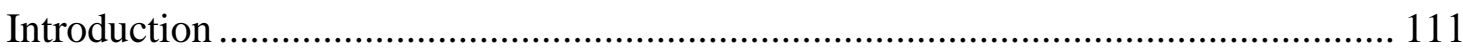

Contribution to success as a CSI principal ......................................................... 112

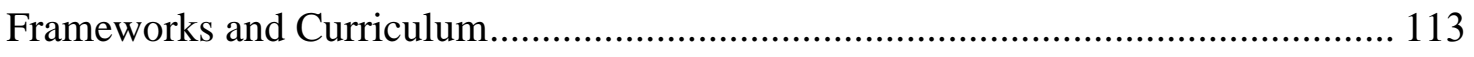

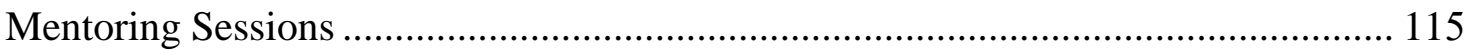

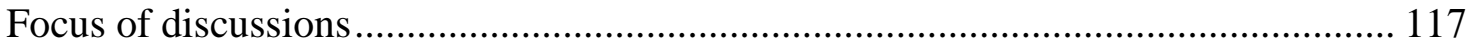

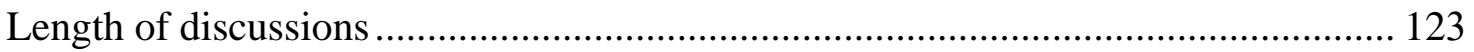

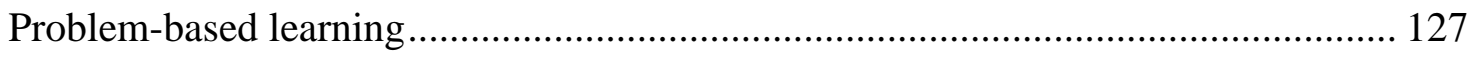

Mentor qualities: honesty, trust, openness ..................................................... 129 


\section{TABLE OF CONTENTS CONTINUED}

Social position of the mentor in the district ........................................................ 133

Recommendations for Future Practice .............................................................. 134

Recommendations for Future Research ......................................................... 143

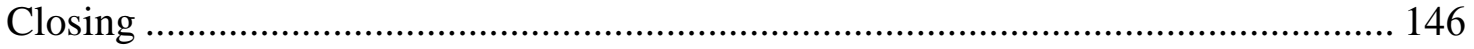

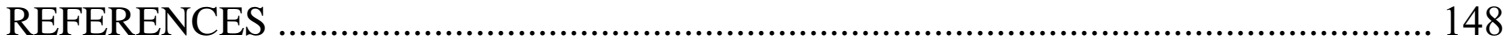

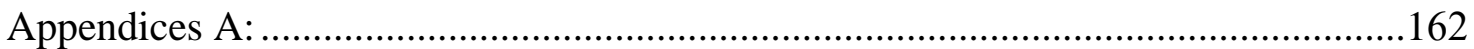

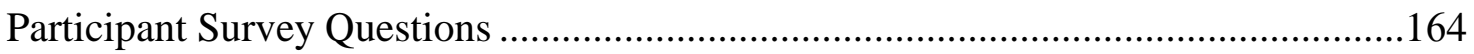

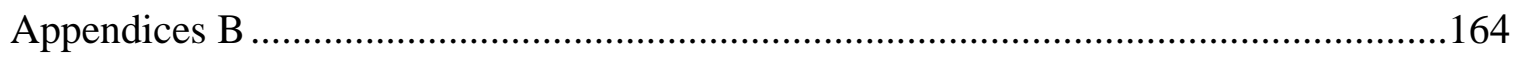

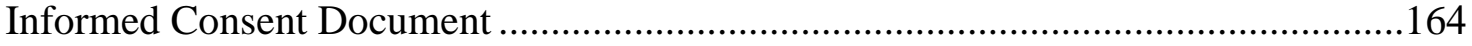

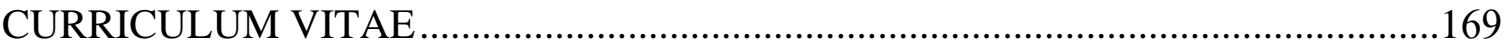




\section{CHAPTER I}

\section{INTRODUCTION}

High turnover in schools is not an outcome that schools or school districts seek. Retention of newly appointed school leaders benefits districts that have invested time and capital into hiring new principals and applicants who have completed pre-service and committed financial capital to their specialized training. The principal's role is complex and demanding, with nearly $40 \%$ of new principals feeling unprepared for their first day in the role (Helber, 2015). Nearly one in six principals leave their school each year, and in Title I schools (schools exceeding a threshold of $41 \%$ free and reduced lunch students), this number is closer to one in five (Goldring, 2014). According to Goldring (2014) in the Principal Attrition and Mobility survey in 2016-17, the national average length of stay for a principal was under four years. Of those surveyed, $35 \%$ percent left within two years, and only eleven percent stayed over ten years.

Consistently identified as a primary driver for principals leaving the role is stress, specifically over the complexity and pace of the job (Daresh, 2001, 2004; Shoho \& Barnett, 2010). Turnover in Comprehensive Improvement Schools (CSI) is a particularly glaring issue in educational leadership. The preparation and retention of high-quality teachers and leaders are desirable outcomes for any school; CSI schools struggle more in comparison to non-CSI schools due to their complex needs, diverse student educational requirements, higher rates of poverty, and the significant increase in local, state, and federal oversight. 


\section{Purpose of the Study}

The purpose of this study is to examine Comprehensive Improvement Schools (CSI) principals' experiences with mentoring programs and their perceptions of how such programs may mitigate administrative attrition. The principals' lived experiences will be further analyzed for themes to increase understanding of what works and what does not work in administrative mentoring programs. This analysis will render a broader understanding of principal mentoring and how it can increase novice principals' effectiveness.

There has been significant research into the reasons educators, from teachers to administration, leave the profession and the actions administrators take to retain teachers, with a significant amount of research centered on the effectiveness of teacher mentorship. There exists a gap in the literature on the effectiveness of principal mentorship, and this study seeks to add to this body of literature. This study seeks to answer the research question: Are mentoring programs increasing CSI principals' retention and better preparing them for their assignment? This study matters because there is room for expansion of the literature in an analysis of CSI principals' retention, specifically through the strategy of early service mentoring. By examining the approach of principal mentoring programs in CSI schools, we can better serve practitioners by understanding the specific experiences of individuals who are new to the profession and those charged with retaining them.

Broadening the discussion surrounding how we can positively influence principal retention is a useful aim for research. From this study, we can identify specific high yield 
strategies for future implementation by using the qualitative lens to dive deeply into belief, examine lived experiences, and from this analysis draw inferences into broader pragmatic implications for the field all of which is based in the nuanced response of individuals currently 'in the trenches.'

\section{Significance}

The phenomenon analyzed within this study is not new as there has been a wealth of inquiry centered on teacher and principal retention. However, even with all the inquiries related to the retention issue, the phenomenon persists as a pressing need for districts across the nation. Given the cost to onboard new administrative staff, which is noted to be approximately $\$ 9,400$ per principal (Peters-Hawkins et al., 2018), and the direct harm to students with inconsistent leadership, this phenomenon remains a critical point of study for school districts. Further, in the literature review, I will discuss the principals' impact on student achievement in greater detail.

The implication for practice focuses on identifying high yield strategies that may be garnered and implemented from mentoring programs to positively influence CSI principal retention. This is a pragmatic goal, as increased principal retention in CSI schools is a positive action school districts seek. A possible high leverage strategy for retention is well-constructed mentoring programs for new principals. While this concept is not new, it is one that has seen limited deployment. Principal mentoring first saw a nationwide initiative in 2002 with the National Association of Elementary School Principals' (NAESP) introduction of the Principals Advisory Leadership Services (PALS) Corps. This program was constructed to train new and aspiring principals in a 
yearlong professional development program centered on the National Principals Mentoring Certification Program. This initiative trained current principals to functions as mentors to guide new principals. This model has served as foundational work in several districts across the United States (Gimbel \& Kefor, 2018).

A secondary implication for practice is that district leaders may utilize these results to critically analyze what factors they believe lead to higher retention and adopt mentoring as a strategy in their practice. This supports a critical reflection of practice in light of the research. Education is a profession dotted with programs and initiatives, and program analysis for large districts is often confined to the central office level or done in schools in quasi action research approaches. Formal discussions on retention and critical analysis of what school leaders believe influences retention is a worthwhile pursuit. By focusing specifically on beliefs, we can elicit broader themes for future study, and district leaders can compare their belief structure and practice to the experiences of those in this study with the goal of creating effective principal mentoring policy.

Further avenues of study include a specific analysis of the commonalities between CSI principals participating in this study and non-CSI principals for further studies. Understanding the commonalities between participants' perceptions can lead to replicable strategies that can be implemented in a myriad of schools and districts to positively influence principal retention. Further studies could delineate the different strategies in principal mentoring in CSI vs. non-CSI schools. Qualitative research best supports a deep dive into the participants' mindsets and decision-making, and from these rich 
conversations we can garner information for a broader study and replicable strategies for action.

The principal is a force multiplier or factor that influences effective strategies that impact student achievement (Manna, 2015). Mentoring is a demonstrated retention strategy for novice teachers. Small studies indicate its effectiveness with principals, as respondents in Vermont reported a staggering $94 \%$ belief that their experience with mentoring as a novice principal better prepared them for their future years (Gimbel, 2018). However, there is a gap in the literature in the study of principal mentoring effectiveness, most notably in a broad study of policy at the state and national levels and in the context of CSI schools. This study seeks to narrow the gap in regard to CSI schools.

There exists a gap in the literature about the effectiveness of mentoring for principals (Lochmiller \& Chestnut, 2017; Murphy, 2005; Young, 2019) with calls for further research extending back nearly forty years (Kram, 1985). My review of the literature found only one description of a preparation program in regard to mentoring activities focused specifically on turnaround leadership in a priority/cSI school (Duke, 2014). Broadening the work of Duke, this study seeks to advance the knowledge in this specific domain, as we know that turnaround leadership results in principals' highest attrition rate. Duke utilized mentoring as a practice but did not tease out the details of what it entailed or how it was delivered, nor did he measure its effectiveness either quantitatively or qualitatively. I believe a wide body of work can be done in this area of research that will be beneficial to the retention of CSI principals, but the gap in the 
literature does not end with CSI schools. This problem persists on the state level of educational policy. I cannot find a more recent study than 2004 by Daresh to indicate state-level adoption of mentoring programs, another gap in the literature. Manna (2015) argues that, although the body of literature recognizes that principal leadership is associated with student achievement, the role remains overlooked in terms of state policy; often, the first initiatives to lose funding are internships and on the job support for new principals.

\section{Conceptual Framework}

I believe that phenomenological inquiry is the best methodology for this study since I will seek meaning in the participants' experiences through the interview protocol outlined below. I am interested in the wholeness of their approach to principal retention and believe that from the participant's responses, I can elicit further understanding on what works with mentoring. As this study seeks practical use of the data gathered, a pragmatic framework is the most logical choice to use as the grounding of this study.

Pragmatism is rooted in the understanding that the data yielded from the study is collected with a priori intent to utilize the data in the field. This study, as it is designed for use by current practitioners, will be conducted from the pragmatic interpretive framework. Pragmatism focuses on the outcome of the research and usability in the field. Creswell (2010) describes pragmatism as existing in the current social, historical, and political contexts, noting that pragmatic researchers are concerned with the "what" and "how" of research. Pragmatic researchers have freedom of choice in methods to fit the need of the question they have posed. Greene and Caracelli (2003) refer to pragmatism as 
the stance at the interface of philosophy and methodology. Greene and Hall (2010) explain that pragmatism, by its design, seeks results in problem-solving, action inquiry, and progress of the given field. Given these philosophical underpinnings, pragmatism seems the most logical interpretative framework for approaching the proposed study.

Given the relative freedom of the pragmatic research framework, a study can be designed specifically with the intent to use the information gathered from the field, and the design can be suited to best gather the information in a manner that will yield results from which recommendations and practical application can be garnered. This interpretive framework is the best fit to elicit the information the study seeks to understand. Phenomenological study best fits the examination of the beliefs, attitudes, needs, and perceptions of the study (Creswell, 2010).

\section{Definition of Terms}

The following terms are used in the context of this study:

- Mentoring: A professional relationship of an experienced practitioner assisting a novice practitioner in developing job-specific skills and dispositions to both prepare and enhance their effectiveness, characterized by formal and informal meetings, over a defined period of time.

- Comprehensive Improvement Schools (CSI): Formerly known as 'priority' or persistently low achieving schools, this is a federal classification that denotes a school is performing in the lowest $5 \%$ in the state as ranked by annual standardized testing. For Kentucky, these tests are the KPREP tests. A school can also be identified as CSI if their graduation rate is less than $80 \%$, or if they were a 
previously identified Additional Targeted Support and Improvement (ATSI) school for the three years without improvement. Typically CSI schools are high poverty, high turnover, and high needs schools.

- Turnaround leadership: The informal jargon used in education circles to characterize principals and administration in CSI school environments and an emergent study area among school administration. Denoting the concept that a school in crisis must be "turned around."

\section{Scope of the Study}

The study will take place in a large urban district in the southeastern United States. The district serves over 100,000 students, has recently shifted to a predominantly 'of color' demographic, and faces chronic teacher shortages and administrator turnover. The district is characteristic of urban school districts (Office of Management \& Budget, 2006) and is among the largest thirty school districts in the United States. The district incorporates citywide bussing, neighborhood schools, and magnet school programs into its menu of services. The district consistently performs below the state average in reading and math on yearly state standardized tests but is above the state average in the graduation rate. The district has several Title I, CSI schools and recently was audited by the state for critical deficiencies in special education, early childhood education, and career and technical education.

Further, the district has a robust tradition of collective bargaining with the teacher (certified) and non-instructional non-certified role groups. This district's teacher retention 
issues are consistent with large urban districts. The district had an attrition rate of teachers and administrators of $14 \%$ at the elementary level in the previous year, $13 \%$ at the middle level, and 12\% at the high school level (JCPS Databook, 2019). The district's trends are comparable to national trends identified by Ingersoll and Grissom (2011, 2012). Gathering data from the context of a single urban public school district in the Southeastern United States that is characterized by a great diversity of student demographics in both terms of socioeconomic status and race will serve as an appropriate sample district from which to draw information that can be applied to similar urban districts, which have a similar need of assistance in administrator retention.

Eight principals, drawn from either current or former CSI school leadership, will serve as the interviewees. The study collected information from the subjects via a semistructured interview model. The questions were asked virtually and in person by the interviewer, with the questions provided before the interview so the participants could prepare responses geared toward richer data and deeper analysis. The study asks respondent to describe and make meaning from their experiences with a principal mentoring program, or lack thereof. The questions centered on principal perceptions regarding participation in a mentoring experience. What hallmarks of the experience were perceived as effective, and if they did not have a mentoring experience, what areas they found difficulty with as new CSI principals?

\section{Limitations}

The limitations of this study are the methodological limitations of small respondent size qualitative research. The study's scope is limited to a small number of 
principals and their lived experiences of mentoring. Further limitations are the narrow scope of principal respondent selection which is limited to one urban district. However, as a phenomenological qualitative researcher is not interested in the concept of generalizability but rather an analysis of in-depth experience, these limitations are acceptable as the goal of this study will be to deepen the understanding of this phenomenon.

\section{Organization of Chapters}

The remainder of the dissertation is organized into the following structure. Chapter II reviews the relevant literature to principal retention, linkages to teacher retention, and the existing gap on principal mentoring scholarly study. Chapter III describes the methodology, including the research design, data collection, coding structure, and qualitative analysis of the data. Chapter IV reports the results of the data analysis. Chapter $\mathrm{V}$ is the discussion of the findings, recommendations for practice, and implications for future research. The study will impact the body of literature around principal mentoring programs focused on CSI schools and, from the experiences of the participants, offer suggestions for best practices for mentoring programs. 


\section{CHAPTER II}

\section{LITERATURE REVIEW}

\section{Introduction}

This chapter examines the existing literature on educator retention, focusing specifically on mentorship programs that seek to mitigate their loss. Teacher retention has been widely studied, and a subcomponent of that body of research examines the importance of mentoring for teachers. There exists a gap in the literature regarding the effectiveness of mentoring for principals (Lochmiller \& Chestnut, 2017; Murphy, 2005; Young, 2019) with calls for further research extending back early forty years (Kram, 1985). Further, the literature review will summarize the body of work existing on principal mentorship programs with a critical eye towards Comprehensive Support and Improvement (CSI) schools. CSI schools are schools that score consistently in the bottom $5 \%$ of schools in a given state or fail to graduate one third of their senior class, as identified annually under the Every Student Succeeds Act (ESSA). Previously, these schools were identified as priority schools and, prior to that, persistently low achieving schools. The term "turnaround school" is often used interchangeably with CSI in describing these learning environments.

This study seeks to answer the question: "How do CSI principals perceive principal mentoring programs in terms of benefits and intentions to stay in CSI schools?" 
The purpose of this study is to examine the experiences of CSI principals in a racially and socioeconomically diverse district in the southeastern United States with mentoring programs and their perceptions of how such programs may mitigate administrative attrition.

The literature discussed below builds the case that both teacher and principal retention is a desirable outcome for schools and districts. The review will illustrate that teacher retention will be connected heavily to the role of the principal. Mentoring will be defined for the context of the study, and the literature will show the connection of mentoring as an effective practice for retaining principals. As mentoring is a strategy that retains teachers, it can be effectively applied to principal retention. The review will then illustrate the history of efforts of principal mentoring, demonstrate the gaps in the literature, and identify what attributes of mentoring programs could be effective in retaining high quality educators.

A review of the literature (Crisp \& Cruz, 2009) found fifty-seven different definitions of principal mentoring at the time of publication among large districts and state definitions. These definitions occur independently, in the context of local mentoring programs, or in state policies that, with the exception of the New York initiative, have been largely abandoned. NAESP and the National Association of Secondary School Principals (NASSP) published a report centering on the preparation and attraction of high-quality leaders. A key finding of this report, based on the responses of those surveyed, indicated that there was a highly positive response for "good on-the-job training under a mentoring principal” (Capasso \& Daresh, 2001, p. 11). Yet, despite early 
reports of this practice's success, there is a lack of literature to support its continued growth. There is a body of literature that identifies several university-based principal preparation programs as exemplars (e.g., Cosner et al., 2015; Donmoyer, Galloway 2012;

Merchant \& Garza 2015), but Darling-Hammond et al. (2009) produced perhaps the most thorough study of principal preparation programs at the university level but failed to mention mentoring as a component.

\section{The Role of the Principal}

The role of the principal is the center point of this study; therefore, the reader should have a sound understanding of what is expected of a modern school principal, including the additional expectations placed on a CSI principal when compared to a traditional school principal role. The principal of a school is the head of the school administration, responsible for overseeing all of the employees within the building, the operations of the building, the instructional program, and budget. Their duties include school-based policy development and enforcement, student discipline, employee management and evaluation, school safety, and compliance with local, state, and federal regulations. Other responsibilities include overseeing the delivery of services to special education, English as a Second Language, gifted and talented, and other special populations. They are also often in charge of interviewing potential hires, recommending hires of staff to central office, and providing employee discipline. Often they work in collaboration with a school based decision making team. In the Commonwealth of Kentucky, where this study took place, schools have Site-Based Decision Making Councils (SBDMs) of elected parents and teachers, with the principal serving as the chair 
of this council. This council is responsible for budget and the general direction of the school.

The CSI principal has additional responsibilities. Most often, they do not have an SBDM, as state or federal law will remove that decision making body and place it into the hands of the local district superintendent, who, in turn, commonly places it into the hands of the school principal to oversee the school turnaround effort. In a CSI school, the principal is often the final decision maker regarding most curricular and operational decisions. They are subject to state audits of their progress, as guided by federal law, roughly every two years. These audits can result in their removal for lack of progress in the school turnaround, removal of half their staff, or the closing of their school. As discussed previously, CSI principals have the highest level of attrition of all principal role groups (Duke, 2014).

The principal is one of the primary drivers for student achievement (Bryk et al., 2010) and, in most circumstances in the United States, they hold the ability to hire their teaching staff, considered to be the most significant driver of student achievement (Grissom, 2011). Principals have several factors that they can influence to increase teacher retention to positively affect student achievement and lessen the costs of onboarding new personnel. As the principal has a direct influence on shaping, defining, and stewarding the school's culture, their impact on teacher retention has a large effect. Therefore, retaining and preparing effective principals is a worthwhile pursuit of a school district. 
The impact of the principal on student achievement has been well documented, primarily from the role of hiring, developing, and retaining high quality instructional staff (Bryk et. al, 2010; Grissom et al., 2015; Leithwood et. al, 2004; Waters et al., 2003). Waters et al. studied the effectiveness of school principals on student achievement, finding them to be the second most significant driver of achievement behind the teacher. Agreeing with their findings, Clifford and Darling-Hammond found that the principal's role in development of the comprehensive plan, and retention of effective teachers was a driver of student achievement (Clifford et al., 2011; Darling-Hammond et al., 2009).

Boyd et al. (2011) report in their quantitative analysis of teacher retention of urban, new-to-the-profession teachers that the primary reasons for leaving the teaching profession were dissatisfaction with the job stemming from lack of administrative support, student behavior, and district policies. It must be noted that in this study over $40 \%$ reported that lack of administrative support was their reason for leaving, with the second reported reason (i.e., student behavior weighing in at just above 15\%). As administrative support was twice as likely to be the next highest factor for teacher retention, reason stands that administrative support is a critical factor of influence on teacher retention. This is further supported by the positive impacts of leadership in defining a clear vision, and how structures for teaching (Grissom et al., 2015) directly impact teacher retention. Providing specific supports and strategies for teacher coherence and performance (Wahlstrom et al., 2015) also have been shown to dramatically impact whether teachers stay or go. It is from the research of Boyd, Grissom, Wahlstrom, that we establish that administrative impact on teacher retention is a guiding force on whether a 
teacher stays in the profession or not. It is administrator's action, or lack thereof, that will be critical levers to teacher retention. This issue is only exacerbated in the CSI school environment, where attrition rates among both the teacher and principal ranks are markedly higher than non-CSI schools (Duke, 2014).

Reichardt et al.'s (2008) qualitative study of school personnel, both in the profession and those who had exited, indicated that school leadership was a primary reason for attrition. They conducted a series of interviews with exited teachers centered on their reasons for leaving the profession, primarily focusing on those who left for reasons related directly to the profession. They did not include in this study those who left for other reasons such as child rearing, moving to another state, etc. Teachers reported the principals' lack of ability to influence support, opportunities to grow, and general working conditions as the primary reasons they left the profession. This was supported in the researchers' interviews of current personnel, who supported that school leadership ranked higher than compensation among other factors as a primary motivator to stay in a given school. Wynn et al. (2007) found that teachers who transferred from schools ranked seeking work environments that fostered respect and guidance from the principal as a high indicator of leaving. As these studies took a broad approach to teachers' perceptions, this study seeks to narrow the focus to a specific sample of principals and dive deeply into the same arena of questions that Reichardt studied, looking specifically at the mentoring aspect of their development.

Teacher retention is connected to the principal's support of student discipline, as the literature tells us that school's response to student behavior via discipline practices 
consistently influences teacher retention, with lax response to behavior being a contributing factors for teachers to leave the profession or leave the school in which they work for a lateral opportunity. Bush (2018), Curran et. al (2002), and Hughes (2012) found that schools that have unsafe environments have higher teacher turnover. They continue the discussion by making connections between schools with fewer free and reduced lunch students and teachers reporting higher levels of satisfaction, which translated to higher teacher retention. CSI schools are most often identified as Title I and as having a high percentage of free and reduced lunch students (Duke, 2014). With magnified issues of discipline, it is important that the principal possess the skills to deal with infractions and create systems to support positive behavior. This study will look at what component discipline plays in the mentoring relationship for new principals.

A recent comprehensive study of the national crisis of teacher shortages once again paints the following picture: "Administrative support is the factor most consistently associated with teachers' decisions to stay in or leave a school. Our study found that teachers who find their administrators to be unsupportive are more than twice as likely to leave as those who feel well-supported" (Sutcher et al., 2016, p. 7). In their mixed methods public policy recommendation report, the researchers noted additional findings consistent with previously mentioned studies. Teacher turnover is higher in highpoverty, high-minority schools, as well as schools where the teacher population does not reflect the demographics of the school (Sutcher et al., 2016). Their findings paint a bleak picture of minority, high-poverty students having been subject to four times as many uncertified teachers than average. "When there are not enough teachers to go around, the 
schools with the fewest resources and least desirable working conditions are the ones left with vacancies" (Sutcher et al., p. 9). Their findings are consistent with Boyd et al. (2011), Burke et al. (2013), Grissom et al. (2015), and Stockard (2004).

Burke et al. (2013) researched 31 factors that teachers utilize when making decisions regarding whether to stay or leave. The researchers utilized Best-Worst scaling and had the respondents complete a survey with a 5-point Likert scale to measure their ratings on the 31 factors. In their analysis the researchers identified key factors that had the highest level of influence on a teacher's decision to remain in the profession. The researchers reported that new teachers required collaboration, support from leadership, and assistance with student discipline. They also noted that new teachers indicated that leadership support and guidance from mentors helped most to make their determination to remain in the profession. This study underscores the multivariate influence that school administration, from the role of the principal, has on teacher retention.

Grissom et al. (2015) reported that evaluation performance has linkages to teacher retention in the sense that organizational measures of high performance must be clearly communicated to the employee. When a teacher does not understand their evaluative measures, it leads to frustration, lower job satisfaction, and higher turnover. In their quantitative analysis of teacher factors for mobility, they found that the more ambiguous standards of evaluative measures were, the more likely a teacher would leave. As teachers reported that they had less understanding of what an adequate standard of job performance was, the likelihood that they left the profession increased significantly. Administrative support consistently rises to the top as a factor of teacher retention, 
particularly on the type of atmosphere they create in the school. The connection of the principal to teacher retention is evident, and below teacher mentoring as a positive practice that promotes teacher retention will be discussed. The vast majority of principals' rise from the ranks of teachers, and it is highly likely that they had a teacher mentor while in the classroom as this is common practice; this suggests that the practice of mentoring would hold promise for principal retention. To better understand mentoring, a definition for this study is constructed below.

\section{Functional definition of mentoring}

As we delve into the effectiveness of mentoring as a retention and preparation practice it is helpful to have an understanding of what mentoring constitutes. Among the educational profession it is an emergent field of personnel development (Young, 2019), focusing more at the teacher level than the administrative ranks. There is a wealth of literature to support mentoring as an effective retention and preparation practice in the corporate sector (Lear 2003; Dehann \& Burger 2005; Nakamura et al., 2009), and I will make the case further that at the teacher level in education it stands out as an effective practice.

Shah (2017) defines mentoring as "A complex relationship in which one person, the mentor, facilitates the development of another, the mentee, by sharing his or her knowledge, experiences, network, etc., and customizes it to the needs of the mentee" (p. 1). Daresh characterizes mentoring as having components that are longitudinal, relationship based, and specific to the role (Daresh, 2004). Mentoring is a relationship of 
a veteran practitioner offering guidance and wisdom to a novice (Hall, 2008). Mentoring is a temporarily unequal position where an authority guides a novice in the responsibilities of their job (Gay, 1994). Mentoring is the training of a younger colleague by a senior, experienced colleague in a non-evaluative setting (Ehrich et al., 2004). Mentoring is a professional relationship of an experienced person assisting a novice to develop specific skills and dispositions that will promote their effectiveness (David, 2003). Mentoring is explaining what a professional is doing, and the why behind the action (Stanulis et al., 2018).

I believe the definition that encompasses mentoring most succinctly describes a mentor's fundamental purpose as a need for the veteran leader to pass on institutional knowledge and support for the mentee to better prepare them for their new position (Jones 2014). This is vastly different than an apprenticeship or internship, as the mentoring relationship places a premium on the one to one approach of the veteran employee working directly, in a non-evaluative role, with a novice employee.

\section{Teacher mentoring effectiveness leading to principal mentoring practices}

Mentoring as a function of teacher professional development has demonstrated outcomes and is a common facet throughout schools in regard to teacher retention programs. Mentoring policies of one form or another exist at the district or school level, and administration directed mentoring programs for new teachers are an area of leverage for administrators seeking to increase retention that have shown success in a variety of contexts. Ingersoll and Strong (2011) reported that a California based mentoring 
program for new teachers showed a retention rate of $87 \%$ of new teachers over the course of four years of study, compared to a retention rate of $68 \%$ for teachers who were not mentored. This is further supported by an $88 \%$ retention rate for a mentoring program in Louisiana (with no comparison to those who had not been mentored), and less significant but increased retention rates in Montana, Wisconsin, Texas, Ohio, and Georgia (Curran \& Goldrick 2002). As we further explore factors principals can influence to increase teacher retention, the body of research is clear that a quality mentoring program is a factor that will increase teacher retention. It is not a leap in logic to inquire on the effectiveness of mentoring for principals, as we know the effectiveness for teachers.

David (2003) discussed the principal's importance in guiding and delivering new teacher induction programs at the school level and its positive effects on retention of teachers new to the profession. In this study qualitative data was gathered from several new to the profession teachers who reported that more time, intentionality, and structure embedded into new teacher induction programs yielded higher job satisfaction among the new teachers. The researcher further discussed that teachers reported that they benefited from a time intensive, structured mentoring protocol. Brown (2003) conducted a similar study and showed positive connections between principal leadership of new teacher induction programs and new hire retention, with emphasis upon increased reported job satisfaction as a result of time intensive new hire mentoring programs and new teacher induction support.

Brill and McCartney (2008) cited that school administration was a high factor in teacher retention. The study specifically noted factors of school administration: offering 
feedback, assistance, collaborative environments, and decision making were all hallmarks of retaining teachers. As teachers reported high levels of support in these factors, their choice to stay in their position increased. They further found that poorly structured teacher induction programs and mentoring led to lower teacher retention rates. It was noted in their study that many teachers reported that they were observed by their administrative mentor less than three hours in a year, which contributed to the feeling of lack of support for a program. They further explained that an improperly executed mentoring program only offered cursory support for new teachers and overall contributed to the impression that only the appearance but not the actuality of support was given to them.

Yusko and Feimen-Nemser's (2008) qualitative study found that mentoring was most effective with new teachers when the emphasis was placed on assessment and assistance in the classroom. In this study the relationship of mentors in new teacher induction programs in California and Ohio was studied. Researchers found that direct guidance on assessment construction, coupled with substantial feedback on classroom performance from modeling sessions, leveraged higher retention and perceptual reports of classroom effectiveness from new teachers. The researchers further found that it was important for administration to create extensive time for relationships to develop between the mentor and mentee teachers.

In Frels et al.'s (2013) study, mentors and mentees reported positive perceptions of their experience in mentor programs and offered insight that administration should construct and maintain mentor programs that allow for choice of the mentor, rigid 
programmatic components with clear expectations of success, extensive additional classroom management training, and specific coaching on school and district policies. Participants in their study indicated they found the most value in a relationship with a mentor that allowed for trust, with extensive side by side training in the aforementioned factors.

Reiterating that training for the mentors is important, Smethem (2007) found that teachers rated mentor programs unfavorably in the study due to lack of training for the mentors, which in turn created less cohesion and more stress.

Martinez et al. (2010) found that mentorship through a unique program of volunteer corps from retired educators had a net positive influence on teacher retention, with respondents indicating that they felt more supported and connected to the school as a whole. This study found that amount of time spent on mentoring was a significant factor. This further supports Brill and McCartney's (2012) results indicating that more time in a mentorship yields positive results for teacher retention.

The evidence is clear that mentoring programs increase teacher retention, but why do the national statistics show increasing attrition rates? If the profession accepts that mentoring programs are common practice, where are we going wrong with principals, and why is there such a stark gap in the literature involving principal mentorship (Crisp \& Cruz, 2009)?

\section{History of principal mentoring}

Having made the case that teacher retention is tied directly to the effectiveness of the principal and mentoring is a powerful practice for teacher retention, we turn our focus 
to the body of research around principal mentoring as a practice to increase principal retention. Mentoring has been a longstanding component of pre-service preparation programs at the university level (Daresh, 2004; Gay, 1994; Grissom et al,. 2019; Lochmiller \& Chestnut, 2017; Saban \& Wolfe, 2009; Schechter, 2014). This body of literature shows us that while there is study on the pre-service component, there exists room from growth in the literature examining mentoring during the first year of a novice principal, once they are in the position. Here the research begins to thin, as does the public policy.

The role of the principal is complex and demanding, with nearly $40 \%$ of new principals feeling not prepared for their first day in the role (Helber, 2015). Nearly one in six principals leave their school each year, and in Title I schools this number is closer to one in five (Goldring, 2014). According to the Principal Attrition and Mobility survey conducted in 2016-17, the national average length of stay for a principal was just under four years. Of those surveyed $35 \%$ left within two years, and only $11 \%$ stayed over 10 years. A large majority of schools in the U.S. are led by principals with less than six years of experience as a school leader (Manna, 2015). Stress is consistently identified as a primary driver for principals leaving the role is stress, specifically over the complexity and pace of the job (Daresh, 2001, 2004; Shoho \& Barnett, 2010).

The principal is one of the strongest influences of effective practices that impact student achievement (Manna, 2015), and retaining principals is a desirable practice from the district perspective. As demonstrated in the literature review previously, principals are a driving factor of student achievement and teacher retention. While the retention of 
effective principals is desirable, the problem persists in spite of educational leadership degrees being awarded at double the rate in 2016 than they were in 2002 (Perrone \& Tucker, 2018). While degrees are being awarded at a much higher rate, beginning principals throughout the United States report that they are ill-prepared for the demands of the job (Sackney \& Walker, 2006). The gap in the literature in the study of the effectiveness of principal mentoring persists despite our knowledge that teacher mentoring is an effective practice. This stems in part from the lack of concrete policy to mandate mentoring of novice principals. Manna (2015) discussed the findings of his work indicating that policy often overlooks the needs of the development of school principals. "The principal's role has received consistently less attention relative to other topics on state education policy agendas. State policymakers give much more attention to teachers and teacher-related issues than principals" (Manna, p.3).

Mentoring has been used frequently for years in other professional fields. Business, healthcare, higher education, human resources, and manufacturing have successful examples of large mentoring programs to promote employee retention. Business has several examples of large corporate mentoring programs elucidated in Dehann and Burger's 2005 study, as well as in works by Lear (2003) and Nakamura et al. (2009). These mentorships focused on experienced executives imparting their wisdom on newer executives and they ranged from highly structured formats to looser relationships between the mentor and the mentee. The above literature suggests that mentoring is an effective retention practice in the corporate sector as well as at the teaching level in education. There exists a gap in education K-12 research to identify 
principal mentoring effectiveness (Daresh, 2004; Young, 2019). As we continue the literature review, these is a gap within specific on the job mentoring research, especially in the CSI realm, but there has been some study on broader programs.

Principal mentoring first saw a nationwide initiative in 2002 with the National Association of Elementary School Principals' (NAESP) introduction of the Principals Advisory Leadership Services (PALS) Corps. This program was constructed to train new and aspiring principals in a yearlong professional development program centered on the National Principals Mentoring Certification Program. This initiative trained current principals to be mentors to guide new principals. This model has gone on to serve as foundational work in a handful of districts across the United States (Gimbel \& Kefor, 2018). However, it has not seen widespread acceptance, nor been adopted into any state policies.

At the federal level there has been a recent increase of funding support for principal retention. The Every Student Succeeds Act (ESSA) provides federal dollars that states can use to support principal retention under Title II. Title II funding is designated by the federal government to strengthen the quality and effectiveness of principals, teachers, and school leadership. The regulations state that $5 \%$ of the Title II budget may be set aside for leadership investment. This money must be utilized with evidence based strategies to increase retention, and mentoring is recognized as such a strategy. As part of Title II, higher education institutions have been offered competitive grant monies in excess of $\$ 30$ million annually for leadership development, with a specific component set aside for formal mentoring programs. However, these grants are 
overseen at the university level and often placed into principal preparation programs, rather than at the school level once a novice principal is on the job. However, we continue to see a lack of consistent policy specifically related to principal mentoring at the state or local level, despite the provision of this funding.

Few formal standards exist for pedagogical skills covered in principal mentoring. In Kentucky, KPIP was created with the specific intent to focus on leadership standards and professional practices; successful completion of the program was tied to continued licensure. However, the program was discontinued with limited study on its effectiveness (Mitgang, 2007). Kansas provided guidance for mentors to help their mentees obtain necessary professional development hours, but did not offer guidance on the content (Augustine-Shaw, 2015). In New Mexico work on national standards is called for, but no specific pedagogical skills are mentioned (Villani, 2006). The closest to formalized standards for skills development comes from the Illinois Principal Association, a nonprofit entity that calls for work from mentors with teacher professional development, mission building, and strategic planning (Augustine-Shaw, 2015). It is clear there are no standards that are utilized across states, while mentoring relationship content is left to individual districts or mentor-mentee pairs.

At the state level by the mid-2000s over 32 states have, or had at some point, a policy mandating mentorship for novice principals (Daresh, 2004). However, many, like Kentucky with the Kentucky Principal Internship Program (KPIP), have defunded them within the first decade of their inception. KPIP was created with the specific intent to focus on leadership standards and professional practices, and was tied to continued 
licensure on successful completion of the program. However, the program was discontinued with limited study on its effectiveness (Mitgang, 2007).

In Ohio the Lead Center was created in 1986, which persists in the form of state regulation that requires some form of loose mentorship (Daresh, 1990). As of the writing of this document, Arkansas, Iowa, Kansas, Maryland, Massachusetts, South Carolina, Texas, Utah, Virginia, and West Virginia all require new principal induction programs where mentoring can be a component of the induction; it is not however formalized, meaning no concrete guidelines or policy is laid out. In California, Hawaii, Missouri, New Jersey, Vermont and Delaware, similar regulations exist and persist for two years rather than one year as in the previously mentioned states; but, again, none formally require mentoring, only offering it as a component of a novice principal induction program. I have found no analysis or research indicating whether or not these induction programs have been successful, and in many cases they are not funded at the state level but rather left to be operationalized and funded by the local districts. In Vermont for example, where a new principal is required to have a mentor for two years, the regulations call that the experience be based on best practice and research, while it is clear that the research is limited at best. Similarly, in Kentucky there are no specific standards mentioned, not even national performance standards. I have found that one state, New Hampshire, addresses more specifically what is required for a mentor relationship, which includes three days of training for mentors. This training centers on mentor competencies, articles supporting mentoring, evaluation standards, and planning 
models (NHASP 2014). In a cursory review of other states regulations, there is not so much specificity.

Illinois has engaged in some effort for a mentoring component in their principal development programs. Illinois law established in 2006 mentoring to be provided by regional education offices, higher education institutions, and school districts. However, once again, these programs are placed in the pre-service phase of principal development, rather than once the novice principal is on the job.

Perhaps the most promising state level policy is the New York Aspiring Principals Program, which services aspiring New York City principals. This program has a component of mentoring once a principal is in the role, for up to one year from the reception of the role (Corcoran et al., 2012). In Corcoran's analysis over a six year period of principals who had completed the program, results were not promising. The study found virtually no effect on math achievement and negative effects on reading achievement. These areas were the only measures Corcoran used to judge the effectiveness of the Aspiring Principals Program. Corcoran is quick to point out that these results are due to a variety of factors, the least of which being a mentoring component; more of the blame was placed on the initial selection of applicants to the program. The framework for the mentoring component was drawn heavily from the work of the Wallace Foundation, referenced further on.

There have been a variety of efforts advocating for public policy for formalized mentoring programs (Briggs et.al, 2013) involving a variety of non-profits who provide capital for startup programs (Shelton, 2009), including significant investment from the 
Wallace Foundation (Briggs et. al, 2013) and a policy push from the Alliance for the Reform of Educational Leadership. However, there exists a lack of public policy mandating mentorships for novice principals, as none of these nonprofit foundations' recommendations or investments have persisted in formal state policies.

The professional organization NASSP has created several initiatives for mentoring with limited success. More recently their initiative of principal mentoring focused on providing veteran retired leaders to serve as novice leaders' mentors (NASSP, 2014), but the initiative has only had pockets of acceptance, no widespread research done into its effectiveness, and again, no adoption at the state policy level.

\section{Attributes of effective principal mentoring programs}

While the literature contains a gap, there has been some work attempting to identify effective components of principal mentoring. A review of the literature (Crisp \& Cruz, 2009) found 57 different definitions of principal mentoring at the time of publication among large district and state definitions. There is currently no literature that has been updated into the current context, but this can serve as a useful initial framework. NAESP and the National Association of Secondary School Principals (NASSP, 2018) published a report centering on the preparation and attraction of high-quality leaders. A key finding of this report was that based on the responses of those surveyed there was a highly positive response for "good on-the job training under a mentoring principal" (Capasso \& Daresh, 2001, p. 11). Yet, with early reports of the success of this practice, there is a lack of literature to support its continued growth. 
There is a body of literature that exists highlighting several university based principal preparation programs as being exemplars (e.g. Cosner et al., 2012; Donmoyer \& Galloway, 2012; Merchant \& Garza, 2015), but none of these are specifically mentoring programs. Darling-Hammond et al. (2009) produced perhaps the most thorough study of principal preparation programs at the university level but failed to mention mentoring as a component. In some instances, we see that mentoring is formalized into training before the principal takes the role (Corcoran et al., 2012), including a pre-service program to prepare principals before the job is offered. While digging heavily into the lived experience of new principals, especially their training involving climate and culture, they did not mention what formalized training happened for the principals after they took their first position. However, these studies, in the context of university preparation, can lead to some understanding of the programs and characteristics of effective mentoring programs by drawing from the exemplary preparation programs for inspiration. As such, we look to the existing literature to analyze and pinpoint characteristics that can be considered effective for principal mentoring programs as a further consideration of study.

Schechter (2014) examined determinant factors in the mentor-mentee relationship in New York City schools, seeking to analyze characteristics of a productive mentoring relationships. Mentees "...identified direct support, feedback, empathy for the work, and clarification of the roles and rsponsibilities as the most beneficial items rceived from mentoring (Schechter 2014). This builds upon the work of Ehrich (2004), who argued that effective mentoring must be centered in a continual teaching and learning process that is empathetic and supportive. Both researchers agree with Hall (2008), who found 
that perceptual data from his study indicated that the mentor-mentee relationship must be non-evaluative, centered in mutual trust, and serve as a scaffold to support the growth of the mentee. The belief that the relationship must be based in one of support, with mutual trust in a non-evaluative setting, is critical. Alsbury and Hackman (2006) indicate that the ability for a mentor to provide guidance from an informal place of non-evaluation is a critical component to the process. Mentees who described mentors as harsh, judgmental, or reserved in their support found the relationship to not only be not beneficial, but also detrimental to their growth as new administrators. Among new superintendents and principals surveyed, the two primary attributes they found most helpful in a professional mentor were honesty and a disposition to listen (Metzger, 2003).

Indeed, Daresh (2004) has consistently stated that the relationship between mentor and mentee must be positive, open, and honest. This is characterized by mentees' perceptions that the mentor is in no way evaluative and serves as an ally for them to with whom they can have confidential conversations. This is supported ny Saben and Wolfe's study (2009) in which mentees reported that favorable dispositions from their mentors began and ended with an open, honest, and confidential relationship. From this research we can paint a clear picture that, for mentoring to be effective, it must live in the world of support and non-evaluation; this is only compounded in the environment of the CSI School, where the pressure is innately intense.

Like most relationships, personality characteristics are a large factor of the success of the mentor principal to mentee relationship. Research has indicated that the personality characteristics of effective mentors are respect, admiration, openness, 
honesty, trust, and sincerity (Schechter, 2014). These personality characteristics have a profound influence on the initial stages of the mentor-mentee relationship. Successful mentoring programs place emphasis on personality fit of the mentor to the mentee (Muse \& Wasden, 1992). Trust is a common trait that emerges among a variety of studies (Lochmiller 2017; Duke et al., 2004; \& Fry et al., 2005), with a clear picture that trust is a cornerstone of a successful mentoring arrangement. Lochmiller further expands on this notion and agrees with Goldring (2014) that both trust and honesty are key components of the mentor-mentee relationship.

Trust coupled with listening was a central attribute reported as desirable in a mentor (Augustine-Shaw, 2015). Hall further explained that a mentor who spent more time listening to the mentee and then offering questions to work towards understanding was reported as helpful (Hall 2008). Hall expands this notion among respondent novice principals who found value in mentors that did not give them specific answers but instead served as a listening sounding board for them to work through the difficulties of their school issues. Having a relationship where a mentor asks questions, helping their mentee establish decision making schema on their own rather than being told the answer, was found to be a powerful reflective aspect of the mentor-mentee relationship (Daresh, 2004).

Time for mentor-mentee work is also a critical component after trust is established. The vast majority of the respondents in Schechter's study indicated that constant, on-demand communication was critical (Schechter 2014), and a premium was placed on face-to-face communication. Face-to-face communication in a non-evaluative 
setting, with a sense of trust and honest feedback, was found to be an effective practice (Alsbury, 2006). Daresh (2004) concurred, finding that the more effective time commitments for mentoring were face to face and on demand based on situational need. Time for lengthy discussion and coaching was a key finding among novice principals' perceptions of improved preparation (Clayton et al., 2013). Respondents noted that they found structured conversations with their mentors in the context of a trusting, private environment to be crucial to their development, further reporting that these one-on-one sessions influenced their perceptions of both their preparation and their decision and confidence to stay in the profession. This is a key finding for effective mentoring practices, as time can be an affordable component of a program for a school district. The district must determine specific time for mentors and mentees to discuss the work, as this shows promising areas of growth. While time is limited, especially in the CSI environment, a district can determine the workload of their principal mentor/mentee and support setting aside specific time for this work to occur.

Mentees reported favorably that face-to-face communication schedule outside of the normal school day was a positive aspect of mentoring (Augustine-Shaw \& Funk, 2013). "Being able to call my mentor and meet up for coffee whenever I needed was important" (Augustine-Shaw \& Funk, 2013, p. 20). These findings continue to highlight the importance of on-demand communication and readiness to serve as a sounding board by the mentor as critical to the mentoring relationship. Metzger's (2003) results concurred with the concept that frequent, on demand communication to talk through problems was highly valued by mentees. 
Villani (2006) provides insight into best practice for principal mentoring. The component of feedback to interns on the mentoring is absent from the study, so assumptions must be taken without feedback from the participants on the effectiveness of practices. Villani found that basing mentoring around a key series of standards is essential to a mentoring program. These standards should be developed in the local district or state context, specific to the needs of the school being served. This bears further investigation in the realm of CSI schools, where the need is immediate and pressing. Similar to Villani, Daresh (2001) argues that, in addition to standards, principal mentoring must be centered in problem analysis and solving. Problem solving skills rise to the top of the effective practices (Daresh) "Mentoring relationships for administrators must be directed toward the discovery of ways to refine problem-solving " (Daresh, 2001, p.43). Capasso agrees that principal mentee experiences must be centered around real situations encountered on the job, guided by a professional mentor (Capasso 2001), and that these learning experiences are what mentee respondents consistently identified as the most helpful to their development. Students reported that post-collegiate preparation program experiences with problem tasks for their new position, with guidance from existing principals, were valued as experiences for their preparation (Stevenson \& Cooner, 2011).

Research indicates that preparation experiences connected with real-world experientials hold promise (Harvard et al., 2010; Perez et al., 2010) when the context is provided in a mentoring or internship format. For the purpose of this paper, there is a clear distinction between an internship, wherein a prospective principal works at a school 
where they will not likely be hired, and a mentoring relationship, which exists after the novice principal is hired into their role. The importance of these experientials has been noted thoroughly as far back as 2005, when the Southern Regional Education Board (Fry et al., 2005) documented the common complaint from both fieldwork leadership students and novice principals centered around too much conceptual learning versus too little problem based contextual learning. The SREB noted that less than a quarter of the respondents to their study found that their experiences adequately prepared them for the demands of the position. While many university programs contained experiential problems in their curriculum, I believe there is no substitute for experientials developed and experienced with a successful practitioner.

Further successful university preparation programs have noted that hallmarks of exemplar practice include critical program inquiry through proble- based learning (Honug \& Donaldson, 2019). These problem-based experiences were developed with local school districts, garnering real-world scenarios on which aspiring principals could train in a low stakes environment. This relevancy component garnered high praise from participants and I believe, connects directly to experience-based learning through mentoring. Successful practice-based methods created with partner districts and implemented in principal preparation programs (Darling-Hammond et al., 2009) yielded critical acclaim from principals surveyed years after initial licensure. Post graduate principals surveyed after being on the job for a number of years reported that problem solving lessons garnered from real-world situations were powerful practices in their preparation (Harvard et al., 2010; Stephenson \& Connor, 2011). Dodson (2014), in his 
study of principal preparation programs, noted that $60 \%$ of principal respondents responded that field based mentoring experiences better prepared them for their role before further expanding this idea to university preparation programs, where $60 \%$ responded that field-based experiences provided a critical piece to their preparation. When those without field-based experiences were asked if they believed that a fieldbased experience would have better prepared them, $83 \%$ responded that it would have.

Problem based skills form an important part of principal mentoring in Singapore. A specific curriculum of simulations is prepared for novice principals in Singapore that include how to navigate common issues, dialogues with effective administrators, and experience with real-world scenarios (Jensen \& Clark, 2013). I believe we have much to learn from Singapore's model, as it clearly articulates common issues a school leader would face and pairs novice leaders with effective senior leaders to teach them the correct framework of response. Given that we already know that problem solving is a key competency for a school administrator, it is reasonable to assume that more exposure to real-world problems would result in better preparation for novice principals. Mentees reported that they found the most value in on-the-job problem-solving strategies (Augustine-Shaw \& Funk, 2013) when they had a mentor they could call with a contextspecific question and ask for advice. This points to the importance of the novice principal having a veteran to coach them through difficult situations.

The fundamental purpose of mentoring is for the veteran leader to pass on institutional knowledge and support to the mentee to better prepare them for their new position (Jones, 2014). Coupled with situational leadership scenarios, personality traits, 
and time discussions, a mentor's professional acumen is a premium component of the mentor-mentee relationship. Participants found that mentors with a strong understanding of the current district situation is critical to mentees (Schechter, 2014). Effective navigation of a district was a professional trait that mentors have reported bringing to their mentees (Duke, 2014), and that this political acumen better prepared their charges to be effective school leaders. Mentors reported that discussion of the political nature of the principal role and leveraging community support were important componants of the relationship (Briggs et al., 2013). Mentor principals reported that they found most value in working with their mentees, helping them navigate how to access support and understand the nature of their district initiatives (Lochmiller, 2017). Coupled with this, a sound basis in pedagogy, with a premium placed on experience with multiple initiatives (Daresh, 2004), was desirable. Leaders who were successful in their setting, especially if it was similar to the setting of the novice principal, were reported to be more effective mentors than those from a dissimilar setting, such as a different grade span (Alsbury, 2006), so this begs the question must be asked in the context of CSI schools: Where do the mentors for the principals of the schools with the most need come from? There exists a stark gap in the literature of responses to this question, and in reviewing the literature there was no mention of Persistently Low Achieving schools, the previous label for CSI schools in previous reviews of the literature (Ehrich et al., 2004); (Crisp \& Cruz, 2009). Having an experienced principal as a mentor was also perceived to help the novice principals career (Metzger, 2003), as it increased the perception that the novice would benefit from the sage wisdom of the experienced principal. This idea was further 
supported in Duke's (2014) work highlighting that mentees appreciated a well-regarded principal as their mentor. A strong, well-regarded mentor also increases the novice principal's ability to network and enmesh themselves in their district hierarchy (Hean, 2009). The importance of socialization to district personnel that a mentor can facilitate for new leadership cannot be underestimated (Saban \& Wolfe, 2009).

New principals consistently report that the perception of the effectiveness and relative success of their mentor is an important factor (Wahlstrom et al., 2010). The mentor must be a successful practitioner that commands respect from their colleagues. Wahlstrom found that positive praise and affirmation from the mentor, when they are regarded highly, is a desirable outcome for a mentee. This becomes more difficult in the environment of the CSI school, for in the land of turnaround leadership we have noted that the average tenure of a principal is far less, which, therefore means less access to quality mentors from which to pattern behavior.

Digging into specific pedagogical and managerial skills, Duke (2014) reported that data analysis, motivating teachers, and short-term planning were the primary skills that mentors taught their mentees. Teaching mentee principals how to understand and allocate the resources available to them (Fullan et al., 2006) and allocating resources using data analysis protocol (Bryk et al., 2010) were reported in both studies as being one of mentees' prominent areas of need. The notion of data analysis as an area of growth is further supported (Lochmiller, 2017), coupled with a keen understanding of the right type of student achievement data to track (Goldring, 2014) in the context of the school and districts' needs. Dodson reported that Kentucky principals most noted the need for 
specific training on the improvement planning process and resource allocation. (Dodson, 2014).

Wahlstrom et al. (2010) noted that time management for a new administrator was also a worthwhile area of training. New principals often reported they did not fully understand the scope of the time commitment of the job, and that learning from an experienced administrator how best to budget and protect their time was important. Again, this is a skill that is further magnified in the environment of the CSI school, where time is often limited in terms of time to improve, and time to prepare for a school audit that may result in removal of the principal. In this environment, time becomes an especially precious commodity; however, if the mentorship will improve the retention and preparation of the principal positively, the district can support specifically setting aside time for this work to occur, perhaps especially in the CSI environment.

Mentors reported the primary components of their work with mentees centered on planning, supporting on demand problem solving, and giving emotional support (NHASP, 2014). Digging deeper into the report, mentors indicated that a significant amount of time was placed on specifically planning structures in line with the current educational trend of systems thinking. These skill sets were tied to areas of growth for most of the mentees reported. This is in line with further research that reports that primary skill focus was on systems development, communication with stakeholders, and relationship building within the school (Jones \& Larwin, 2015). A study of Rhode Island novice principals' experiences in development concurs, showing that the predominance 
of time spent with mentors was on time management, data analysis, and communication with stakeholders (Helber, 2015).

Support with performance evaluation of staff and having performance conversations were also a common topics of discussion between mentors and mentees (Gimbel, 2018; Helber, 2015; Duke, 2014). Many novice principals reported this was an immediate area of growth. We can surmise that, in the CSI school environment, this is only magnified as turnaround schools have the most inexperienced teachers and, in many cases, teachers that have not found success elsewhere (Duke, 2014). Performance evaluation was reported as a consistent topic of conversation that mentees benefited from, especially in an environment with a trusted colleague who could answer questions without the mentee appearing to have a lack of knowledge to a superior (Goldring, 2014). New principals report stress as the primary reason for leaving the role, and specific work with their mentor on work-life balance has been explored in some studies (Shoho \& Barnett, 2010). A study of new principals and superintendents utilizing mixed methods indicated that, among the 40 urban educators surveyed, most found that the inability to cope with stress and time management were reasons they had left or strongly considered leaving the profession (Metzger, 2003). Villani (2006) agreed, citing his results which concluded that the principal working alone and consistently on the clock contributed to a large body of stress that eventually manifested into health concerns. Similarly, respondents indicated that time management, evaluation standards, and data analysis were areas of premium usability from their experience with mentoring (Augustine-Shaw \& Funk, 2013). Villani (2006) echoed this sentiment, specifically with 
time management as a major problem reported by novice principals. There has been some evidence that conversations with experienced administrators could benefit novice administrators in regard to time management. This assertion is supported in Metzger (2003), in which respondents reported that mentoring experiences led to decrease in both stress and anxiety on the job.

Budget development was reported as an area of need and development with their mentors (Shoho \& Barnett, 2010) and is further identified as areas of high stress for novice principals. Secondarily, they identified development of instructional systems as a high area of stress. Shoho and Barnett correlate with numerous studies recognizing systems development as an often-overlooked area of preparation for principals, one that can be uniquely addressed by a competent mentor who is experienced with developing systems on the job. Common areas of discussion for newly minted principals with their mentors included hiring, improving their own weaknesses, removing ineffective staff, and development of instructional systems (Whitaker, 2012), further highlighting the prevalence of systems discussion among mentors and mentees.

Targeting mentee identified needs for improvement also holds promise. Metzger (2003) identified in his research that mentees identified a needs assessment highlighting their personal areas of need and growth as beneficial. This most often manifested in the context of understanding district politics and policy, personnel evaluation, and time management.

While there is much similarity between skill sets on which mentors and mentees spent their time, there remains a lack of concrete guidelines across programs. In fact, as 
referenced before, while many states have mentoring suggestions as part of their principal induction programs, there exists a wide range of ambiguity.

We can determine that the shared attributes from the research analyzed here for effective mentoring have the following common themes of trust and honesty among personality traits; time for face-to-face and on-demand communication; access to situational leadership scenarios and problem solving; the perception of the mentor's professional acumen; and the discussion of specific skills (most commonly systems development, data analysis, communication, time management, and personnel evaluation). As these themes come from the principalship studied in the non-CSI realm, this study seeks among other avenues of inquiry to see if these themes emerge within the CSI principalship.

In this research, I will contrast the broad list of identified practices from the body of research outside of the CSI experience to the lived experiences of the principals in this study, specifically identifying what they report as effective, and if there are specific strategies that occurred in their mentoring experience in a CSI school. In the context of the CSI school, where time is limited and results are expected rapidly, the formalization of mentoring with successful attributes contribute to the novice principal's retention is an area worthy of scrutiny. Pinpointing what exact experiences novice principals who have stayed on the job report as being effective components of mentoring will better inform district and state policy recommendations to increase principal retention and change the current reality that CSI school principals have the lowest tenure on the job of any principal role group. Increasing the length of time principals remain in our most needy 
schools has been demonstrated to have significant impact on student achievement, making it a highly desirable outcome for school districts and state education organizations.

\section{CSI Principal Mentoring}

Indeed, my review of the literature found only one description of a preparation program in regard to mentoring activities focused specifically on turnaround leadership (Duke, 2014). As with other studies, Duke's research offered little insight into the effectiveness of mentoring, highlighting mentoring as a practice but not describing the details of what it entailed, how it was delivered, or measuring its terms of effectiveness either quantitatively or qualitatively. I believe there exists a wide body of work that can be done in this area of research that will be beneficial to the retention of CSI principals.

In the context of CSI schools, the schools with the most pressing needs, we see a growing interest in the concept of "turnaround leadership." Turnaround leadership studies the skills and actions leaders take to improve the performance of their schools (Fullan, 2006). It is becoming a common understanding in the realm of turnaround scholarship that the skills and dispositions needed for already moderate or high performing schools are not the same as a CSI school (Duke et al., 2007). It is logical then to conclude that within this emerging sub-field of education, which requires specialized dispositions that specialized care must be taken to the construction of mentoring programs. The analysis of turnaround strategies is a growing body of scholarship, and, as their tenure is usually the briefest, there is some intersection with mentoring of new turnaround principals (Murphy, 2008). 
The gap in the literature does not end with CSI schools. In fact, this problem persists in all facets of school leadership. Manna argues that, although the body of literature recognizes that the principal's role directly impacts student achievement, this role remains overlooked in terms of state policy and is often one of the first initiatives to lose funding (Manna, 2015), specifically in terms of leadership development.

\section{Summary}

This review of the literature has made the case that retention of both teachers and principals is a desirable outcome for schools and districts, and that teacher retention is connected heavily to the role of the principal. Mentoring has been illustrated as an effective practice for retaining teachers, with a variety of efforts, policies, and programs in place to mentor principals, but no consistent programs are currently operating across a wide variety of districts or states. These programs have a variety of attributes that indicate what could be an effective principal mentoring program, but there remain gaps in the literature to present a full picture of what is working to promote the retention of principals by utilizing mentors for novice principals.

This study draws some material from the university and apprenticeship programs but draws a clear line in the deeper analysis of the concept of novice principal mentoring. This is a specific relationship designed and formalized between a novice principal who is on the job and an experienced principal paired with the novice to better prepare them for the role in a manner that will increase the likelihood they stay in the position. While the 
research presented exists for principal mentoring, there is a critical gap in the CSI principal world.

The practical application of this study is evident from the pragmatic theoretical lens, as it seeks to find real-world application for effective principal mentoring programs. As there exists a gap in the literature on the effectiveness of principal mentorship, this study seeks to add to the body of literature. This study seeks to add to the analysis of the question: "Are mentoring programs increasing retention of CSI principals and better preparing them for their assignment?" The focus of this study is to broaden the body of literature of mentoring for CSI principals. There is a gap in the literature, specifically around the CSI principal experience with mentoring, and, from the lived experiences of the principals in this study, we can increase the understanding of how mentoring impacts their preparation and retention. From this study we can identify specific high-yield strategies for future implementation and study derived from the lived experience of those in the field who have been mentored in some capacity. Rather than have a wide variety of mentoring strategies, we can narrow what is effective and put it into practice. It is from the qualitative lens that we can dive deeply into belief to identify commonality for practice. The next chapter describes the methodology that will be utilized to study this phenomenon, and the participants from whom I seek to find meaning. 


\section{CHAPTER III}

\section{METHODOLOGY}

\section{Introduction}

The purpose of this chapter is to explain the research methodology for this qualitative study regarding principal mentoring. The qualitative approach allows for a deeper understanding of principals' experiences within mentoring relationships and how they inform novice principal preparation. The applicability of the pragmatic framework examining this phenomenon change to "is" discussed in this chapter. The research plan, methodology, participants, procedures, ethical considerations, and data analysis methods are also included.

\section{Research Purpose}

The purpose of this study is to examine Comprehensive Improvement Schools (CSI) principals' experiences with mentoring programs and their perceptions of how such programs may mitigate administrative attrition. The principals' lived experiences will be further analyzed for themes to increase understanding of what works and what does not work in administrative mentoring programs. This analysis will render a broader understanding of principal mentoring and how it can increase novice principals' effectiveness. This study seeks to answer the question: "How do CSI principals perceive principal mentoring programs in terms of benefits and intentions to stay in CSI schools?" 


\section{Methodology}

Qualitative study allows researchers to dive into the detailed descriptions of lived experiences. A broader understanding or depth of the human experience can be understood in a deep study of human behavior and perception. This depth is often referred to as "thick description" (Geertz, 1973). Qualitative research is utilized to learn about the experience, perspective, and meaning, most often from the lens of the participants of the experience. Often in-depth interviews about a phenomenon are conducted to dive into the experience (Hammerberg et al., 2016).

Among the common qualitative research methods are grounded theory, narrative study, ethnographies, case studies, and phenomenological inquiry (Creswell, 2010). Grounded theory examines existing documents and interviews to create a theory of an event. Narrative study analyzes events, interviews, documents, and supporting material to tell a story about a given theme. Ethnographies study participants' environments to garner a deeper understanding of the culture, themes, and motivations. Case studies are deep dives into various data to either describe, explain, or further explore a topic.

Phenomenology is utilized when the research aims to describe a phenomenon from the perspective of those who lived it and utilize this perspective to understand meaning. Phenomenological inquiry is the best approach to this study, as I will seek meaning in the experiences of the participants through the interview protocol outlined below. Phenomenology is the best approach because it is utilized to study experience as it is created and lived by the participant (Neubauer et al., 2019). In these lived experiences, we can make meaning of the phenomenon, viewed from the lens of their collective, 
subjective experiences. I am interested in the wholeness of their approach to principal retention and believe that I can see common factors to elicit a further understanding of the nuance of the participant response. This research study presents practical considerations for the field that can be further studied or implemented to increase principal retention and effectiveness, a desirable outcome in terms of increased student achievement and lower cost to schools and districts to onboard new principals.

This study is designed for usage by current practitioners in the field. This study will be conducted from the pragmatic interpretative framework. Pragmatism focuses on the research outcome, and, as this study is constructed for practical usage in the field, the pragmatic framework has a good fit. Creswell (2010) describes pragmatism as existing in the current social, historical, and political contexts, noting that pragmatic researchers are concerned with the "what" and "how" of research. Pragmatic researchers have freedom of choice in methods to fit the need of the question they have posed. Greene and Caracelli (2003) refer to pragmatism as the stance at the interface of philosophy and methodology. Greene and Hall (2010) explain that pragmatism, by its design, seeks results in problemsolving, action inquiry, and progress of the given field. Given the relative freedom of the pragmatic research framework, a study can be designed specifically with the intent to use the information gathered from the field, and the design can be suited to best gather the information in a manner that will yield results from which recommendations and practical application can be garnered.

Pairing this interpretive framework with a phenomenological study is the best fit to elicit the information the study seeks to understand. A phenomenological research 
design is an appropriate choice for studying the beliefs, attitudes, needs, and perceptions of the subjects of the study (Creswell, 2010). As the nature of the pragmatic framework is designed to be flexible for the research purposes, studying this phenomenon within that lens is the best fit to elicit the study's information.

\section{Positionality of the Researcher}

Positioning myself within the phenomenon is not difficult. My first year as a teacher was not the most positive experience. I was placed into a collaborative special education setting with relatively no guidance, given a caseload, and told to go to work. Teachers I collaborated with recognized my inexperience and relegated me to making copies and being a 'helper.' I was ready to resign and return to the corporate world within two months. On a Thursday, I was pulled into an assistant principal's office, and my role was changed effective Friday to a self-contained Emotional and Behavioral Disability teacher. This further pushed my desire to resign, and I vividly remember sending resumes out to secure employment back into the private sector.

What made me stay was that I was patterned with a different assistant principal and a new teacher mentor once assigned to this new and very difficult role, both of whom took specific actions to influence my retention. They demonstrated not only care for my practice but care for me as an individual. In this humane interaction, with care for my success on a professional and personal level, I found the tools necessary to survive my first year and thrive in subsequent years as a teacher. This lived experience of my own shaped my conception and understanding of teacher retention as a leader. In designing this study, it forces me to set assist my biases as best I can and critically analyze the 
phenomenon from the perspective of others. While my experience shapes the beginnings of this study, it is the participants' experiences upon which the findings will be based.

I am an experienced principal serving urban students in a school that employs over two hundred individuals. My current assignment is principal in a high school ranked among the ten lowest schools in our state, with the highest needs index of our district. I was asked to lead this school mid-year by our district superintendent, as it was a crisis school. My previous role in our district was to lead the district's largest school for approximately four years, moving to a CSI school to out of federal classification. My first year in my previous assignment was hallmarked by hiring over 75 staff; additionally, I hired over 50 new staff in my second year and over 25 in year three, so I am well acquainted with the teacher retention problem. As a school administrator, I had no formal mentoring program as a first-year principal. In my third principalship, my first CSI principalship, I had a relatively ineffective mentorship experience.

My only experience with a principal mentorship was when I was assigned a mentor at the end of his career who assumed that, as a principal in two previous schools, I had a sound understanding of my role. While this was correct in terms of overall management and pedagogy, I believe the missing ingredient of this relationship included on specific strategies and nuances indicative of a CSI school. Therefore, I'd like to examine what we are doing to prepare individuals for CSI school leadership. As a practitioner, I position myself seeking better answers as to how to retain promising principals in our most difficult schools. 
I believe that retaining high-quality teachers and principals is conducive to increased student success. This is not to say that we should retain all staff, as, doubtlessly, there are less than stellar examples in the profession that need to be exited; I have encountered my share over the years. However, in broader terms, I remain concerned with the number of principals that show promise and have the potential to be highly effective educators that we lose in their first few years in the profession. I believe both from my practical experience and study of the research that retaining principals is worthwhile. I see every day in practice the dividends that students reap from school leaders that are experienced, invested, and have been in the profession long enough to develop the pedagogy to be effective educators. I approach this study with that mindset, and, while I recognize that we do not want to retain all principals, we should, retain the vast majority as if we have done our due diligence in hiring selection; it is a net benefit for the school to retain in employee both in terms of student success and financial encumbrance in onboarding new staff. As we understand that mentorship can play a critical role in teacher retention, I believe it can also do so with principals. It is important to understand that I enter this study assuming that retaining quality staff is better for our students and better for our school systems' bottom lines.

I further enter into this study believing that, as we are dealing with people's feelings and perceptions, the best way to approach this phenomenon is through the qualitative lens. While there is a wealth of data on the teacher side of the retention subject, I believe a large space for further study from the administrator lens exists. From my perspective, I know my primary factors to remain in the work. 
At the heart of this study is my desire as a practitioner in a position of direct influence on principal retention to improve the craft of education and give others access to analysis to improve leadership retention efforts. I approach research from the practitioner's perspective, and, at this point in my career, I cannot approach it in another manner. As I am immersed in leading a school, I need more and better information to lead my school. Positioning myself in this research is natural, and the outcomes that I seek are pragmatic information to influence my practice and the practice of others in similar positions. I cannot wholly remove myself from the phenomenon, but I can clearly understand my relation to it and use it to help guide my analysis while paying due diligence to the participants' voices.

\section{Context of the Study}

Subjects of the research were selected from the single urban public school district in the Southeastern United States. This district has the preponderance of CSI schools in the state, which generates wide variety of principals available for study participation. This district is among the top thirty in size in the United States and is characterized as an urban school district.

\section{Data Sources}

Eight principals, drawn from either current or former CSI school leadership will serve as the interviewees for the perspective of school administration. The criteria for selecting the participants will further include that the principals must have had in their early preparation some form of mentoring and at least four years' experience as a school 
principal. Four years' experience as a school principal in a CSI school will indicate that they are above the national average for CSI school leadership tenure.

\section{Data Collection}

Interviews took place in the setting most comfortable for the subjects. Consent forms contained specific elements explaining the research, the participant's right to voluntarily withdraw at any time, protection of the respondents' confidentiality, any known risks, and a clear explanation of the procedures that were used to collect the data. The study collected information from the subjects via a semi-structured interview with ten questions. I provided the questions before the interview so the subject may prepare responses geared toward deeper analysis and rich data. The respondents were asked to describe experiences and make meaning from their experiences with a principal mentoring program or lack thereof. The questions (Appendix A) centered principal perceptions regarding participation in a mentoring experience, what hallmarks of the experience were perceived as effective, and what areas they found difficulty with as new CSI principals.

All interviews were coded manually during open coding utilizing deductive coding. The interviews were analyzed in batches of four participants, allowing analysis time before moving on to additional participants. The researcher coded each batch and analyzed it for categories or themes. Questions or clarifying questions were added to the interview method following the eight interviews or during the second interview series. 


\section{Procedures}

Approval was obtained from the Institutional Review Board (IRB) of the

University of Louisville and the district selected for the study. Once approval was given, individuals selected within the study's scope were offered opportunity to

participate. Participants signed an informed consent document, with further confirmation of informed consent recorded verbally at the beginning of the interview. Each interview was conducted in one session and electronically recorded.

Interviews were sent to a professional transcriptionist for transcription. The interviews were conducted face to face and recorded electronically. As the format was semi-structured, questions that open opportunities for further depth were allowed. Participants were given their transcripts before analysis to ensure they were comfortable with their responses and provide an opportunity to correct any transcription errors. Their commentary was synthesized into the analysis of the common themes included in the discussion and recommendations for further research.

\section{Data Analysis}

Coding of the interview transcriptions was conducted case-by-case as transcribed, and final approval from participants was given once they reviewed their transcript. Interviews were coded for themes, with analysis along common themes for each participant included in the final analysis. Analysis of codes began by looking for patterns in the data across all participants (Fetterman, 1989; Miles \& Huberman, 1994). The common themes for coding were drawn from the literature surrounding the topic. The first group of themes was focused on the mentoring sessions, including direct support, the focus of the work, empathy for the work, clarification of the roles and responsibilities 
(Schechter, 2014), lengthy discussion (Clayton et al., 2013), and problem-based learning (Honug \& Donaldson, 2019. The second group of themes centered on mentor qualities. Schechter (2014) reports that respect, admiration, openness, honesty, trust, and sincerity are reportedly effective characteristics; these are affirmed and added upon with demonstrated effectiveness of the mentor (Honug \& Donaldson, 2019), the perceived success of the mentor (Daresh \& Playko, 1993), and social position of the mentor within the school district (Frels et al., 2013). The final group included any specific frameworks, programs, or curriculum used in the mentoring relationship.

The research's transferability will be evident from a pragmatic lens, as the research generated from the participants' lived experiences will broaden the understanding of the relationship of the principal mentor to their mentee. Future researchers that use this study's work will be able to make judgments on the sensibility of the transfer of this research according to their context.

\section{Ethical Considerations}

Institutional review board authorization was obtained from both the university review board and the local district review board. Informed consent were secured in written form (Appendix B) before the interviews, and verbal consent was electronically recorded at the beginning of each interview.

The risks to human subjects associated with this study are minimal. There are no foreseeable risks other than possible discomfort in answering personal questions or a potential report of a breach of ethics by the mentor. If such is reported, the investigator shall inform the proper authorities of the nature of the complaint. All participants are over 
the age of majority, do not demonstrate any impaired capacity, and meet the professionals' criteria outlined above.

Study materials and transcripts will be retained on an encrypted hard drive on a password-protected computer. Further protections for their anonymity will be provided via pseudonyms and created school names. Participants will be given a copy of their transcripts for approval before included in the study's analysis. No identifying information of the participants will be shared, as each participant will be given a pseudonym name and school, with the master copy secured on an encrypted hard drive. All materials of the interviews and the master interview list will be erased from the encrypted hard drive within five years from completion of the study following final approval by the research committee.

\section{Summary}

This chapter outlines the research method constructed to analyze the question provided. The research plan, methodology, participants, procedures, ethical considerations, and data analysis methods have been discussed, all of which contribute to this study's viability. A pragmatic approach will yield actionable analysis from the lived experiences of the participants. Chapter IV will provide the results of this study. Chapter V will analyze the results of this study, demonstrate data garnered from the participants' lived experiences, and make recommendations for implications to practice. 


\section{CHAPTER IV}

\section{RESULTS}

\section{Results}

This chapter presents the research findings of the data collected from the participant interviews. The purpose of this study is to examine Comprehensive Improvement Schools (CSI) principals' experiences with mentoring programs and their perceptions of how such programs may mitigate administrative attrition. This study seeks to answer the question: "How do CSI principals perceive principal mentoring programs in terms of benefits and intentions to stay in CSI schools?"

\section{Participant Profiles}

Participants all fulfilled the criteria discussed in Chapter III. All were principals and have served in CSI school environments. Of the participants, two were men and six were women. Racial demographics included five Caucasian principals, two African Americans, and one Latino principal. Their professional experience included four serving at the high school level, four serving at the middle school level, and two at the elementary level. Four of the principals had served at multiple levels of CSI schools.

The age range of the participants was 39 to 54 years old, while experience in education ranged from 17 to 26 years of service. All participants had served as CSI principals for over four years. Four principals (Principals Smith, Jones, Paul, and Wine) had more than 10 years of experience. Principals Fitch, Logan, Grey, and Greenall had 
experience ranging from four years to nine. All participants were assigned pseudonym names and schools.

Principal Smith has over 20 years of experience in education, with over 10 as a principal. The bulk of his principalship has been centered in CSI schools, predominantly middle and high schools. When describing why he sought the principalship, he noted:

I was interested in making a difference. I thought I could lead a school, and do well at it.

Principal Jones has over 20 years of education experience, with over 10 as a principal, and all of it in the CSI school environment at the middle school level. When describing why she sought the principalship, she said:

I come from a family of educators. It's in my blood; even if I tried to deny it, the calling was there.

Principal Fitch has just shy of 20 years' experience and five years' experience as a principal, all in a CSI school. The majority of her experience has been in high schools. She said she sought the principalship:

Because I knew I could make a bigger impact on students as a principal.

Principal Logan has over 20 years' experience and nine years' experience as a principal, with five of it being in a CSI school. His work has predominantly been in middle schools, with some experience in high schools. He sought the principalship: 
I was mostly lucky. Pushed into it because we had an early retirement, then a vacancy, and I was asked to step in. I decided after a while I wanted to stick it out.

Principal Paul has over 25 years of experience with over a decade of service as a principal, all at a CSI school. The predominance of her work has been at middle school, with some high school. She found herself seeking the principalship:

It is my calling. I'm doing worthwhile work, and fulfilling work.

Principal Wine has nearly 30 years' experience, with over a decade as a principal. Her work has been in middle, high, and elementary schools, with almost all of it in CSI schools. She sought the principalship because:

It's my mission. I knew then, and I know now, I can lead schools and make better outcomes for our kids.

Principal Grey has over 30 years' experience, with seven years as a principal. Her experience ranges from elementary, middle, and high school, with the predominance being in the middle grades. She sought out the principalship because:

I felt I could do a good job at it. I had seen so many mistakes over the years; I wanted to be part of the solution.

Principal Green has over 20 years' experience, with four years' experience as a principal. Her work has been both elementary and high school, with four years as a CSI principal in elementary. She sought the principalship because: 
I have a passion for the work. I believe that we must center ourselves in our why, and my why is helping students and families every day.

\section{Findings}

The findings will be presented via the themes outlined in Chapter Three. Participants were asked if they were a part of any specific framework, mentoring program, or guiding curriculum for their mentoring arrangement. The themes will first be focused on the mentoring sessions.

The sub-themes of this will be direct support, the focus of sessions, empathy for the work, clarification of roles and responsibilities, length of discussion, and problem-based learning.

The second set of themes will focus on mentor qualities. The sub-themes of this will be respect, admiration, openness, honesty, trust, sincerity, demonstrated effectiveness of the mentor, the perceived success of the mentor, and the social position of the mentor in the district.

Seven of the eight participants were assigned a mentor. Principal Logan was not assigned a direct mentor, however upon interviewing, it was found that he had informal mentors during his first year, and his responses elicited a perspective of a practitioner who believed he would have benefited from a more formal relationship.

Once I became principal, there was no mentoring for me, no formal mentor program. I had some folks that helped when I reached out, but I didn't have a 
formal person. I think I probably would have benefited from that, but it wasn't a thing that was done at the time (Principal Logan).

The remaining seven were all assigned a mentor through different manners during their first year as a principal. Some assignments were formal; some more informal. One was assigned from the state department of education, an outlier assignment from the other seven's experiences. This experience was an outlier because the mentor was assigned by the state department as part of a pilot mentor program. Principal Grey reported that she was assigned a mentor by the district and, at the time, the state of Kentucky as part of KPIP (Kentucky Principal Internship Program).

Principal Paul was assigned a formal mentor from the district under a districtbased mentoring initiative that is now defunct. The program was rooted in the work of the Wallace Foundation as part of a grant to the district. Several principals were mentored under this program over the course of half a decade until it was terminated due to a lack of funding. When researched, there were no documents or analyses of its effectiveness by the district.

Several of the participants were assigned mentors in a less formal manner, stemming primarily from their supervisors. Principals Smith, Fitch, Grey, and Green were all assigned mentors through their supervisor. It is worth noting that Grey was assigned a district mentor, a successful practicing principal in a similar situation as a leader of a CSI school, and she went the further step of hiring a successful retired principal as an in-house mentor. 
The remaining participant, Principal Jones, had a different experience regarding mentor assignment, one that involved more self-selection. She was directed by her assistant superintendent to have a mentor but given leeway on determining how to facilitate the relationship. Principal Jones reported that she was not assigned a formal mentor by the district but did seek out two informal mentors during her first year as a principal. She further offered that, later in her career, she was asked to be a mentor for a new principal but was given no guidance, framework, or direction as to what that meant. She was told to be somebody that the new principal could ask questions of when needed.

The participants were asked about the nature of this mentoring arrangement. Was it guided by a specific framework? Was there a curriculum or pre-packaged program used? Did the district create a program for their mentoring relationships, or were the relationships based solely on what the mentor or mentee needed in the relationship?

\section{Frameworks and Curriculum}

Two of the eight participants reported utilizing a formal, pre-determined framework to guide the mentoring work, one reported a semi-formal framework developed by their mentor, and the rest responded that there was no curriculum or predetermined framework for their mentorship.

Of the five that did not have a formal program, they indicated that the ebb and flow of their work with their mentor was centered on dialogue about the work. While some differences existed between mentors in the manner of how they covered material with their mentee, a common characteristic was a dialogue based on two areas: the needs 
expressed by the mentee, and topics the mentor thought would be pertinent at a given time. For example, several of the participants said that their mentor covered budgetary work from November to January, which is traditionally the time within the district when a school's budget for the following year is constructed.

Similarly, all of the participants said that their mentor covered personnel movements in April, the time in the district when most personnel actions for the following year occurred. Of the two respondents who were a part of a formal mentoring program, one (Principal Wine) was a part of KPIP, and the other (Principal Paul) was part of a structured district mentoring initiative. Principal Wine reported that her general perception of KPIP was that it was helpful, albeit cumbersome at times:

It seemed like we did a lot of work to fulfill state requirements. Some of it was really good, exercises and stuff to help you through the year; some of it was not (Principal Wine).

When asked for more specifics on the content covered, the participant responded that the majority of it included structured models that could be adapted to the district context, such as a module on personnel management, with ample space for the mentor to insert district-specific policies and practices. When asked further if it prepared the principal for CSI or high-needs school work, the participant had a negative response:

KPIP didn't do anything for a tough school. There wasn't anything like CSI or PLA yet; this was back in the dark age. But we still had Title I and tough schools. It didn't cover any of that. Just more general stuff (Principal Wine). 
When asked if she thought revival of the KPIP program at the state level would be beneficial:

I don't know. It would have to be modernized. It didn't really account for equity, racial equity, or high stakes testing. I think it would have to be modernized for that to be effective (Principal Wine).

Principal Paul was part of a structured, now defunct district initiated mentor program. She was a part of the last year of the work, and, while she found it to be generally helpful, she found one particular area to be lacking:

We had to do all of these reports of what our sessions were about. I think they were so my mentor could get paid, but sometimes we'd spend 20 minutes just filling out a report. It would have been better to, I don't know, trust the person you asked to be a mentor than to have them fill out meaningless reports that ended up in a file folder somewhere (Principal Paul).

When asked how the inclusion or absence of a formal framework was perceived by the participants, only two had strong perceptions on the matter:

I think it helped, at least for guiding what I was supposed to be doing during that part of the month. I would even reference it outside of working with my mentor, like a checklist of things I needed to be thinking about (Principal Paul).

Another had a strong belief towards the opposite: 
Honestly? I don't think it mattered. I didn't really want another document to fill out. I was glad that I had someone I could work with and tailor my questions to my needs at the time. I think it would have got in the way (Principal Grey).

Upon elaborating, the participant reported that it was more beneficial that their mentor was not following a script or pre-determined curriculum, not only for the ability to tailor questions but for the perception that it was an open relationship rather than another formal meeting.

The principals reported that the majority of them, five of the eight, did not use a predetermined curriculum, framework, or guiding document for their mentorship. Of the two who indicated the use of a developed curriculum, one was associated with a statemandated program (KPIP), while the other originated in a program developed by a district. Both of these programs are defunct as of this writing. When asked about whether or not they thought using a curriculum or framework was beneficial, one of the two thought it was generally helpful while the other did not. When those who had no framework were asked if they thought a pre-determined curriculum or framework would have been beneficial, the participants indicated neutral responses. They had no polarized opinion, positive or negative, on the inclusion of a framework.

With an understanding of the participants and the inclusion or lack of formal frameworks, participants were asked to discuss the content of their mentoring sessions and the attributes of their mentors. 


\section{Theme One: Mentoring Sessions}

The theme of mentoring sessions revolves around the time spent during mentor and mentee meetings. Formal mentoring processes that include established meeting times and topics were felt to be helpful.

Principal Smith reported that his mentoring sessions were both highly structured and informal. For him, formal meant that the sessions followed a prescribed agenda, and informal meant that it was a generalized discussion with no prescribed agenda. This understanding was common among all participants. For Principal Wine, direct support sessions manifested in a formal setting with weekly meetings. She reported that most of these meetings occurred as scheduled, and their topics centered on the specific activities of the structured KPIP framework. During these sessions, they discussed personnel management, daily task management, budget concerns, and long term planning activities. Also, her mentor was on-demand primarily through phone calls and occasional emails. During her first year, her mentor invited her to observe her in practice at her school and conversely visited her mentee's school to observe her as part of fulfilling the KPIP requirements.

As this experience was unique among participants, Principal Wine was asked about the effectiveness of observing her mentor in action at her school. She reported that, while it was good to see general leadership strategies, she found that the time was not always well spent as they were at different education levels. She believed that, if they had been practicing at the same level as principals, it would have been more effective. 
In addition to formal sessions, participants also found informal check-ins to be helpful. Participant two's mentoring sessions occurred off-campus, after school, and on the weekends. This participant reported that, through these sessions' structures were mostly informal, she prepared questions and topics of discussion with her mentor in advance. In addition to this, frequent phone calls, school visits, and text messages occurred.

She reported that the sessions after school were most helpful, as they allowed her pre-determined time and space to reflect and strategize her next steps. Participant five reported that the mentors she sought out provided direct support primarily through text messages and roughly weekly face-to-face meetings. These face-to-face meetings were conducted at her school and occasionally after school or on the weekends over dinner. She also remarked that she would often call her mentor to come out when needed after school to strategize about particular issues at the time. Principal Grey noted that her district-assigned mentor was not readily accessible; as they were both practicing principals, it required time outside of school for them to meet and work. For this reason, she took the additional approach to mentorship in hiring her own mentor, an experienced, retired principal, in addition to the district-assigned mentor. She utilized this resource for day-to-day direct support, such as how to handle discipline issues from the principal's perspective, noting:

Having the doctor being in my building, it just worked out because she was just right there, and she knew how to do it.... For the first year she held my hand 
while I did the budget, and then the next year I did the budget, but then gave it to her to let her make sure everything was correct (Principal Grey).

Her experiences align with Principal Green's experiences:

I knew how to do discipline from being an AP, but the principal hat was different. Having to navigate my APs, it was good to have someone who had dealt with a variety of APs over the years (Principal Green).

Principal Fitch reported that her mentor reached out several times throughout the week. Her mentor also offered direct support through consistent text messages, emails, and access. She reported there was not often a formal meeting time, but her support was on demand.

For Principal Smith, the highly structured portion manifested as a weekly meeting with his mentor with a pre-determined agenda covering instructional topics, management concerns, budgetary items, and a space for general questions and dialogue. The informal component occurred during phone calls, emails, and numerous text messages.

Smith reported that their support during the informal times was on demand and readily available. When asked what the typical topics were between formal and informal sessions, Smith said that the informal topics were typically needs-based, immediate feedback items such as employee discipline, problem-solving, or budget questions. Formal sessions revolved around the pre-determined agenda of his mentor. 
Principal Logan did not have a mentor, so there was no direct support or sessions to report. When asked what would have been helpful in a hypothetical mentoring situation, this participant responded that someone outside of his direct supervisor to bounce ideas off would have been helpful. He reflected that he identified experienced peer principals that he trusted to reach out to during his first year but would have preferred to have a more formally assigned point of contact.

Participants reported that their sessions were mixed. Some were formal sessions lead by the mentor, while many were informal sessions on demand from both the mentor and mentee's request. There was little consistency among the participants other than the ondemand feature was found to be effective by the mentees. With an understanding of the participant's structure of their sessions, they were asked about the mentoring sessions' content.

\section{Theme Two: Focus of Discussions}

To further understand the content of the mentor and mentee sessions, the participants were asked about the second theme, the focus of their discussions, to strengthen a deeper understanding about specific job responsibilities that was found to be helpful by most participants. Principal Paul reported that feedback particularly in the area of personnel was important. Logistical concerns were an area she had the most difficulty with during her first year as a principal:

I would ask my mentor things about, can you do this? Because I'm looking at the contract and it says this, but what does that mean? And I'm thinking about do I 
need to go to this, on this, or this person? Do I have to get a union rep in on this? Those logistical kinds of things were invaluable (Principal Paul).

She further stressed that it was important to be able to ask these questions of someone who was not evaluating her, as it didn't create the perception of incompetence. Principal Grey noted that feedback on decision making given by her mentors was important to her success as an early principal. This manifested often in process and procedural duties. My mentor was all about management. It was all about, okay, here's the budget. I got to make sure to do this correctly. Here's this report, we have to fill out this report correctly. This teacher did this, and now we have to call there, we've got to do this due process, and here is how to do it. Can you walk me through that? That kind of thing was critical. My other mentor focused our conversations all on instruction, ideas. How do we motivate kids, teachers, and staff? I did nuts and bolts with my in-house mentor, and with the other, we did big ideas (Principal Grey).

She went on to stress that this dichotomy, having one mentor for process and procedural needs and one for the "bigger picture", was important. She reported that this allowed her to bounce ideas for the larger scope, while also having a direct resource to give her feedback on conducting the day-to-day business of the school.

Budget and an understanding of school finance was a consistent area of direct support from mentors: 
I think probably the month that we spoke the most was February, because I think he helped... I remember him helping me a ton with budgets. I remember sitting down in February that first year as principal and kind of almost having one of those moments like, "Holy shit, I'm in control of a $\$ 7$ million budget right now." I really felt like my training had been nonexistent in that area. So I remember lots of conversations about budget (Principal Fitch).

The sentiment that budget was highly important in these discussions was echoed by Principal Wine:

But we could talk about how she created her budget. Okay. So, you created your budget that way and did your schedule, okay. That's great. I may be able to use some pieces of it, but I can't use all of it. And I'll give an example. Like the way she sought input from teachers on what their teaching assignment would be for the next school year. Well, that's something I used. I got that idea from her (Principal Wine).

Aside from budget, the primary topic of feedback from mentors was how to work with personnel relations and evaluation of employees:

They stressed the importance of know the contract, operate around the contract. But what they told me was, it's not a barrier, and oftentimes you'll know it more than your teachers. But they stressed to me like read it, highlight it, take notes, be able to cite it and go from there (Principal Jones).

Other participants stressed the importance of knowing when to invoke the contract: 
And I quickly found out that navigating the contract issues, you can be right and still not want to go all the way to the table (Principal Paul).

This nuanced approach differed from always going by the letter of the contract, a distinction that many of the novice principals found to be helpful. Principal Wine remarked about the importance of the labor union contract with the teachers and how it was stressed by the mentor:

Read the contract. So I always got that, but nothing was explained in detail about labor relations. It was just, know the contract. And it could be because she didn't know the contract as well, or it could be that the contract changed so much, or that you had people that would... What's the word I'm looking for? Contest the contract in your dealing. I still think to this day, I think they've gotten better with explaining the contract. But when I first started, it was just read the contract and know it (Principal Wine).

This continued to be a common theme: a novice principal's lack of understanding of the contract and the mentor's intercession to provide an experienced lens:

Know the contract, he said often. So we picked it apart often (Principal Smith).

Data analysis was also an area discussed by some participants in terms of walkthrough systems. When repored by the principals, walkthroughs indicated administrative informal evaluations of teachers, lower-stakes observations to see what teachers were doing, and measuring it against a variety of instruments. 
I took from that was the importance of instruction and going in, but how to effectively use walkthrough data to move people's practice. (Principal Jones).

She further elaborated to include how to set up walkthrough systems, an area in which she had little expertise. Principal Fitch also supported the idea that building effective walkthrough development was an area they received feedback on

Walkthroughs were discussed, like what tool to use, and how to use it to develop key performance indicators. He also stressed the importance of just being visible (Principal Fitch).

As she referred to key performance indicators, she indicated data points that are important to monitor in a CSI school, including, engagement, level of rigor, task complexity, and teacher time spent in lecture versus guided instruction. She went on to say that this pedagogical focus was worthwhile; as with Principal Jones, it was an area in which she did not have as much expertise. While admitting to having implemented a wide variety of walkthrough systems over the years, Principal Smith indicated that one area of feedback that he found particularly useful was tailored work with his mentor on walkthroughs and feedback systems

We spent time on working through a system to support feedback for teachers. I had done several different types over the years, but he made me look at how I could do one to support the amount of new teachers that I had... in our environment, we had a ton of new teachers, this was important for our growth (Principal Smith). 
Continuing in his remarks, he noted that this specific support was something that he took with him further in his career and tapping his mentor's expertise for this support was worthwhile. He reminisced that in two different settings as a principal, he had tapped his mentor for continued help and professional discussion on pedagogical concerns over the span of a decade. He thought it important to note that his mentor continued to help him, even after he was an experienced principal.

The sessions' foci revolved heavily around budget, with most participants indicating the importance of a deep understanding of the budget construction process and indicating that, going in, they knew very little. Secondarily, labor relations and personnel management were discussed often. The labor relation contract with the teachers was a consistently reported topic. Finally, a discussion on monitoring curriculum through a variety of pedagogical tools was found among several participants. With an understanding of their discussions' foci, participants were asked to elaborate on the length of their mentoring sessions.

\section{Theme Three: Length of discussion}

After some understanding of their sessions' content, participants were asked to expand on the amount of actual time spent with their mentor. The effectiveness of the amount of time spent working with their mentors was reported to differing degrees by each of the participants, with no clear emerging consensus among them. Principal Fitch 
expressed that the majority of their discussions were completed via lengthy text messages across the day and that this was helpful.

Formally, just like we do with our teachers in our building, we had PLCs for the four high school principals in our area... But besides those monthly PPLCs, I mean, I would say I reached out to my mentor probably on a weekly basis would be the frequency. Again though, my recollection was it was almost always, if not always initiated by me. I would send a quick text, or I would call, or I would shoot an email. My mentor was always super responsive. But I don't ever recall a time him calling me or setting up a meeting with me or any kind of a check in. So it was more as I was navigating things in the principal seat, if I had a question, he would be my go-to. So I'd fire off a text or call him real quick. I would say those informal conversations, probably at least on a weekly basis (Principal Fitch).

When asked if this served her needs, she indicated that it did, and that she found electronic communication to be more helpful than spending a lot of time face to face I needed him when I needed him. Having to go somewhere just took up time. I was glad he didn't set up a bunch of meetings, and that he served as my go-to (Principal Fitch).

Some found the face-to-face meetings to be more effective. Principal Wine reported that their meetings with their mentor were more formal, conducted in a weekly face-to-face session in her building in addition to phone conversations. She reported there were little to no electronic communications, and that often there would be more 
informal sessions where her mentor would randomly show up at her school to observe and help or would invite her to her own school to observe her practice.

We had very little electronic communication. That's probably because of the time that we were in. But she and I had probably daily communication. She would either come visit me at my school, and that was at least once a week, or I would go visit her at her school. We did a lot of afterschool hours, not any weekends, and she was just really there (Principal Wise).

For context, the 'time' that they were in was the early age of email. It had been used for a short amount of time in education and was not yet as prevalent as it is in 2020. She stated that this commitment of time met her needs as a mentee.

Face to face was a theme continued among other participants:

A mix, but a lot of it was in the beginning was dinner conversations. I think because this job can be lonely, I valued having dinner with who I consider my mentors and listening. And a lot of times, some of my mentoring wasn't because I asked questions, it was listening to their stories of what they went through and what they talked about, and me processing what they talked about and asking myself, "So how would I do this differently? How could I avoid the stress that they went through?" (Principal Jones)

In connecting to the theme of empathy for the work, it was noted that some of the participants saw the idea of these sessions serving as a de-stressor: 
The buck stops with you. But when me and him sat down, he knew that, had lived it. So we could talk about that (Principal Smith).

Principals Smith, Jones, and Wine all found face-to-face sessions to be more helpful.

Some participants favored a balanced approach. Principal Grey reported that discussions with her mentors varied. With her external mentor, they consisted of lengthy text messages, the occasional face to face meeting, and phone calls. With the mentor she hired in her school, they met daily, strategized over major initiatives, and conducted business together regularly during her first year as a principal. It must be noted that her experience hiring a second mentor is not a typical practice, nor have any instances of such been found in the literature.

She hired this mentor from specific monies allocated by the state department to her school for being in CSI status. This was deemed an acceptable usage of this grant money as it connected to leadership and capacity building for her school. When asked why she needed two mentors, she said she wanted as much help as possible. She found that on-demand help was most beneficial, as did Grey.

I didn't always have time for a sit down. It was best for me to shoot a text message, make a quick call. That first year is so busy-busy, it was better to just have a resource I could access when I needed it (Principal Grey).

The disposition towards on-demand help also appeared among the final participant:

Texts. I must have sent five thousand that year! (Principal Green). 
Among the participants, three found a balanced approach, leaning towards ondemand help as being the most beneficial. Three participants preferred face-to-face meetings, their mentor acting as a sounding board. One participant favored text only, ondemand mentoring, as they believed that more meetings were not beneficial.

Consistently, they all indicated that short communications about specific problems were very helpful to their practice. As many had indicated in their interviews, reflecting difficulty and fast-paced nature of the work, specific attention was paid to their mentor's empathy in the context of supporting their work as novice principals.

\section{Theme Four: Empathy for the work}

As all participants noted the highly stressful, difficult nature of the first year of being a CSI principal, they found that empathy for the work and support with work-life balance to be an important quality of their mentorship. It was a universally shared concern among participants that the role and the first year were intense:

I looked up, and it was Christmas break. You blink, and it just passes so quickly (Principal Smith).

The first year sucked. It seemed like I never had any time to breathe (Principal Jones)

It was good, cause I would have been lost otherwise, the first year as you know, its nuts. (Principal Fitch).

I was left alone, and it was tough. Would I have liked one (a mentor)? Yes. (Principal Logan) 
You know how that first year is, sink, swim, drown, and do it again (Principal Paul).

That first year is crazy. You have so much to do, so much to memorize, so much to take care of (Principal Wine).

Like I've got way more important things to deal with, it's a mile a minute, and it's something new every day (Principal Grey).

The first year is so difficult (Principal Green).

Among all of them, they stressed the complex demands, lack of time, and continual 'newness' of the first year as a principal. Consistently, they found a lack of time and understanding of certain aspects of the job and continual change to be stressors during the first year as a principal.

This is consistent with the literature in both non-CSI and CSI schools, with the preponderance of literature supporting the perception of the difficulty of being a first-year principal in a high-needs school. Supporting the person within the work was evident as the role of the mentor. Participant four emphasized that his quasi-mentors' belief in a work-life balance was helpful during his first year to know when to leave the work at work. Principal Wine noted that it was important to her that her mentor had done the work for some time and understood the time and commitment the job required. She further remarked that it was helpful to have someone readily available that could tell her if certain practices were normal, including spending a duration of time on a process or working on weekends, and listen to how her mentor balanced the stress of the position. 
Similar findings presented themselves from Principals Smith and Jones, who both said that their mentors support from the standpoint of emotional support was helpful. Both remarked that it was nice to have someone who had done the work and understood the job demands. Principal Green echoed this with specific feedback on their mentor.

She would write me encouraging notes. Leave them on my desk, or in places for me to find later. That was really nice. I took up that practice with my people, and still do it. Just a nudge to let them know I care (Principal Green).

The sense of emotional support extended further into gifts from some mentors, as Principal Paul spoke about:

I remember at the end of the year, she sent me a bottle of wine. A nice note attached to it, for surviving the first year (Principal Paul).

Principal Grey also noted the importance of this emotional support when describing celebrations to mark the transition into year two:

We went out to eat in May, right after the end of the calendar. Just decompressed, talked about how crazy it was. It was nice to just relax (Principal Grey).

The continual support manifested throughout the mentor-mentee relationships acting as a sounding board for participants:

One of the best things that came out of it was having a safety valve. You know how it is, it's difficult and lonely being the boss. I could call him and talk stuff 
through. I could have someone tell me I wasn't crazy when I felt so overwhelmed (Principal Grey).

Consistently among participants, they found the mentor to be beneficial support for their emotional well-being and the stressors associated with their roles. This most often manifested as support for the mentee by indicating that their stress level was normal and part of the first year of being a principal in a high needs school. Participants were further asked to expound on their work with their mentor on roles and responsibilities, specifically how their mentor clarified their responsibilities as a principal.

\section{Theme Five: Clarification of roles and responsibilities}

Given the complex nature of the principal's role and the myriad demands placed on their time, many participants felt that clarification of roles and responsibilities was important. This manifested in two ways; the first regarding roles and responsibilities of the job, and the second in terms of role and responsibilities for district personnel.

Principal Wine noted that the clarification of responsibilities was an important part of her mentorship, specifically in personnel evaluation and budget. She remarked that her mentor provided her with direct understanding of critical timelines for budgets and procedural guidance for employee evaluation and discipline.

Having never built a budget, we did it together. That was helpful... I had an understanding of what was expected come budget time, and who I needed to call (Principal Smith). 
He went on to further elaborate on how his mentor aided in understanding of the intersection of district roles with budget construction

He took me around to everyone. Told me who did what, and how they could help me. You know, who you are supposed to really call to get an answer... Who the real experts where in the district. I learned a lot from that (Principal Smith).

The clarification of budget and district roles continued:

Like I'd been handed this huge multi-million dollar budget. And I didn't know much, I mean I had sat with my predecessor and helped, but it's not the same. Mike, he had done it for decades. So he worked with me step by step, and explained exactly what I was responsible for, and who in central office was responsible for, and who to call when I needed something to happen (Principal Fitch).

The one participant without a mentor lamented specifically on the lack of support in budget construction and the lack of understanding of what was required when developing a budget. Principal Logan was entirely unclear during his first year of what his responsibility was and who he needed to work with in terms of budget:

Of all the areas I needed help most it was building that budget. I must have called a dozen people for help. They don't train you for budget, nothing more than an hour presentation at the time. I needed help in that. If you ask me where I needed clarification most... it was budget (Principal Logan). 
Principal Grey reflected that her work with her mentors contributed to her overall understanding of what a principal must do now versus what could be done later. She remarked that this aiding with personnel management and developing an understanding of due process in employee discipline. She found it effective to walk through potential discipline outcomes, strategize how to hold the disciplinary meetings, and conduct due process. She further indicated that both of her mentors did an excellent job teaching her about the various positions and their shifting influences in the district hierarchy. She elaborated that both mentors could give her a direct understanding of the job responsibilities that were most important in her role and what could be delegated to assistant principals. The idea of delegation to assistants came up in two other interviews:

One area that was good was working on division of duties for my assistants. I had to hire two in my first year. I knew I wanted to re-work their roles, because I had done it, and seen where some areas to improve where. So me and her worked on that, on how to build new AP roles. That was really good, because she had dozens of APs work with her over the years and understood how to work with people's strengths (Principal Green).

One response of note was how a mentor taught their mentee to measure their relative success in a school in terms of the state audit. This relates to responsibilities as every CSI school is audited by the state department yearly for progress. Principal Jones reported that clear understanding of the audit, the tools used, and the expectations attached were helpful. 
Any feedback or anything that I've always, anytime I've asked for it, it's always grounded in the tool that I'm being measured against and nothing else (Principal Jones).

Her mentor stressed the importance, especially in a CSI school, of understanding the nuance of the accountability system, including the metrics by which her school, and ultimately her job, were measured. Understanding the metrics their school was measured against and their responsibility in the audit process was an important part of her mentors' training. They felt it was highly important, and she agreed that she had a clear understanding of the process, how to prepare for it, and what she was responsible for in the context of the yearly audit. This sentiment was echoed further by Principal Green:

I didn't have the lens to understand accountability, until the entire system was explained to me. We spent a lot of time working on exactly what was expected by the state, and how we could influence and control parts of the test (Principal Green).

Multiple participants also discussed the added stress of being subject to an accountability system that could result in the principal losing their job:

So if you fail an audit, you've got two years, just like two years before your audit. And if you fail, that's it, your names in the paper, you're out. Me and my mentor worked on how to make sure that didn't happen (Principal Paul).

Principal Paul found that her mentor's clarification of the audit process, legislation, and regulations around CSI (at the time Priority status) related to her school. She noted that, 
without her mentor's guidance to understand these laws (as they were in their infancy at the time on a national level), her understanding of their impact would have been limited She found it helpful to have partners read through the new regulations and aid in interpreting them into her context as a CSI school. She further remarked that her mentors helped clarify whom to go to within the district with questions or resource needs. She noted that she had to learn all of this from a 'brand new' perspective, as she had not come from the CSI environment as an assistant principal, and her previous school was not CSI. Beginning her principalship in a CSI school, she was initially confounded by the audit process. Without the help and clarification, she would not have been aware of the tremendous responsibility of time and resources that a principal in a CSI school must commit to the audit process.

Participants found that clarification around the auditing process, the audit's metrics, and their responsibility for the preparation of the audit to be crucial. They also reported that it was important to have clarity regarding timelines, especially with budgeting, personnel management, and employee evaluation. Another support that emerged was the participants' needs for their mentors to indicate what they were responsible for 'right now' versus what could wait to prioritize the principal's responsibilities. As all these ideas are rooted in the principal's real-world work, participants were asked to shift their recollection and indicate if any of their mentorships was centered on hypothetical, constructed scenarios and if these theoretical problems were a part of their mentoring work. 


\section{Theme Six: Problem based learning}

For this study, problem-based learning is defined as a structured hypothetical scenario that the mentor and mentee would discuss. As referenced in the literature, some mentoring programs have these scenarios built into the mentor and mentee's predetermined work, most notably the Wallace Foundation work regarding principal mentoring. Problem-based learning was an inconsistent component of the participants' mentoring experiences. For the context of the interview, problem-based learning was described as being a hypothetical situation for a school designed by the mentor, or the mentors' guiding framework/curriculum, that they would discuss with the participant, outside of hypothetical problems of practice related directly to the happenings in the school.

Many participants reported there were no pre-constructed problems discussed in their mentorship. Principals Jones, Paul, and Green indicated no constructed problems that they worked through with their mentors. All three and their mentors would discuss context-specific hypotheticals, such as constructing a new schedule. They would leverage their experiences to help shape and mold what they intended to do within her school. All three indicated that at no time were hypothetical situations or constructed problems a part of their mentorship.

Principal Grey did not report any specific problem-based learning scenarios, instead noting that most hypotheticals were situationally based on current needs in her school. When asked to clarify, she indicated that all hypotheticals came directly from the 
context of her school. She did not report any structured problems that her mentor presented her to work through as a pair, with the exception of scheduling.

The only hypothetical that comes to mind is scheduling. I wanted to change the schedule, so she helped me by constructing three mock schedules, all different. We worked through what a day, a year would look like with each. That was helpful (Principal Grey).

She noted the importance of having a direct resource that had done many things in education and being able to ask about hypotheticals such as the scheduling scenario example, further positing that it would have been beneficial to do the same for other areas, such as adoption of various literacy programs.

Some participants reported that, while there were pre-constructed problems as part of the mentoring framework, their mentor ignored them, such as with the predetermined problems in the KPIP framework. Principal Wine said that the work with her mentor was only centered on real issues within the school.

We worked on real life problems. It wasn't problems that were posed to us, it was real life... she wanted me to see the workings of a school... it was really hands on real life things (Principal Wine).

She also added that they were given several hypothetical problems as part of the formal component of their mentoring arrangement, but her mentor chose to ignore them in favor of focusing on real issues within the school. When asked to recall the problems that were ignored, she could not. She found this to be effective, as it also indicated that her mentor 
was tailoring her work to align with the real-world needs of her school rather than to appease the mentoring program.

Further highlighting the adaptability of the mentor to their mentee, another participant reiterated that their mentor ignored pre-constructed scenarios, eschewing them in favor of working on the work that was already present in the school:

We had some hypotheticals that he had used in the past, but we didn't really do much with them. Like I remember him mentioning them, but it wasn't like we sat down and did them. I think they were just designed to jog thinking (Principal Smith).

This sentiment was consistently iterated by other respondents:

No, I don't remember any specific scenarios, other than if an issue came up, we problem solved it. Other than that, nothing like a written out problem for us to solve (Principal Jones).

Participants also indicated the potential for pushback against the use of scenrios not rooted in their day-to-day work:

We didn't do problem based work, and honestly, it would have been distracting. I had enough going on in the school that we worked around that, and that was far more helpful than something made up (Principal Fitch).

Consistently, the response among participants was that problem-based scenarios of a pre-constructed format were not, or would not have been helpful, instead finding 
importance in utilizing their mentors' experiences in working on real-world problems existing within the school. Moving away from the content of the sessions, participants were asked to discuss the attributes of their mentor and what they found most effective as qualities of a successful mentor.

\section{Theme Seven: Mentor Qualities}

Participants were asked about what qualities of their mentor they found to be effective. As openness, honesty, and trust were all similar qualities found universally positive by the participants, it was separated for analysis.

Outside of those qualities, participants were asked to respond to what specific qualities they found effective in their mentors. When asked if their mentor was assigned by any specific attribute they had requested, most participants responded no, outside of those who self-selected their mentors. Principal Paul self-selected her mentors based on her admiration for their work in the field and success in their relative assignments.

I chose mine because I wanted people I knew were successful and had done the job well (Principal Paul).

Principal Wine noted that her mentor was someone who was respected, seasoned, and considered to be a no-nonsense practitioner. This worked well with her own approach to the work. This connected to Smiths' response, and is noted several times throughout the literature; a mentor with a track record of success was found to be a successful attribute for the mentee. 
Principal Jones noted that success in a difficult school was a quality she admired in her mentors:

What I liked most about my people were that they had been successful, and that they were no-nonsense. Past that, I liked having folks teach me that were good at their job, and had done the hard school work (Principal Jones).

Principal Grey noted that her mentor was someone who was willing to try and not shortcut issues. She reported that this was an effective way of being coached, as her mentors were like-minded to her own approach.

She was someone who tried. I mean really tackled things head on. That was good for me to see, to not shy away from issues (Principal Grey).

She further noted that she respected creative thinkers, and both of her mentors exemplified this trait.

They were creative thinkers, as they approached issues in the school from a different lens but always student centered (Principal Grey).

A sentiment echoed by others, the need for creative, fresh approaches was appreciated, especially mixed with the experience of having been successful in the role.

She looked at things outside of the box, but with the nuance of having 'been there, done that.' She had seen so many reforms, programs, and initiatives she was able to filter a lot of that for me and say 'this isn't worth doing, this is.' That's pretty 
important during that first year because you are balancing one thousand plates in the air (Principal Green).

Additionally, the attribute of systemic knowledge came up among the participants. This manifested in a mentor who was able to parse information and create systems to manage and organize the work:

He knew how to build a schedule for himself. To this day, I still use a similar system in structuring my week. How much time to spend in walkthroughs, in the office, in the hallways, in the lunchroom. That was extremely helpful (Principal Smith).

I liked that he could tell me what I needed to do in a given day, in each week, and organize out my instructional calendar (Principal Fitch).

The principals found that admiration for the work of their mentors, belief in their success, ability to approach a situation from a new perspective, and systemic knowledge were all attributes they found to be successful.

\section{Theme Eight: Honesty, Trust, Openness}

Delving deeper into mentor qualities, participants were asked to respond about traits they found effective in their mentors. The sub-theme of honesty, trust, and openness was created as it was a consistent response among all participants, particularly the idea of honest feedback in a non-evaluative setting. Participants were asked to respond to the personality traits of honesty, trust, and openness; as all had expressed these to be desirable attributes, a follow up was asked of each to expound on this notion. The 
participants' responses robustly supported the literature. Principal Fitch cited her mentor's authenticity as a beneficial trait:

He was very straightforward and even candid and honest (Principal Fitch).

Principal Paul stressed the importance of trust. She found it critical that her mentors were not her evaluators, nor did they work for her supervisor. She noted that it was important to have critical, reflective, off-the-record conversations that did not reflect poorly on her or lead to an impression of incompetence. Principal Grey found that trust and honesty were important traits of her mentors.

I don't like sycophants. I don't like people who are loyalists, who are just going to say whatever they think I want to hear, because they think that's going to further them. I mean, I do like people to push back on me because I can have some great ideas and I can have some stinker ideas. I need people to keep me in check, because I can go off on tangents... and my mentor's really good at that. She's been really good at that, even after non-mentoring, just being a friend. (Principal Grey).

She further elaborated that the qualities of honesty and trust were important in regard to having critical conversations about practices in the district. Being able to have these conversations while in an environment of trust was critical to her development as a new principal, as they allowed her to push boundaries of policy and understanding in a safe space with her mentor, because she trusted in their confidentiality. 
You've got to have that person that you can trust to have those critical conversations with, and a lot of times it can't be your boss (Principal Grey).

The theme of being non-evaluative was important, as many participants indicated that having a resource that was nonjudgmental increased their comfort level, and that the openness and honesty of candid non-evaluative feedback was important to their development.

Without even really knowing me, just looking at my data and little surveys and perception data, she nailed it on the head. She was like, "Jones, you will fall if we don't allow other people to fall." The best coaching advice she gave me was you have to allow people to make mistakes if you expect them to get better, and you have to stop micromanaging and that your ego has to be set aside. And so that's a different type of coaching that was just as valuable for me, and it was real. I didn't worry that she was going to mark me down on my summative; she was my mentor, and not my boss (Principal Jones).

As with most highly valued non-evaluative feedback, this came from a position of trust and honesty. Participants were consistent in their perception that open and honest feedback was important to their development. This could not have come from a supervisor or in an evaluative setting. The lone participant without a mentor echoed the sentiment of the important on non-evaluative feedback:

If I call my boss, he thinks I don't know what's going on, so mostly, I'd just call other people and beg, borrow and steal what I needed (Principal Logan). 
The concept of honest, non-evaluative feedback manifested as a driving force in many of the participants relationships with their mentor:

The best part about this was that she was honest with me about what my deficits were (Principal Grey).

The principals liked the opportunity to analyze their practice and shortcomings in a setting that was non-judgmental and found this to be an important part of their mentorship:

It was real, and it made me think. I didn't worry about it being something that would get me dinged. She could sit across from, shut the door, and be real with me (Principal Wine).

This honesty would cause deeper introspection, and shift in practices at the school:

I ask for help with something, she tells me, "I want you to figure out the solution and come tell me what you think the solution is, and then I'll give you feedback." Then she would pick it apart, tell me where I was making a misstep, and we'd fix it (Principal Jones).

The honesty and openness of the relationship also served as a place for the participants to be able to express their feelings to someone of authority without seeming to lack knowledge in their position:

I asked her things I didn't want to ask my assistant superintendent. Stuff I should have probably known, but didn't know, or was too naïve to ask (Principal Green). 
Universally among the participants, the concept of an open, honest, nonevaluative mentor was a net positive in their experience. Most notably, they remarked on the importance of analyzing their work and reflecting in a non-judgmental, nonevaluative setting with someone they perceived as being honest with them. It allowed them to work on their foibles without the threat of their job hanging over their heads. They found the trust of this relationship to be very important.

\section{Theme Nine: Perceived and Demonstrated Effectiveness of the Mentor}

The perception of and demonstrated bona fides of the success of the mentor has been touched on in previous themes, with an importance placed by several principals on the success of their mentor. When asked to expound on this theme, participants indicated the overall importance that their mentor was a successful practitioner with experience in actually working to turn around a CSI or struggling school.

Principal Jone's mentors both were seasoned veterans, with a history of success in their schools:

One of my mentors has been an assistant superintendent and gives me feedback from a systems level, always pushing you to think critically about why decisions have been made. She knows her stuff, had done her stuff for years, and everyone in the city knows she's the real deal (Principal Jones).

This sentiment is by other participants regarding their mentors; Principal Smith who also noted that success was an important factor in taking his mentor's advice. He found it 
foolish not to do so, as his mentor had been so successful and regarded as a great principal in the district.

It was nice knowing he had been there, done it, and was successful. If he said 'do this', odds are, I probably should (Principal Smith).

Principal Fitch was told she was paired with a very seasoned principal, and she reflected that his more than three decades of experience enabled him to contribute a wealth of situational knowledge to her early practice. She indicated that his experience working in several schools gave him positional authority to have seen almost everything in education. For her, this meant that, as he had been a principal in so many schools, a district leader in a separate district, and had taught administrator preparation courses in which many high-level district personnel had been students, she viewed him as a positional authority in the district able to speak on all issues she encountered. She found that his wealth of experience, which was nearing 40 years at the time of her mentorship, was an advantage to her preparation as a novice principal. She accepted it as truth when he told her that this one issue was more important than another. She took direct guidance from his experience on doing her daily work and understood that he had given the same guidance to many of the people now higher up than both of them in the district.

Principal Paul self-selected mentors based on their success in previous buildings and their standing in the district. She found having an experienced principal from similar circumstances to be beneficial, especially for logistic, process, and personnel issues. Her 
self-selection is consistent with the now defunct program of the district placing experienced, successful principals with new principals.

Principal Wine reported that having a CSI principal as her mentor was effective and contributed to her overall success as a principal.

I think just having that person who knows that work or has at least experienced it, has been really beneficial. Not to demean or anything anybody that can just come and give you assistance, because I think they can. But it's a little more impactful when they've already lived through it (Principal Wine).

Principal Grey noted that both of her mentors had been successful principals in the district and, as this gave them positional authority, she trusted their guidance. She remarked that, having mentors that had non-renewed many teachers in their careers, helped them "hold her hand" through the process during her first year.

It's got to be somebody who will tell you the truth, give you their experience, but is not beholden to you and is not evaluating you. For it to work, they have to have been there, done that (Principal Grey).

Principal Green agreed that having an experienced, successful person to give her guidance was beneficial. She found that she accepted feedback more readily when it came from someone who had demonstrated their strategies worked in practice.

Interestingly, Principal Logan, with no mentor, made it a point to seek out those he felt were successful in the district and tap them for help when he needed it: 
I was pretty much left on my own to figure it out and rely on my own network of people to ask questions of and seek advice and whatever else. So I went and talked to the best in the district and asked them when I needed advice (Participant 4).

His experience was consistent with the rest who expressed that experience and success of mentors were desirable qualities.

Consistently, all participants, even Principal Logan who was not assigned a mentor, found value in someone who had been successful, demonstrated that success over several years, and was well regarded by their peers. All principals reported that they were more ready to accept feedback from a practitioner who had been successful. To further analyze this theme, the mentor's social position in the district was discussed with each participant.

\section{Theme Ten: Social position of the mentor in the district}

The literature surrounding mentorships noted that the mentor's social position in the district was often perceived as an important factor in the mentor-mentee relationship. The mentor's success in the field has been discussed, but further discussion was warranted regarding their social position, how others perceived the mentor in the district, and how they related to their relationship with the mentee. The relevance of this theme was confirmed by the participants' responses. Principal Fitch responded that, as her mentor was well respected in the district and had seen almost everything in education, she believed her mentor's experience contributed to her authority as a principal." 
It was nice to have a conversation with somebody who would just be honest and straightforward, who had taught most of the principals and central office people (Participant Fitch).

Principal Grey responded that the positions of both of her mentors as being respected, successful principals in the district enhanced her credibility with her peers:

Everyone knew her. Everyone knew she was effective. I knew she was effective (Principal Grey).

This perception of effectiveness of the mentor was reiterated by Principal Smith, who found that having a mentor who was seen by others to be effective, led others to perceive him as more competent.

My guy was probably the best in the district. He had been recently promoted to assistant superintendent, so everyone knew how good he was. Did that rub off on me? I hope so (Principal Smith).

The idea that the effectiveness of the mentor transferred some credibility to the mentee was further elaborated on:

Everyone in the district knew them both. They knew that they had been the best, and, when I had an idea that I needed to take to my boss, I could say that they had weighed in on it, which meant something to my boss. They were trusted, so I could use their word to back my ideas when they had vetted them (Principal Jones). 
This also manifested in terms of belief in their ideas and the perception that their ideas came from a wealth of experience. Principal Paul, in particular, found this to be important, as she believed that an idea posited by her mentor would be perceived as sound, as her mentor was well respected in the district.

She had done everything, so if she said "Do this" I listened for the most part (Principal Paul).

The social position of the mentor also aided in navigating the complicated bureaucracy of the district. All participants indicated at some point in their interview how difficult and complex the first year as a principal in a high needs school was, and they often remarked that part of this complexity was due to the fact that they worked in a large district with over ten thousand employees. They found that their mentor's social position, as people who stood out among their relative role groups as being effective, was important in helping them navigate the complicated network of positions within their district.

She knew what everyone did, because she had been around for so long. So that helped, because she could introduce me to people I didn't even know I needed to know (Principal Jones).

He knew everyone and had taught most of them. So he made it a point to introduce me to people and tell me what they did for me (Principal Fitch).

This also appeared as generate positive perceptions from peers: 
I think sitting with her at principal meetings introduced me to folks. Like, if she is with her, she's probably going to stick around (Principal Green).

However, there was some distinction between the different levels of K-12 schooling. Principal Wine responded that her mentor's social position in the district was well respected, but that she employed at different level (elementary versus the participant's role at a middle school). She remarked that this was the one thing she would have changed about her mentorship, as, while her mentor was a respected principal, being a different level did offer some hindrances of understanding of the needs of middle school students. She also reported that her supervisor did not think that having an elementary mentor was effective and would often question guidance from the participant's mentor when discussed.

My mentor that was the only thing I would probably change. My mentor was an elementary school principal, and she was at one of the more successful elementary schools in the county. So, our experiences were different, since I was in the middle school. So, if I could change that quality. I mean, she had the knowledge base there, because she had been a principal for so long. But I think when you talk about somebody mentoring somebody else, they need to have lived in that particular place. So, having a middle school principal as a mentor, and you're a middle school principal (Principal Wine).

All participants responded that the social position of their mentor mattered. This aided them in terms of perceived credibility from others for working with their mentor, 
navigating the complicated bureaucracy of their district, and the idea that their solutions to problems would be well respected by others because of their social position within the district.

\section{Theme Eleven: Disagreements with the mentor}

Participants were asked if there was a time when they disagreed with their mentor's approach or advice and how this was navigated. Principal Paul discussed a context in which she and her mentor disagreed, specifically on their different approach to positional power.

Positional power became less of a thing for me as a principal, which is strange, and probably sounds counter intuitive, but I knew I was going to win, but you win the battle, but maybe you lose the war. And Jill always wanted me to go to war (Principal Paul).

She found that their differing approaches helped codify her approach to both employee discipline and navigating union relations. She indicated that the complexity of the contract and dealing with labor unions was an area that much of their mentoring sessions focused on, and she found effectiveness in being able to codify her thinking and approach versus her mentors'.

Then to some extent, that's why I backed off of her advice because she always wanted me to go toe-to-toe with the teacher, and get the union reps in, and do all of that with the contract, rather than trying to work it out with the teacher. And I always tried to tell her there's a difference in being able to keep staff at North 
Hope and being able to keep staff at West Hope. And so I made sure that everything that I wanted to do was contractually legit. So I didn't ever ask anybody to do anything that was against the contract, so that then I knew I could never be grieved and really for real lose. And if I came across a decision that I had made that I knew was grievable and could lose, then I changed the decision (Principal Paul).

Principal Grey noted that she often disagreed with her mentors, and this served as a sounding board to influence her decisions.

That discussion is always good, and I would throw out some things to my mentor would be like, "Oh, I don't know about that." I don't remember any specifics, but yeah, there were times when there were disagreements about... not disagreements, but just it goes back to that whole questioning thing. So, I'm pretty strong willed, and if I really get something in my head that I think is going to be a good idea, I'm going to plow through it, but I do like, just those questions. "Did you think about this? Did you think about this? Did you think about this? Did you think about this?" Because there's some real landmines that you can fall into, and just having that person be that check... I don't know if that I would couch it as necessarily disagreements, as in so much that I think both recognized in me that, if I really had an idea in. If I really felt strongly about something and had an idea, then I pretty much was going to try to remove every barrier, but I wanted them to give me the barriers. Like, so what are all the barriers going to be? So I can 
figure out how to remove those barriers, because I really think this is a good thing (Principal Grey).

She noted that this mostly often occurred when discussing scheduling concerns and barriers to reconfigure staff around newly constructed uses of learning time. She described an exchange consistent with this area of disagreement:

Oh yes. We disagreed hard about block versus trimester. I was highly in favor of tries and she tried to talk me out of it. She was rooted in the idea that block was best for our kids. We argued a lot over that, but it was good. It only made me dig in harder to the trimester (Principal Wine).

When asked if this disagreement led to a perception of animosity with their mentor, the participant said it did not, instead only serving to enrich their professional dialogue.

Principals Smith, Jones, Fitch, and Green could not recall when they specifically disagreed with their mentor. When pressed for further commentary, the consistent response from the four was that, while a minor disagreement might have occurred, it only existed to further elicit deeper thinking on an issue. All in all, disagreements with mentors were reported as rare, and, when they occurred, it only served to help solidify thinking and practice for the participant and was viewed as a positive experience.

Having explored various themes regarding the content of the mentoring session, in addition to the attributes the principals found as important for their mentors, the principals were asked for their overall impression of their mentoring exerience's contribution to their success as a principal of a CSI school. 


\section{Theme Twelve: Contribution to success as a CSI principal}

Participants were asked if they believed their mentoring experience contributed to their successful retention during both year one and subsequent years in CSI principal roles. Of the seven participants who had a mentor, all but one agreed in their response that they believed the experience not only contributed to their retention year one but their subsequent years in CSI work. While some of the participants had since moved out of CSI work, all had several years in high needs schools.

Principal Jones responded that she would not have finished her first year if she did not have access to a principal who had lived the same experience of a high stakes, high accountability school

She was my life saver at times. Could talk me down off a ledge when I thought it was time to quit... I didn't realize how much you needed somebody to talk to, almost like a therapist. So when they assigned me a person that really got me through (Principal Jones).

This sentiment was echoed by other participants such as Principal Jones who found the overall experience to be effective and supportive of her growth:

You get your feet under you, and it's like okay, I'm brave enough now to pick up the phone and call the district, and I don't really need Jill. And then I'm also smart enough to know the contract myself, and read the contract myself, and be able to figure all of this out. And so then Jill became less important. But that 
wouldn't have happened without her coaching me to that point. So yes, without a mentor, I don't think I would have gotten there (Principal Paul).

Some indicated that the support of the mentor had a direct effect on their retention:

Yes, it sure did. I would have probably quit mid-year if I wasn't able to decompress with her. I needed that, you know? Someone to just sit with who knew the stress, and make sure I was okay and not overwhelmed (Principal Wine).

Yes, I thought about quitting by December. My mentor took me out to dinner, and told me it was normal to feel that way (Principal Green).

One participant specifically addressed how their mentor talked them through a difficult time during their first year:

I remember calling him and being like I'm ready to day drink. He did a good job of listening and working through the issue at the time. I felt like I was being pressured from central office to do one thing, but it wasn't right for my students. He ended the call with "You do right by your kids, always" and that stuck with me. I had to do some explaining later on, but I did the right thing, and I think it empowered me to hear him say that. He had done it so long, and everyone knew he would do what he wanted, but hearing him say it was okay to push back, yea (Principal Fitch).

Consistently, participants responded that having a seasoned practitioner by which to gauge their own stress level was important. All of the participants said during their 
interview how stressful the first year as a principal was. The sentiment also manifested with one participant specifically about how to end their first year, and subsequent years:

We talked about getting through the first year, how hard it was, how it never really seemed like anything went very well. We talked about how the next year was better, and that the work could be heartbreaking, but that the progress, any progress like that, was good and worth doing. She helped me to understand why I wanted to continue to do this. I knew why I wanted to start, but she helped to work out for me the why of staying (Principal Grey).

Only one respondent replied in a more lukewarm manner when they were directly asked about their perception of their mentor's influence on their retention

I mean, I would say the informal mentoring that I received was beneficial. I don't think I can say that it increased my likelihood to stay in the role. I think I would have continued regardless of that (Principal Fitch).

Even as the same participant had indicated that their mentor had helped them through a tough time, they did not feel that their mentor directly influenced their retention, as they would have stayed in their role regardless.

Aside from the near universal praise of retention and support, some participants indicated more specific items that their mentor influenced over the years. Principal Grey responded that she could not have had the gains she did as a school, nor would she have been as successful as she was, without her two mentors: 
I learned so much from my people. I learned how to prepare for accountability at the end of the year the right way, and to be able to prepare my teachers for it, and my kids. That's hard, when it's your first time. I wouldn't have been able to know some of that without my mentors (Principal Grey).

Accountability preparation was similarly referenced among other participants. It is relatively important to note that, in a CSI school, accountability is extremely important as the school is audited by the state department once a year. These audits can result in the principal being removed from the role, half the staff being removed, or the school being shut down by the state. Most often, if an audit finds deficiency, the principal is removed. This is a public process that is stressful and can put a large damper on a promising career. Because way back then it was even more stressful, especially being a black female, trying to get ready for an audit. And you don't know what their perceptions or stereotypes and things of that nature. So she always felt like if you needed this much evidence, she needed that much evidence. You know what I mean? But I remember saying to myself, "If I'm a principal, I'm not doing that." You know? And so those are the type of things that helped shape me and then just listening to their feedback (Principal Jones).

This was said in a similar manner in other interviews, specifically noting the importance of the pedagogical impact of their mentor:

I learned more in my one on ones than I did in principal meetings that year. I was drowning in principal meetings, but one on one, we could work on exactly 
what it was that I needed. Reflecting back, that was probably the most impactful, was just being able to process with my mentor (Principal Green).

The idea of the impact of one-on-one time came up among other participants:

I got a lot sitting down with him. I got a lot just being able to talk through my frustrations. That helped me during the first year (Principal Smith).

Consistently seven of the eight respondents indicated that their experience was positive, with six attributing their retention in some respect directly to their mentoring experience. All indicated positive perceptions of the experience, manifesting in many aspects of pedagogical, management, and emotional support. 


\section{CHAPTER V \\ DISCUSSION AND CONCLUSIONS}

\section{Introduction}

The purpose of the study is to examine Comprehensive Improvement Schools (CSI) principals' experiences with mentoring programs and their perceptions of how such programs may mitigate administrative attrition. This study seeks to answer the question: "How do CSI principals perceive principal mentoring programs in terms of benefits and intentions to stay in CSI schools?"

The study was designed for the results to be used by current practitioners in the field to better develop mentoring programs. This study was conducted from the lens of the pragmatic interpretative framework. Pragmatism focuses on the outcome of the research and its usability in the field. Creswell (2010) describes pragmatism as existing in the current social, historical, and political contexts, and that pragmatic researchers are concerned with the "what" and "how" of research. Pragmatic researchers have freedom of choice in methods to fit the needs of the question they have posed. Greene and Caracelli (2003) place pragmatism as the balance between philosophy and methodology.

The literature indicated that while mentoring has been generally found to be effective by participants, there is no consistent policy regarding mentoring at the national, state, or local level. There was limited research in the realm of CSI work, with few studies specifically analyzing principal mentoring in CSI schools. There exists a gap in the literature in both the realm of CSI principalship and in providing recommendations 
for model mentoring policies, gleaned from the experiences of those who have been mentees.

\section{Contribution to success as a CSI principal}

The principals included in this study reported that their mentoring experiences were positive and contributed to their retention as CSI principals. They reported a wide variety of positive outcomes from their experiences, and, from their experiences, we can see a variety of recommendations when paired with the existing literature regarding principal mentoring. The experiences of these principals are consistent with mentoring programs at the teacher, assistant principal, and principal levels in education. They, like many others, found value in being paired with a seasoned professional with certain attributes and experiences to better prepare them for their own practice and to act as a guide through their first year as principals. All of the respondents discussed to varying degrees the level of complexity of their role as a principal, the level of stress, and the added stress of being in a CSI school, where pressure from both their district and the state department of education were intense. In fact, there were no net negative outcomes that the principals of this study reported, with all finding differing degrees of value in the mentorship.

Separating out what worked for each principal within their own experience creates strong recommendations for policy and future practice. To begin, we look at the impact of using a specific mentoring program, curriculum, or framework. 


\section{Frameworks and Curriculum}

The principals reported that the majority of them, five of the eight, did not use a predetermined curriculum, framework, or guiding document for their mentorship. Two did: one, notably, with an at the time state-mandated program, the Kentucky Principal Internship Program (KPIP), and the other in a district developed program. Both of these programs are defunct as of this writing. When asked whether they thought using a curriculum or framework was beneficial, one of the two thought it was generally helpful, while the other did not. When those who had no framework were asked if they thought a pre-determined curriculum or framework would have been beneficial, they indicated neutral responses. They had no polarized opinion, positive or negative, on the inclusion of a framework.

Their experience mirrored much of what the literature indicated. While principal mentoring has seen some attempts at nationwide initiatives (NAESP and PALS), there has been no widespread acceptance of common professional development. The Every Student Succeeds Act (ESSA) provides federal dollars that states can use to support principal retention under Title II. The regulations state that $5 \%$ of the Title II budget may be set aside for leadership investment. As of this writing, the state in which this study was conducted had not utilized this Title II component for a statewide mentoring program; however, New York State and Iowa had utilized the funding in new initiatives (Lochmiller, 2017). While this has inspired some attempts at other state levels to develop mentoring programs, only one of the participants was in a program remotely similar to 
this initiative, and, while their report of the initiative was positive, they did not feel that the framework was what made it overly positive.

The principal who was a part of a district-led initiative echoed the response from many in the literature (Kram, 1985; Hall, 2008; Helber, 2015; Manna, 2015; Lochmiller, 2017) in that, while they saw value in being mentored, they did not necessarily attribute success to the content of the program but rather to their relationship with the practitioner. The significant aspects of the participants' responses run parallel to the body of literature regarding mentoring. For educational institutions that want to have effective mentoring programs, their emphasis must be placed on the mentor's human capital rather than the pre-determined curriculum. Consistently, this study found that the participants either had indifferent feelings toward the inclusion of a curriculum in their program or found it to be a barrier in their mentoring relationship as paperwork distracted from the time that could be utilized to tap their mentors' professional acumen. Their experiences runs counter to Villani (2006), who found that basing mentoring around a key series of standards is essential to a mentoring program. These standards should be developed in the local district or state context, specific to the needs of the school being served. In New Mexico, work on national mentoring standards was requested by state educational leaders, but no specific pedagogical skills were mentioned (Villani, 2006) and the initiative never gained traction. The closest document to formalized standards for skills development comes from the Illinois Principal Association, a non-profit entity that calls for work from mentors with teacher professional development, mission building, and strategic planning 
(Augustine-Shaw, 2015). However, this initiative has no available white papers or formalized study on its effectiveness.

There are no standards that are utilized across states, and mentoring relationship content is left to individual districts or mentor-mentee pairs. In balancing the experiences of the principals within this study with the existing body of literature, recommendations to local districts regarding policies would begin with fostering the estblishment of a strong relationship between the mentor and mentee. Second, identifying key learnings and desired knowledge tranfer the district would see accomplished, and establishing a bssic outline for the mentorship. This outline would include items that all principals, regardless of individual skillset would need for their first year. Lastly, give the mentor the freedom to tackle the content in a manner that makes the most sense in the context of the mentorship. This flexibility seems to be a consistent need as reported by mentees.

\section{Mentoring Sessions}

Participants in this study reported mixed perceptions of the varied types of mentoring sessions, specifically in regard to formal sessions versus on-demand sessions. Some engaged in formal sessions led by the mentor, while many attended informal sessions on demand from both the mentor and mentee's request. There was little consistency among the participants other than that the on-demand feature was found to be effective by the mentees. The study's findings support many of the findings of the body of literature (Helber, 2015; Lochmiller, 2017; Manna, 2015). Mentees reported the most beneficial items received from mentoring were direct support, feedback, empathy for the 
work, and clarification of the role's responsibilities (Schechter, 2014), which was upheld by the participant's belief that on-demand support from their mentor was worthwhile.

On-demand support is a theme that emerges consistently both from the literature (Daresh, 2004; Dodson, 2014; Duke, 2014; Lochmiller, 2017) and the principals surveyed within this study. The literature tells us that mentees reported that face-to-face communication outside of the normal school day was a positive aspect of mentoring (Augustine-Shaw \& Funk, 2013). Metzger's (2003) results concurred with the concept that frequent and on-demand communication to talk through problems was highly valued by mentees, supported further by numerous studies (Daresh, 2004, 2006; Schechter, 2014).

Given the fluid nature of a school and the variety of issues that crop up daily, the idea that a novice principal needs on-demand support makes sense. The principals of this study and principals within other studies (Duke, 2014; Frys et al., 2005; Gimbel \& Kefor, 2018) consistently report that there is not enough time in the day and that the first year is overwhelming in terms of work. For practitioners overwhelmed with the work, having a trusted advisor to call upon as needed would be a benefit, serving to troubleshoot, ask advice, and support due to the variety of needs presented by a high-paced CSI school.

While the preference from the respondents leans toward on-demand support, there also exists room for deeper conversation in scheduled sessions with the mentor to discuss standing agenda items, provide additional training, or simply give a structured space to bring long-term concerns to their mentor. The principals within this study reported some 
favorability in these structured meetings, with participants' preferences leaning towards more on-demand communication and fewer structured, face-to-face meetings. This is further supported by Schechter (2014), Davis (2015), and Daresh (2004, 2006).

A model mentoring program would make room for both on-demand and structured, face-to-face communication for deeper learning with the mentee. The ondemand portion would require the mentor to understand that they are a resource for their mentee when the mentee needs advice and direction. The mentor must understand that most of these communications would occur via electronic means i.e., text messages, and emails. Mentees reported their preference for these quicker modes of communication, with text messaging being the primary preference. One principal mentioned they preferred not to use email because, if it was work email, it was subject to open records requests and therefore not confidential. For the face-to-face components, the meetings would need to be scheduled in advance to respect the complex time demands of both practitioners.

\section{Focus of discussions}

The content of the mentoring sessions was an area heavily discussed with the participants. The principals' predominant areas of conversation were budget construction and allocation, personnel management and labor relations, and monitoring curriculum.

The study found that the budget was a heavy topic of an ongoing conversation. Principals reported universally that the creation of the school budget was an area in which they had little to no training before becoming a principal, they found the task to be 
daunting, and they reported that their peers told them that budget construction was an area in which they could not afford to do poorly.

The literature supported the importance as significant factors of training, preparation, and clarity around budget construction. Budget development and creation of instructional systems were reported as areas in need of development with their mentors (Shoho \& Barnett, 2010) and are further identified as high stress areas for novice principals. In multiple studies, principals reported that they found the budget to be a stressor and asked numerous questions of their mentor involving budget. Mentors within the realm of literature supported this statement, teaching mentee principals how to understand and allocate the resources available to them (Fullan et al., 2006) being a consistent area of focus.

Reflecting on their experience with budget construction, the principals reported that it was daunting and a stressor to be suddenly in charge of a multi-million dollar budget with little understanding of the various funding pools available to them. Principals reported that they lacked an understanding of the difference between their general budget, federal budgets, federal, state, and local grants, and the other variety of funding sources. During their mentoring sessions, they requested specific feedback and discussion on what these 'pots' of money could be used for and how to best allocate them in light of their mentor's experience.

Second, labor relations and personnel management were discussed often. The labor relation contract with the teachers was a consistently reported topic by the 
principals. This manifested in understanding the limitations placed by the contract, how to navigate union management, and how to conduct employee performance evaluations in accordance with the labor contract.

The importance of labor relations as a topic of frequent discussion is consistent with the literature. Common areas of discussion for newly minted principals with their mentors included hiring and removing ineffective staff (Whitaker, 2012). Respondents also indicated that employee evaluations were important learning components from their experience with mentoring (Augustine-Shaw \& Funk, 2013). The difficulty with labor relations is oftentimes centered on understanding how to build an effective personnel evaluation system. Results from studies conducted by Gimbel (2018), Helber (2015), and Duke (2014) support the principal's experiences. Support with staff performance evaluation and having performance conversations was also a common topic of discussion between mentors and mentees (Duke, 2014; Gimbel, 2018; Helber, 2015). Duke (2014) illustrated that staff evaluation was an area in which many novice principals found frustration, and Gimbel (2018) and Helber (2015) reported that employee evaluation was a level of stress for principals.

The mentor's availability as a non-evaluative person was also important to the principals, as they found value in asking questions to someone other than their boss. Each mentorship of which the respondents were a part was reported to be a confidential relationship, which is the trend among mentorships across education. This notion was also supported by Goldring's (2014) findings that a trusted colleague was important to the mentees. 
Performance evaluation was reported as a consistent topic of conversation from which mentees benefitted, especially in an environment with a trusted colleague who could answer questions without the mentee appearing to have a lack of knowledge to a superior (Goldring, 2014). The idea of a mentee being able to ask questions without appearing to lack knowledge is repeated in other themes throughout this chapter. Hall (2014) expanded this notion by finding that among respondent novice principals, value was placed in mentors that did not provide specific answers but served as a sounding board for participants to work through the difficulties of their school issues. Having a relationship where a mentor asks questions, helping their mentee establish decisionmaking schemata on their own rather than being told the answer, was found to be a powerful reflective aspect of the mentor-mentee relationship (Daresh, 2004).

The third focus of the discussions with their mentors revolved around monitoring a variety of curriculum strategies. Data analysis was a particular trend observed in this study, as several of the principals indicated the need to have a better understanding of student data to monitor school effectiveness. This is doubly important in the CSI environment, where the principals' job performance is tied directly to ever-changing student outcome metrics. This concept is prevalent throughout the literature, including in Augustine-Shaw and Funk (2013), in which respondents indicated that data analyses were important components from their experience with mentoring. Byrk et al. (2010) indicated that allocating resources using data analysis protocol was reported in both studies as being prominent areas of need of mentees. Lochmiller (2017) and Goldring (2014), the notion of data analysis as an area of growth is further supported with a keen 
understanding of how to identify the right type of student achievement data to track in the context of the school and districts' needs.

With the variety of student data available in the modern educational setting, it is not surprising that principals want their mentor's assistance in understanding what to monitor and creating systems to monitor key data. Principals consistently reported that they were confronted with a plethora of data, and monitoring it all was not possible. This data manifests as state accountability test results, interim assessment results from districtmandated tests, school-level assessment results from common formative assessments, attendance data, behavior data, mental health data, crisis intervention data, free and reduced lunch data, and a wide variety of other data points. The mentor served as a guide, from their experience, on what data was worthwhile for the mentee to monitor closely.

Beyond the three major focus areas of their discussions, the principals reported various nuances in the instructional planning processes for which they sought support. The literature confirmed this basic notion that the principals reported; the ability to call with on-demand questions and receive feedback was critical. Mentees reported that they found the most value in on-the-job, problem-solving strategies (Augustine-Shaw \& Funk, 2013) where they had a mentor they could call with a context-specific question and ask for advice; this idea was supported heavily by the principals in the variety of smaller instructional planning needs they reported. Program planning was an area in which participants felt they had little preparation as assistant principals. 
This manifested broadly in terms of program planning for the novice principal. Once they understood what and when to monitor, they wanted support on how to influence the data in a positive manner by improving the instructional programs they monitored through adjustment of programmatic offerings in their school. Common areas of discussion for newly minted principals with their mentors included development of instructional systems (Whitaker, 2012) focused on how to best leverage existing resources and strengths of their instructional staff to reflect the articulated goals for the school. Intersection of available strengths with long-term goals was also an area of need, as long-term planning was reported as an area of need by the mentees. Coupled with this was an understanding of how this intersected with the school's long-term goals, supported by Dodson (2014), who reported that Kentucky principals most noted the need for specific training on the improvement planning process.

Sometimes, this came as a confirmation of their solution, the mentor's use as a sounding board, or support for a decision. Mentors reported that work's primary components with mentees centered on planning, supporting on-demand problem solving, and giving emotional support (NHASP, 2014). The importance of having the mentor's experience, on-demand to assist in instructional planning, problem-solving, and support, cannot be overestimated. The majority of the principals in this study indicated that simply having someone experienced and trusted to whom they could bounce a idea was the most important aspect of their mentorship. 


\section{Length of discussions}

The amount of time spent in the mentoring arrangement and communication flow between the mentor and the mentee was discussed among the participants. The literature found that having a relationship where a mentor asks questions, helping their mentee establish decision-making schemata on their own rather than being told the answer, was found to be a powerful reflective aspect of the mentor-mentee relationship (Daresh, 2004). Time for lengthy discussion and coaching was also a key finding among novice principals' perceptions of improved preparation (Clayton et al., 2013). This is reflected in the principals of this study's experiences.

The principals reported that on-demand access to their mentor was particularly beneficial to their support. Consistently, they all indicated that short communications revolving around specific problems were very beneficial, and on-demand access was more favorable than face-to-face meetings. The principals preferred to have a trusted, knowledgeable colleague on whom they could call for advice regarding practice problems. This supports Schechter's (2014) findings, in which the vast majority of the respondents indicated that constant, on-demand communication was critical.

The principals consistently discussed how busy the first year as a principal was, along with the pressure of being a principal in a high-needs school. They valued using electronic communications, most often text messages, to reach out to their mentor for immediate support. Supported by the literature, mentees reported that they found the greatest value in on-the-job problem-solving strategies (Augustine-Shaw \& Funk, 2013), which they accessed by calling their mentor with a context-specific question to solicit 
advice. Coupled with this was the idea that their time was valuable, and that their mentor understood this because they had lived in the same environment. Trust, coupled with listening, was a central attribute reported as desirable in a mentor (Augustine-Shaw, 2015), and the principals communicated this notion in this study.

\section{Empathy for the work}

The principals in the study often discussed the complexity, fast-pace, and stress of their first year. The attrition for first-year principals is well known and more prevalent in high needs, CSI schools. The concept of first-year principal stress has been studied, most notably Metzger's (2003) study of new principals and superintendents utilizing mixed methods which indicated that, among the 40 urban educators surveyed, most found that the inability to cope with stress and time management were reasons they had left or strongly considered leaving the profession. Villani (2006) agreed, citing his results that concluded that the principal working alone, consistently on the clock, contributed to a large body of stress that eventually manifested into health concerns. The body of literature has also looked at the intersection of the stress of a new principal and how a mentor can mitigate it. As Shoho and Barnett (2010) noted, new principals reported stress as the primary reason for leaving the role, and specific work with mentors on work-life balance has been explored in the work of Lochmiller (2017) and Goldring (2014) among others.

As stress and attrition of new principals are both known in the literature (Mitgang, 2007; Reichardt et al., 2008; Sana \& Wolfe, 2009; Schechter, 2014) and discussed with 
the principals in this study, participants were asked how their mentors supported them through the trying times. Consistently, the principals found their mentor as beneficial support for their emotional well-being. Several reported that their mentor was a 'saving grace' for their stress levels during their first year. They found it very helpful when a mentor told them that the stress was normal, part of the job, and that there was nothing wrong in feeling stressed during their first year. The emotional support was a critical piece of their mentoring arrangement, also supported by Ehrich's (2004) findings. Ehrich argued that effective mentoring must be centered in a continual teaching and learning process that is empathetic and supportive. Support in these terms is described as being emotionally available, understanding of the time commitment, and offering insight on how to deal with the stress of the position. It cannot be overstated how important this study's principals found this emotional support to be during their first year.

More specifically, the principals found that mentors who assisted them with time management and understanding how to structure their day, week, and month as a firstyear principal was an important piece of training. This is supported by several studies of mentoring, with Wahlstrom et al. (2010) noting that time management for a new administrator was a worthwhile area of training and Villani (2006) echoing this sentiment, specifically identifying time management as significant problem reported by novice principals. Further, Metzger (2003) found that respondents in his study reported favorable support for mentors who focused on mitigating stress with their mentees and supporting them through training in managing their day. 
Woven throughout all of this is the idea that the mentor is non-evaluative and serves as both a coach and a trusted figure to vent frustration and seek emotional support without it entering into performance evaluation. Daresh (2004) found that trust was a large part of the mentoring relationship, which is characterized by mentees' perceptions that the mentor is in no way evaluative and is an ally with whom they can have confidential conversations. This concept is explored more deeply in subsequent themes and is supported by Alsbury's (2006) analysis of various mentoring strategies, in which communication in a non-evaluative setting, with a sense of trust and honest feedback, was found to be an effective practice. The principals within this study reported that serving as a confidant to vent to and providing feedback on their stress level and frustrations was a highly effective practice of their mentors.

\section{Clarification of roles and responsibilities}

Schechter (2014) found that mentees reported the most valuable item received from mentoring was direct support, feedback, empathy for the work, and clarification of roles and responsibilities; the principals of this study supported the notion that clarification of their responsibilities and roles of district support were areas in which their mentors assisted significantly. The study's principals further elaborated that the most helpful assistance by their mentor was helping them understand what was expected of them 'right now' versus what could wait, further highlighting their need for assistance in managing their time. The idea that a new principal needed to be able to differentiate between what was necessary today, versus what was a long-term planning item, versus what could be delegated, was a key understanding from the participants. 
Mentees' lack of understanding of how to navigate large district hierarchies, roles with which they were unfamliar, and a general lack of knowledge of who to 'go-to' for certain items were areas they found their mentors supported well. Given the size of the district studied, one of the largest in America, the respondents found that having a guide to explain positions at the board level, including what they influenced and how they could aid their school, was beneficial to the mentees. Lochmiller (2017) noted this idea for a need to support navigating complicated bureaucracy. Mentor principals reported that they found the most value in working with their mentees, helping them navigate how to access support, and understand the nature of their district initiatives.

\section{Problem-based learning}

This study's principals found little value in pre-constructed, theoretical problems for their mentor to work through with them. They found that the day-to-day aspects of the role presented far more organic problems that provided better opportunities to practice analysis and problem-solving skills than hypothetical problems. Their reported experience differs somewhat from the body of literature.

Research indicates that preparation experiences connected with real-world experiential learning hold promise (Harvard et al., 2010; Perez et al., 2010) when the context is provided in a mentoring or internship format. Further, university preparation programs have shown some success with hypothetical problem-based preparation, as Honug and Donaldson (2019) noted that exemplar practices include critical program inquiry through problem-based learning. Dodson (2014), in his study of principal preparation programs, noted that $60 \%$ of principal respondents reported that field-based 
(problem-oriented) mentoring experiences better prepared them for their role (Dodson 2014). Dodson further expanded this idea to university preparation programs where $60 \%$ responded that field-based experiences provided a critical piece to their preparation.

However, the body of literature argues the opposite is more effective, tying to the principals' responses within this study. Augustine-Shaw and Funk (2013) found that mentees reported that they found the most value in on-the-job problem-solving strategies tailored specifically to real-world problems the work presented the mentee. Similar is Daresh (2001), who argues that principal mentoring must be centered in problem analysis and solving in addition to standards of principal evaluation. Problem-solving skills rise to the top of the effective practices in this study. "Mentoring relationships for administrators must be directed toward the discovery of ways to refine problem-solving" (Daresh, 2004 pg. 49). Capasso (2001) agrees that principal mentee experiences must be centered around real situations encountered on the job, guided by a professional mentor (Capasso, 2001), and that these learning experiences are what mentee respondents consistently replied were the most helpful to their development. Students reported that post-collegiate preparation program experiences with problem tasks for their new position, with guidance from existing principals, were valued as experiences for their preparation (Stevenson \& Cooner, 2011). The importance of these (real-world) experientials has been noted thoroughly as far back as 2005 when the Southern Regional Education Board (Fry et al., 2005) documented the common complaint from both fieldwork leadership students and novice principals centered around too much conceptual learning versus too little (real-world) problem based contextual learning. A specific 
curriculum of simulations is prepared for novice principals in Singapore, including how to navigate common issues, dialogues with effective administrators, and experience with real-world scenarios (Jensen \& Clark, 2013). These simulations were reported to be helpful by the participants of the study.

\section{Mentor qualities: honesty, trust, openness}

The principals found that admiration for their mentors' work, belief in their success, the ability to approach a situation from a new perspective, and systemic knowledge were all attributes they found to be helpful. Universally among the participants, the concept of an open, honest, non-evaluative mentor was a net positive in their experience. Most notably, they remarked on the importance of analyzing their work and reflecting in a non-judgmental, non-evaluative setting with someone they perceived as being honest with them. It allowed them to work on their areas of growth without the threat of their job hanging over their heads. They found the trust of this relationship to be very important.

The principals in this study placed a premium on trust with their mentor. The principals' responses were in line with the literature's findings. Hall (2008) found in his study that the mentor-mentee relationship must be non-evaluative, centered in mutual trust, and serve as a scaffold to support the mentee. This is further supported by Alsbury and Hackman (2006), who found that the belief that the relationship must be based in support, with mutual trust in a non-evaluative setting, is critical. The concept of mutual trust was studied deeper by Daresh $(2004,2006)$, who has consistently stated that the relationship between mentor and mentee must be positive, open, and honest. In Saben 
and Wolfe's study (2009), mentees reported that favorable dispositions from their mentors were open, honest, and confidential. Schechter (2014) also reported that personality characteristics of effective mentors are respect, admiration, openness, honesty, trust, and sincerity. The central theme of trust is further driven home by several other studies that reported trust as a common trait that emerges among participants (Duke et al., \& Fry et al., 2005; Lochmiller, 2017), with a clear picture that trust is a cornerstone of a successful mentoring arrangement.

It is not surprising then that the principals of this study placed such a premium on trust, with the reviewed literature being universal in its support of trust. As principals consistently report the level of stress they are under during their first and subsequent years, they find value in support of a colleague that is not their direct supervisor. This confidential relationship is important, as it allows them to work on areas of growth, vent frustrations, or posit ideas in a setting where feedback is given without evaluation.

Having the mentor be non-evaluative was a universal desire from the mentees in both this study and the body of literature. Outside of education, in the medical and business world, a critical component of mentoring is non-evaluative. Being nonevaluative allows the mentee to engage in candid conversations, increases their comfort level, and provides them with a place to run ideas by a trusted, experienced practitioner (Daresh, 2004; Goldring, 2014; Mitgang, 2007; Schechter, 2014).

In addition to trust as a core value, the respondents supported the body of literature (Goldring, 2014; Schechter, 2014) by indicating the importance of positivity, 
openness, and sincerity as mentor attributes. This study's principals' responses supported all of these positive personality traits. Sincerity manifested in the ability to have real, candid conversations about the work and openness in the mentor's ability to be available for all manner of their mentees' questions and needs.

This also appeared in discussing times when the mentees disagreed with their mentor's approach, leading to richer conversations about the pedagogical approach. The principals of this study stressed that, while disagreements with their mentors were rare, they only helped to sharpen practice for the mentee. The mentor acted as an experienced sounding board for the mentee's ideas on how to approach issues within the school, and the principals commented that, because this trust existed, they were able to disagree with them without fear of reproach, tying back to the idea that the mentor serving as a nonevaluative figure was essential. The principals of this study viewed the times they disagreed with their mentor as valuable, serving as opportunities to challenge their thinking and strengthen their knowledge base as a practitioner.

Perceived and demonstrated effectiveness of the mentor

The body of literature supports the notion that the mentor must demonstrate effectiveness and a belief in the effectiveness of their role for the mentee to feel more comfortable in the relationship. Wahlstrom et al. (2010) found that new principals consistently report that the perception of their mentor's effectiveness and relative success is an important factor, and this idea was further supported in Dukes' (2014) work highlighting mentees' appreciation of a well-regarded principal as their mentor. The 
literature has been clear that mentees see their mentor's success as a bona fide that makes their advice usable and well regarded.

This study's principals reinforced the idea that their mentor's success was an important factor in their relationship. They found that they were more ready to accept feedback and direction from a practitioner who had been successful in their field. This is an important idea in the CSI environment, where relative success is harder to find.

Stories of school turnaround are rarer than success at a traditional school, and tapping the principals of successful CSI schools overburdens already heavily worked practitioners. However, the research and perceptions of this study's principals are clear; they want to be paired with successful practitioners.

Aside from the perceptual belief that a successful practitioner is desirable, other factors that a successful mentor brings to a mentee are more tangible. Education in the CSI requires the principal to manage various initiatives to address the systemic issues of the CSI school. Coupled with this, a sound basis in pedagogy, with a premium placed on experience with multiple initiatives (Daresh, 2004), was desirable among mentors, as this translates to practical, real-world experience overseeing the variety of needs among a CSI school. A mentor who has experience juggling the variety of needs in the CSI school is helpful, as they can teach the novice principal how to do so relatively quickly within the high pressure, limited time available during a CSI school tenure. 


\section{Social position of the mentor in the district}

Mirroring the success in their role as principal, the principals within this study also placed a premium on their mentor's social position within the district. They believed that having a strong social position within the district was preferable and offered them various supports in their novice year. A strong mentor, regarded well by the district, aided them in increasing their credibility within the district, and they were offered the mentor's insight on navigating the district's hierarchy. They believed that the solutions they found to problems, aided by their mentor's advice, would add gravitas to the decision because of their mentor's social position. Universally, they found this to be a positive attribute of their mentor.

The perceptions of the principals included in this study connect well with the literature. Hean (2009) showed us that a strong, well-regarded mentor also increases the novice principal's ability to network and enmesh themselves in their district hierarchy. Saban and Wolfe (2009) concurred, reporting that the importance of socialization to district personnel that a mentor can facilitate in new leadership cannot be underestimated.

Most notably, a well-regarded mentor supporting navigation of the district bureaucracy was prioritized. In the literature, we see that this is a widely held belief among mentees. Participants in Schechter's (2014) study indicated that mentors with a strong understanding of the current district situation are critical to mentees. Duke (2014), in the only study that could be found on CSI leadership, shows that effective navigation of a district was a professional trait that mentors reported bringing to their mentees, and that this political acumen better prepared their charges to be effective school leaders. 


\section{Recommendations for Future Practice}

This study is rooted in the pragmatic framework, and, from this perspective, we look to what the participants' experiences can offer us in terms of recommendations for future practice. I believe, as evidenced by the experiences captured from the principals in this study, there exists room for ample improvement in the quality and consistency of mentoring programs for principals in CSI schools. There exists no national, state, or local model policy or program to undertake this work to support new principals.

In the context of the national level, all participants came from a state that had no national model attached to preparation. As indicated in the review of the literature, few states adopt a national model, as there are no good candidates for such. Further study and policy work are needed to design effective principal mentoring programs, especially in CSI schools, where turnover and additional pressures neccesitate high-quality staff. While there has been some effort towards national models, such as the Wallace Foundation's work, there is little study on its effectiveness; despite a push from the Federal Department of Education for such work to be included in a national recommendation of practice, there exist no candidates that have been peer reviewed or widely adopted.

In the context of the state level, all participants came from a state that had previously had a statutorily mandated principal internship component that held some mentoring characteristics. However, of the principals interviewed, only two had been in the role long enough to have completed this program before it was eliminated. Both reported that they perceived this program to be ineffective and that it did not contribute to 
their continued success or longevity. While they reported that the program itself was ineffective, mostly due to burdensome paperwork and a focus on what they perceived to be the wrong ideas, they both indicated that mentoring effectively supported their growth as a novice principal. Both noted that this effectiveness was rooted in the mentor as a person, not in the program conducted. The two participants stated that the program itself, now eliminated, was not effective in supporting their growth as novice principals. When asked to elaborate, it was found that they perceived the structured scenarios to be superfluous and unnecessary, and overly burdensome paperwork took time away from actual discussions with their mentor. What they found to be effective was the pedagogical, emotional, and positional support of the mentors. I believe that this could easily be incorporated at a state level, with a program designed around the effective traits and characteristics indicated by the participants of this study and the existing body of literature.

From the standpoint of state education policy, a program could be designed and adopted to standardize principal mentoring for novice principals, especially in the CSI school realm, with the prime emphasis of the program placed on the relationship between the mentor and mentee to the provision of ample time to work together. There is an existing structure in the state Department of Education to specifically support the work of principal mentoring in CSI environments, as the state department has a division solely dedicated to the support of CSI schools which could oversee the mentoring work.

In the local district's context, there was a vast unevenness in terms of mentoring support for the principals interviewed. This shows a clear area of improvement to better 
prepare principals during their first years in a CSI school. Given the local district's size and the amount of principal turnover in a district with over one hundred and fifty principals, there is a need for standard onboarding and support of novice principals. Additionally, as the local district has the preponderance of CSI schools for the state, with approximately $20 \%$ of schools qualifying as CSI schools for the 2019-2020 academic year, there exists a need to support CSI principals.

The local district can analyze uneven approaches to mentoring in the past to inform the design of an effective program based on the successful components and perception of experienced principals who had been a part of mentoring in past programs. Several effective components gleaned from the participants of this study are synthesized into the following recommendation, born out of the uneven approaches the district has undertaken previously.

From these discussions, some policy recommendations emerge. The focus of the mentoring sessions and the time spent between mentor and mentee must be maximized as both are practitioners and in very busy positions. The mentoring sessions' primary areas of focus are drawn from the experiences of the principals in this study. As budget remained a constant reported area of growth, and principals indicated that they had little to no training on the budget before their first year as a principal, it is reasonable to include budget preparation and training during the pre-principal phase. A district could construct principal training programs for aspiring principals that provides some precursor training within the district's budget parameters. The budget should be a standing agenda item for novice principals as indicated by the participants and supported by the literature. 
With labor relations being a consistently reported area of concern, the policy recommendation includes a call for consistent training in two areas supported by the principal's experiences in this study and the literature. The first is training in the district's specific evaluation system, with a focus on creating a workable system under which to conduct these evaluations. The second recommendation would be coaching from the mentor on how to have evaluation conversations with personnel, as this was an area of consistent need among the mentees. Finally, this is better served to come from the mentor, who is most often viewed by the mentee as a trusted colleague with whom they can have critical conversations without appearing to lose face to a superior.

Data analysis was an oft-reported area of need. Policy recommendations in this area would be that, during the mentorship, the mentor comes to the mentee prepared to focus on what data needed to be monitored closely, what data could be monitored by assistant principals or other personnel, and, most importantly, ideas and systems to monitor this data. Principals reported examples from their mentor and checklists/calendars of what to monitor and when they were helpful. The mentorship would ideally have a data monitoring protocol for the mentee to use, and the mentor and mentee would monitor the school's data together to plan for instructional improvement.

Essentially, as indicated by all the areas of discussion and the nuances in contextspecific needs of a school, important parts of the mentoring arrangement are the ability for the mentor to be called upon by the mentee often and have the mentor possessing a wealth of experience to support the mentee's decision-making process. The principals were clear in this study, and supported in the body of the literature, that the ability to 
have an experienced, trusted, on-demand font of knowledge was an essential component of the mentoring relationship.

Policy recommendations for the length of discussion with a mentor center in the idea of placing value on the mentee's time and providing on-demand support. A model program for mentoring would favor the mentor's accessibility to the mentee in an ondemand setting, preferable via electronic communications. The balance between ondemand supports versus face-to-face discussions should lean towards on-demand support while maintaining a space for face-to-face discussions for richer collaboration of ideas between the mentor and mentee.

Clear policy recommendations emerge from the principal's responses and the body of literature. Mentoring programs should include time management training, construction of daily, weekly, and monthly tasks by the mentor, and training specifically provided by the mentor about how the workflow for the new principal should look. The idea of the mentor being non-evaluative was highly valued, emotional support must also be included in the mentoring program. Mentors should likely have specific precursor training to best provide empathetic emotional support for the new principal before their mentoring assignment. Self-care checks from the mentor and discussions about stresslevel management should be included in the mentoring program.

The policy recommendation for a mentoring program is centered on the pragmatic notion that the mentor can lend their institutional knowledge to the mentee in direct discussion of the district hierarchy. This would manifest in direct training from the 
mentor to the mentee. The mentor would explain the district's various roles, their purposes, how they support a school, and who is currently occupying the roles for the district. Mentors would offer insight into how to best utilize these district-level roles and explain if there are reports or responsibilities the new principal has regarding these roles.

While the literature may be mixed, the respondents of this study were clearly in favor of time spent on real-world problems instead of previously constructed hypothetical issues to solve with their mentor. They saw it as a wise use of time, a precious commodity reported during their first year. From their experiences and the side of the literature that supports their experience, a policy recommendation emerges. Included within a mentoring relationship should be the time, space, and emphasis placed on solving real-world problems as they occur instead of hypothetical situations. The respondents of this study indicated that plenty of real-world problems crop up in the fastpaced, high stakes environment of a CSI school, and that time spent solving these problems as opposed to others was the best usage of their time and their mentor's acumen.

An effective mentoring program will, at its core, have trust and confidentiality as a hallmark of the mentor. The mentor must not be in an evaluative position over the mentee, allowing for confidential conversations that do not reflect a personnel evaluation. A premium should be placed on an open discussion, including the mentee's ability to ask any question relating to their role. When selecting mentors, the program leadership should look for qualities such as positivity, sincerity, and trustworthy nature. 
Model mentoring policies would look for a mentor who was considered successful in their role as a principal. Success would be determined through locally available metrics held important by the district and state; for CSI schools, this would include federally reportable metrics of success as these are the same across all states. This mentor would have experience with a variety of initiatives and strategies. Lastly, the mentor should more often than not come from the same grade span as the novice principal, as mentors from settings similar to the setting of the novice principal were reported to be more effective mentors than those from a dissimilar setting, such as a different grade span (Alsbury, 2006).

A model mentoring policy would look for mentors that are well regarded within the district. This can be different from being effective in their role, as political acumen does not necessarily equal effective work, and vice versa. Ideally, the mentor would have both, in that they are regarded well and are effective in their work for a model program. In selecting a mentor, this can be measured by looking at the mentor principal's connections, experience, and perception from colleagues at the same level and above. Doing so will increase the mentees' political acumen in the district.

Synthesized into clear and concise recommendations for criteria:

The mentor should:

- Be available on demand for the mentee via phone calls and electronic communication

- Provide time and space for deeper face-to-face discussions 
- Value the mentee's time

- Be non-evaluative

- $\quad$ Be respected within the district

- Be viewed as a successful practitioner

- Provide emotional support for the mentee

- Focus on solving real-world problems from the context of the school, rather than hypothetical problems with the mentee

- Have the dispositions of trust, sincerity, and openness

- Have experience working with the same grade span as the mentee

- Be "successful" in their role as a principal

- Be considered to have social clout within the district.

The mentor should support and discuss:

- School budget construction (should be a standing agenda item for novice principals)

- Coaching from the mentor on how to have evaluation conversations with personnel

- Data needed to be monitored closely by the novice principal, what data could be monitored by assistant principals or other personnel

- $\quad$ Self-care and stress management

- Explain the district's various roles, what their purpose is, how they support a school, and who is currently occupying the role for the district 
The mentor should train the mentee on:

- The district's specific evaluation system, with a focus on creating a workable system under which to conduct these evaluations

- Systems on how to monitor school data, a data monitoring protocol for the mentee

- Time management for the novice principal to help construct a daily, weekly, and monthly schedule relative to the school's workflow

- The districts overarching mission and vision, and how this intersects with their school

- The auditing process of a CSI school, how to prepare and navigate the yearly audits

Mentors could benefit from:

- Providing empathetic support for the novice principal

- An understanding they are to serve as an on-demand resource

- A district created 'key learning' or knowledge that the institution wishes the mentor to cover, but the freedom to do so in a tailored manner to the mentee

These recommendations can be utilized by a district, or policy making board in the construction of a model mentoring program. The recommendations cover the gamut of K-12 education, and are not level dependent, and can be utilized in any given school setting, CSI or not. For CSI specific schools, attention must be placed on the auditing process, and mitigation of stress for the mentee principal. 


\section{Recommendations for Future Research}

The literature review indicated gaps in the research regarding executive-level school-based mentorship, where often there are inconsistent programs that are cut quickly due to budgetary constraints. This inconsistency is echoed by the lived experiences of the participants of this study. There exists a need for further research regarding principal mentorships, especially in the high stakes, CSI environment.

Foremost, researchers, local school districts, and state education agencies can conduct research on the effectiveness of programs during their usage and after they have ceased. Often, I encountered within the literature review a mentoring program running in a district or state for a few years before it was cut, and there was no study of its effectiveness. Time must be spent in the field analyzing mentoring programs to assess their effectiveness, and in doing so the body of literature will grow robustly. Specific examples in the local district included in this study showed no less than three different programs that were implemented and subsequently cut, but the district conducted no analysis of their impact.

Further studies could continue to examine the effectiveness of principal mentoring in CSI schools, both from the quantitative and qualitative lens. From the qualitative perspective, more participants' experiences can be studied in-depth, across various states, and their differing approaches to CSI school work. The CSI label is federally applied; consequently studies could be conducted in various states and districts, with the similarity of the CSI label being the basic criterion to look at their mentoring programs. As principal attrition in CSI schools continues to be a national trend, mitigating this is a 
national need. As this is a federally applied label across all fifty states, there should be a wealth of data to analyze. Further, case studies can be conducted with successful or unsuccessful mentoring relationships among CSI principals. There is a wealth of understanding to be gleaned from CSI principals and how mentoring intersects with their effectiveness, longevity, and desire to stay in the field.

From the quantitative perspective, larger data sets could be constructed and studied at the state and national level for mentoring effectiveness. This includes specific attention to work that crosses state lines, such as the Wallace Foundation work. The Wallace Foundation has partnered with many districts in the United States, but there is a lack of research on the effectiveness of these partnerships. Further, states that have adopted and abandoned mentoring programs could go back and analyze data generated from these programs to see what was effective. Paired with a depth of qualitative insight, further study can clearly illustrate effective school principal mentoring in CSI environments.

Lastly, within the quantitative lens, there could be study on the attrition of CSI versus non-CSI principals, filtered further by those who have been mentored versus those who have not. A comparison of national trend data among CSI principals who have been mentored and those who have not, including retention rate and years of service versus the same among non CSI principals could yield interesting results in terms of constructing model policy for principal mentoring. 
This study illustrated a few areas of more nuanced study from the qualitative lens. Chief among these is a further study into the desirable qualities of a mentor and how a local institution could select, identify, and assign mentors. This area was discussed mostly in the realm of trust, admiration for their work, and the mentor's social position. Specific to the research yielded in this study, more research can be conducted on how mentors are paired with mentees. It was found that mentors were consistently selected for participants by their effectiveness in their role rather than their personality traits or perceived fit with their mentees. Research on the selection of mentors, what criteria are used, and how they are paired with mentors could yield more effective practice.

Secondly, this study showed that on-demand communication was more preferred than traditional face-to-face sessions, though participants appreciated face-to-face meetings as well. Specific research and time analysis during mentorships could yield more effective practice for distributing the time between mentor and mentee.

Further qualitative analysis of principals' experiences with mentoring in the CSI realm remains an avenue of study. This study illustrated the experience of eight principals. More research can be conducted with a wider range of principals, across different states, while remaining within the CSI label. From a broader body of lived experience, the recommendations from this study can be supported or modified in light of a larger body of analyzed experience. There is a large area for further study, teasing out the lived experiences of principals who have been mentored and what specific traits they found to be most effective in their mentors. 
The pragmatic framework can be further developed. At its heart, the pragmatic framework seeks to make recommendations of policy and practice that can be utilized in the field of study. This framework is loose, by design, to allow researchers to tackle a problem with the end goal of recommending practical solutions. However, this framework can be further developed through the body of research with hallmarks of successful policy and practice building. The more research conducted within this framework, the larger the body of literature grows, and the more effective this framework will be in practice.

\section{Closing}

The problem of administrator attrition in our most needy schools persists. It is known that an effective principal is highly influential in increasing student achievement, mitigating teacher turnover, and sustaining improvement in a school. The retention of effective principals is of high concern to school districts, and employing strategies to increase the retention of trained, effective school leaders is a desirable outcome. This study examined Comprehensive Improvement Schools (CSI) principals' experiences with mentoring programs and their perceptions of how such programs might mitigate administrative attrition. We learned, through the lens of their experience, what shaped and influenced them in their mentoring programs. From this, we can take practical recommendations into forming effective mentorships to increase the retention of principals in CSI schools.

We heard from them that trust, with a non-evaluative relationship with their mentor was of the utmost importance. We learned that ample time for on- demand 
support was the best delivery method. They said our mentors should be well respected, successful, able to provide emotional support, and should come from the same grade span. That their time together should be spent on real world problems, taken directly from the context of their school. Budget construction and labor relations would be a large focus of a successful mentoring relationship, with a healthy amount of time spent on navigating the complexities of the district and their personnel.

The literature showed that much of this is known in the study of mentoring, but that often states, and local districts shelve their mentoring programs at the first signs of budget stress. We can do better, and leverage existing successful personnel to assist in the transmission of institutional knowledge and success to the next generation of leaders. We can assure our districts and states do better with these programs by further studying their effectiveness, especially before a program is shuttered. As we build the body of knowledge showing successful programs, it will decrease the likelihood that they are closed when budgets become tight. There is much promise in consistent mentoring programs as a strategy to retain effective school leaders. 


\section{REFERENCES}

Alliance for Excellent Education (2005). Teacher attrition: A costly loss to the nation and to the states. https://mk0all4edorgjxiy8xf9.kinstacdn.com/wpcontent/uploads/2007/06/TeacherAttrition.pdf

Alsbur, T. L., \& Hackman, D. G. (2006). Learing from experience: Initial findings of a mentoring/induction program for novice principals and superintendents. Planning and Changing, 37(3), 169-189.

Augustine-Shaw, D., \& Funk, E. (2013). The influence of mentoring on developing leaders: Participants share their perspectives. Educational Considerations, 41(1), $19-26$.

Barnes, G., Crowe, E., \& Schaefer, B. (2007). The costs of turnover in five districts: A pilot study. Washington, DC: National Commission on Teaching and America's Future.

Blackwell, D. H., \& Young, T. (2016). Understanding the relationship between urbancentric locale and teachers' perceptions of school leadership as a working wondition. Journal of Educational Administration, 2(11), 54-69.

Billingsley, B. S. (2004). Promoting teacher quality and retention in special education. Journal of Learning Disabilities,37(5), 370-376.

Boyd, D., Grossman, P., Ing, M., Lankford, H., Loeb, S., \& Wyckoff, J. (2011). The 
influence of school administrators on teacher retention decisions. American Educational Research Journal,48(2), 303-333.

Brill, S., \& McCartney, A. (2008). Stopping the revolving door: increasing teacher retention. Politics \& Policy,36(5), 750-774. doi:10.1111/j.17471346.2008.00133.x

Briggs, K., Cheney, G., Davis, J., \& Moll, K. (2013). Operating in the dark: What outdated state policies and data gaps mean for effective school leadership. George W. Bush Institute.

Brown S. (2003). Working models: Why mentoring programs may be the key to teacher retention. Techniques: Connecting Education and Careers 78(5), 18-21.

Bryk, A. S.; \& Schneider, B. (2002). Trust in schools: A core resource for improvement. Russell Sage Foundation.

Bryk, A. S., Sebring, P. B., Allensworth, E., Luppescu, S., \& Easton, J. Q. (2010). Organizing schools for improvement: Lessons from Chicago. University of Chicago Press.

Buchanan, J., Prescott, S., Schuck, P., Aubusson, P., Burke, J., \& Louviere, J. (2013). Teacher retention and attrition: Views of early career teachers. Australian Journal of Teacher Education, 38(3), 112-129. doi:10.14221/ajte.2013v38n3.9

Burke, P. F., Schuck, S., Aubusson, P., Buchanan, J., Louviere, J. J., \& Prescott, A. (2013). Why do early career teachers choose to remain in the profession? The use of best-worst scaling to quantify key factors. International Journal of Educational Research, 62, 259-268. 
Bush, T. (2018). Preparation and induction for school principals: Global perspectives. Management in Education, 32(2), 66-71.

Capasso, R. L. \& Daresh, J. C. (2001). The school administrator internship handbook: Leading, mentoring, and participating in the internship program, Corwin Press.

Clayton, J. K., Sanzo, K. L., \& Myran, S. (2013). Understanding mentoring in leadership development perspectives of district administrators and aspiring leaders. Journal of Research on Leadership Education, 8(1), 77-96.

Clifford, M., Hansen, U., Lemke, M., Wraight, S., Menon, R., Brown-Sims, M., et al. (2011). A practical guide to designing comprehensive principal evaluation systems. Washington, DC: The National Comprehensive Center for Teacher Quality.

Corcoran, S. P., Schwartz, A. E., \& Weinstein, M. (2012). Training your own: The impact of New York City's aspiring principals program on student achievement. Educational Evaluation and Policy Analysis, 34(2), 232-253.

Cosner, S., Tozer, S., Zavitkovsky, P., \& Whalen, S. (2015). Cultivating exemplary school leadership preparation at a research intensive university. Journal of Research on Leadership Education, 10(1), 11-38.

Creswell, J. (2010). Mapping the developing landscape of mixed methods research. In A. Tashakkori, and C. Teddlie, (Eds) (pp 45-68). Sage handbook of mixed methods in social \& behavioral research.

Crisp, G., \& Cruz, I. (2009). Mentoring college students: A critical review of the literature between 1990 and 2007. Research in Higher Education, 50(6), 525-545. 
Curran, B., \& Goldrick, L. (2002). Mentoring and supporting new teachers. National Governors’ Association.

Curran, F. C., Viano, S. L., \& Fisher, B. W. (2019). Teacher victimization, turnover, and contextual factors promoting resilience. Journal of School Violence, 18(1), 21-38.

David, T. (2003). Beginning teacher mentoring programs: The principal's role. In J.

Rhoton \& P. Bowers (Eds.), Science teacher retention: Mentoring and renewal (pp. 145154). National Science Teachers Association.

Daresh, J. \& Playko, M. A. (1992). Perceived benefits of a Preservice Administrative Mentoring Program. Journal of Personnel Evaluation in Education, 6, 15-22.

Daresh, J., \& Playko, M. A. (1993). Mentoring programs for Aspiring Administrators: An analysis of benefits to mentors. ERS Spectrum, 11(3), 12-16. Daresh, J. (2001). Mentoring for effective school administration. Urban Education, 25(1), 43-54.

Daresh, J. (2004). Mentoring school leaders: Professional promise or predictable problems? Educational Administration Quarterly, 40(4), 495-517.

Darling-Hammond, L., LaPointe, M., Meyerson, D., \& Orr, M. (2009). Preparing principals for a changing world: Lessons from effective school leadership programs. Wiley.

DeHann, E., \& Burger, Y. (2005). Coaching with colleagues. Palgrave, McMillan.

Dodson, R. (2014). Which field experiences best prepare future school leaders? An 
analysis of Kentucky's principal preparation programs. Educational Research Quarterly, 37(4), 41-56.

Donmoyer, R., Yennie-Donmoyer, J., \& Galloway, F. (2012). The search for connection across principal preparation, principal performance, and student achievement in an exemplary principal preparation program. Journal of Research on Leadership Education, 7(1), 5-43.

Duke, D. L., Tucker, P. D., Salmonowicz, M. J. and Levy, M. K. (2007). How comparable are the perceived challenges facing principals of low-performing schools?, International Studies in Educational Administration, 35(1), 3-21.

Duke, D. L. (2014). A bold approach to developing leaders for low-performing schools. Management in Education, (3), 80-85.

Ehrich, L. C., Handford, B., \& Tennet, L. (2004). Formal mentoring programs in education and other professions: A review of the literature. Educational Administration Quarterly, 40(4), 518-540.

Frels, R. K., Reichwein Zientek, L., \& Onwuebuzie, A. J. (2013). Differences of mentoring experiences across grade span among principals, mentors, and mentees. Mentoring \& Tutoring: Partnership in Learning, 21(1), 28-58.

Fry, B., Bottoms, G. \& O’Neill, K. (2005), The Principal Internship: How can we get it Right? Southern Regional Education Board.

Fullan, M. (2006). Turnaround leadership. Jossey Bass.

Fullan, M., Hill, P., \& Crevola, C. (2006). Breakthrough. Corwin Press.

Gay, B. (1994). What Is Mentoring? Education + Training, 36(5), 4-7. 
Geertz, C. (1973). The interpretation of cultures. Basic Books.

Gimbel, P., \& Kefor, K. (2018). Perceptions of a principal mentoring initiative. Nassp Bulletin, 102(1), 22-37.

Goldring, R. (2014). Principal attrition and mobility: Results from the 2012-2013 principal follow-up survey. Urban Education, 21(1), 18-29.

Gray, L., \& Taie, S. (2015). Public school teacher attrition and mobility in the first five years: Results from the first through fifth waves of the 2007-08 beginning teacher longitudinal study. First Look. NCES 2015-337. National Center for Education Statistics.

Grissom, J. A. (2011). Can good principals keep teachers in disadvantaged schools? Linking principal effectiveness to teacher satisfaction and turnover in hard-tostaff environments. Teachers College Record, 113(11), 2552-2585.

Grissom, J. A., Viano, S. L., \& Selin, J. L. (2015). Understanding employee turnover in the public sector: Insights from research on teacher mobility. Public Administration Review,76(2), 241-251. doi:10.1111/puar.12435

Grissom, J., Mitani, H., \& Woo, D. (2019). Principal preparation programs and principal outcomes. Educational Administration Quarterly, 55(1), 73-115.

Greene, J. \& Caracelli, V. (2003). Making paradigmatic sense of mixed methods Inquiry. A. Tashakkori, \& C. Teddlie (Eds.), Handbook of Mixed Methods in Social \& Behavioral Research, Sage.

Greene, J., \& Hall, J. (2010.) Dialectics and pragmatism: Being of consequence. In A. 
Tashakkori, and C. Teddlie, (Eds) Sage Handbook of mixed methods in social \& behavioral research, Sage.

Hall, P. (2008). Building bridges: Strengthening the principal induction process through intentional mentoring. Phi Delta Kappan, 89(6), 449-452.

Halverson, R. (2007). How leaders use artifacts to structure professional community in schools. In L. Stoll \& K. S. Louis (Eds.), Professional learning communities: Divergence, depths and dilemmas. Open University Press.

Hammarberg, K., Kirkman, M., \& de Lacey, S. (2016). Qualitative research methods: When to use them and how to judge them; Human Reproduction, 31(3), 498-501.

Hanushek, E. A., Kain, J. F. \& Rivkin, S. G. (1999). Do higher salaries buy better teachers? Working paper No. 7082. National Bureau of Economic Research.

Harrell, P. E., Thompson, R., \& Brooks, K. (2019). Leaving schools behind: The impact of school student body and working conditions on teacher retention and migration. Journal of Science Teacher Education, 30(2), 144-158.

Havard, T. S., Morgan, J. and Patrick, L. (2010). Providing authentic leadership opportunities through collaboratively developed internships: A university-school district partnership initiative. Journal of Research on Leadership Education, 5, (12), 460-480.

Hauge, T., Norenes, S., \& Vedøy, G. (2014). School leadership and educational change: Tools and practices in shared school leadership development. Journal of Educational Change, 15(4), 357-376.

Haynes, M. (2014). On the path to equity: Improving the effectiveness of beginning 
teachers. Alliance for Excellent Teacher Education.

Hean, L. L. (2009). Highlights of educational research on leadership mentoring: One and a half decades of Singapore experience. International Journal of Evidence Based Coaching and Mentoring, 7(1), 162-171.

Helber, J. (2015). Self-efficacy and instructional leadership: Does mentoring make a difference? [Doctoral Dissertation, Eastern Michigan University], (Accession No. 20443923959). Retried from MLA international Bibliography Database.

Hollingsworth, L. (2016). The impact of personal and program characteristics on the placement of school leadership preparation program graduates in school leader positions. Educational Administration Quarterly, 52(4), 643-674.

Honig, M., \& Donaldson, E. (2019). Learning to lead the learning of leaders: The evolution of the University of Washington's Education Doctorate (Ed.D.). Journal of Research on Leadership Education, 14(1), 51-73.

Hughes, G. D. (2012). Teacher retention: teacher characteristics, school characteristics, organizational characteristics, and teacher efficacy. The Journal of Educational Research, 105(4), 245-55. doi: 10.1080/0220671.2011.584922

Ingersoll, R. M. (2001). Teacher turnover and teacher shortages: An organizational analysis. American Educational Research Journal, 38(3), 499-534.

Ingersoll, R. M., \& Strong, M. (2011). The impact of induction and mentoring programs for beginning teachers: A critical review of the research. Review of educational research, 81(2), 201-233.

Jayapragas, P. (2016). Leaders in education program: The Singapore model for 
developing effective principal-ship capability. Current Issues in Comparative Education, 19(1), 92-108.

Jefferson County Public Schools Data Book 2017-18.

https://jefferson.kyschools.us/sites/default/files/jcpsdbk30.pdf (2019, February $01)$.

Jensen, B., \& Clark, A. (2013). Confident school leadership: An east Asian perspective. National College for Teaching \& Leadership.

Jones, A. (2014, August 5). Coaching v mentoring: What works best for teachers? The Guardian. https://www.theguardian.com/teacher-network/teacherblog/2014/aug/05/ coaching-mentoring-teachers-professional-development

Jones, M. K., \& Larwin, K. H. (2015). Does mentoring make a difference? An investigation of a mentoring program's impact on first year building principal's practices and self efficacy.

Kentucky Educational Professional Standards Board. (2009). http://www.epsb.ky.gov/ teacherprep/prinredesignguidelines.asp

Kram, K. E. (1985). Mentoring at work: Developmental relationships in organizational life. Scott, Foresman.

Lear, J. (2003). Therapeutic action: An earnest plea for irony. Other Press.

Lochmiller, C. (2017). Preparing turnaround leaders for high needs urban schools. Journal of Educational Administration, 55(1), 85-102.

Manna, P. (2015). Developing excellent school principals to advance teaching and learning: Considerations for state policy. The Wallace Foundation. 
Marinell, W. H., \& Coca, V. M. (2013). Who stays and who leaves? Findings from a three-part study of teacher turnover in NYC middle schools. The Research Alliance for New York City Schools, New York University

Martinez, I. L., Frick, K. D., S. Kim, K. S., \& Fried, L. P., (2010.) Older adults and retired teachers address teacher retention in urban schools. Educational Gerontology, 36(4), 263-280.

Merchant, B., \& Garza, E. (2015). The urban school leaders collaborative: Twelve years of promoting leadership for social justice. Journal of Research on Leadership Education, 10(1), 39-62.

Metzger, C. (2003). Self/inner development of educational administrators: A national study of urban school district superintendents and college deans. Urban Education, 38(6), 655- 687.

Minarik M., Thornton B., \& Perreault, G. (2003.) Systems thinking can improve teacher Retention. The Clearing House, 76(5), 230-234.

Mitgang, L. D. (2007). Getting principal mentoring right: Lessons from the field. The Wallace Foundation.

Murphy, J. (2005). Connecting teacher leadership and school improvement. Corwin Press.

Murphy, J., \& Meyers, C.V. (2008.) Turning around failing schools: leadership lessons from the organizational sciences. Corwin Press.

Muse, I., Thomas G., \& Wasden, F. D. (1992.) Potential problems and solutions of 
mentoring in the preparation of school administrators. Journal of School Leadership, 2(3) 310-319.

Nakamura, J., Shernoff, D. J. \& Hooker, C. H. (2009). Good mentoring: Fostering excellent practice in higher education. Jossey-Bass.

National Association of Secondary School Principals. (2014). Coalition draws up roadmap for profession-ready teachers and principals. NewsLeader, 62(3), 1-6.

Neubauer, B. E., Witkop, C. T., \& Varpio, L. (2019). How phenomenology can help us learn from the experiences of others. Perspectives on Medical Education, 8(2), 90-97.

Office of Management and Budget (2000. Standards for Defining Metropolitan and Micropolitan Statistical Areas; Notice. https://www.govinfo.gov/content/pkg/FR-2000-12-27/pdf/00-32997.pdf

Perrone, F., \& Tucker, P. (2019). Shifting profile of leadership preparation programs in the 21st century. Educational Administration Quarterly, 55(2), 253-295.

Peters-Hawkins, A., Reed, L., \& Kingsberry, F. (2018). Dynamic leadership succession: Strengthening urban principal succession planning. Urban Education, 53(1), 2654.

Price, H. E., \& Collett, J. L. (2012). The role of exchange and emotion on commitment: A study of teachers. Social Science Research, 41(6), 1469-1479.

Reichardt, R., Snow, R., Schlang, J., \& Hupfeld, K. (2008). Overwhelmed and out: Principals, district policy, and teacher retention. Connecticut Center for School Change. 
Ronfeldt, M., Loeb, S., \& Wyckoff, J. (2013). How teacher turnover harms student achievement. American Educational Research Journal, 50(1), 4-36.

Saban, J., \& Wolfe, S. (2009). Mentoring principals around leadership practices. Catalyst for Change, 36(1), 1-6.

Sackney, L., \& Walker, K. (2006.) Perspectives on beginning principals: Their role in building capacity for learning communities. Journal of Educational Administration, 44(4): 341-358.

Schechter, C. (2014). Mentoring prospective principals: Determinants of productive mentor-mentee relationship. International Journal of Educational Reform, 23(1), $52-65$.

Shah, A. (2017). What is mentoring? The American Statistician, 71(1), 1-2.

Shoho, A. R., \& Barnett, B. G. (2010). The realities of new principals: Challenges, joys, and sorrows. Journal of School Leadership, 20(5), 561-596.

Stockard, J., \& Lehman, M. B. (2004). Influences on the satisfaction and retention of 1st-year teachers: The importance of effective school management. Educational Administration Quarterly, 40(5), 742-771.

Shepherd, D., \& Devers C. (2017). Principal perceptions of new teacher effectiveness. Educational Administration Quarterly, 97(2), 37-47.

Smethem, L. (2007.) Retention and intention in teaching careers: Will the new generation stay? Teachers and Teaching, 13(5), 465-480.

Stanulis, R. N., Wexler, L. J., Pylman, S., Guenther, A., Farver, S., Ward, A., \& White, 
K. (2018). Mentoring as more than "cheerleading": Looking at educative mentoring practices through mentors' eyes. Journal of teacher education, 14(3), 321-342.

Stevenson, C., \& Cooner, D. (2011.) Mapping the journey toward the principalship: Using standards as a guide. Planning and Changing, 42(3-4), 288-301.

Sutcher, L., Darling-Hammond, L., \& Carver-Thomas, D. (2016, September 15). A coming crisis in teaching? Teacher supply, demand, and shortages in the U.S.

Learning Policy Institute. https://learningpolicyinstitute.org/product/coming-crisisteaching"

Tashakkori, A., \& Teddlie, C. (2010.) Sage Handbook of Mixed Methods in Social \& Behavioral Research. Sage Publications.

Thibodeaux, A. K., Labat, M. B., Lee, D. E., \& Labat, C. A. (2015). The effects of leadership and high-stakes testing on teacher retention. Academy of Educational Leadership Journal, 19(1), 227-249.

Versland, T. M. (2013). Principal efficacy: Implications for rural "grow your own" leadership programs. Rural Educator, 35(1), 1-10.

Villani, S. (2006). Mentoring and induction programs that support new principals. Thousand Oaks, CA: Corwin.

Wahlstrom, K., Seashore-Louis, K. Leithwood, K., \& Anderson, S. (2010). Learning from leadership: Investigating the links to improved student learning. Center for Applied Research and Educational Improvement, The Wallace Foundation.

Waters, T., Marzano, R. J. \& McNulty, B. (2003). Balanced leadership: What 30 
years of research tells us about the effect of leadership on student achievement. Aurora, CO: Mid-continent Research for Education and Learning.

Wynn, S. R., Carboni, L. W., \& Patall, E. A. (2007.) Beginning teachers' perceptions of mentoring, climate, and leadership: Promoting retention through a learning communities perspective. Leadership and Policy in Schools, 6(3), 209229.

Young, M., Eddy-Spicer, D., \& Cosner, S. (2019). What makes a leadership preparation program exemplary? Journal of Research on Leadership Education, 14(1), 98115.

Yusko, B., \& Feimen-Nemser, S. (2008). Embracing contraries: Combining assistance and assessment in new teacher induction. Teachers College Record, 110(5), 923953.

Zhang, G., \& Zeller, N. (2016). A longitudinal investigation of the relationship between teacher preparation and teacher retention. Teacher Education Quarterly, 43(2), 73-92.Appendices A: 


\section{Appendices A:}

\section{Participant Survey Questions}

1. Tell me about why you are an educator, and why you sought to be a principal?

2. As a novice principal, how were you assigned a mentor? Was there any specific criteria used to assign your mentor?

3. In your mentorship did you use a specific framework, guiding document, program, or direction for the relationship? If so, what was it, and was it implemented loosely or with fidelity?

4. How often did you work with your mentor, both formally or informally? Where was the work conducted? Face to face, over electronic communications? How did this time serve your needs?

5. What professional traits, and personality attributes did you find effective, or ineffective in your mentor? Did your mentor have previous CSI principal experience?

6. What were the topics you and your mentor discussed? Was there a preponderance of management, instructional, personnel, or other areas in your discussions? How much of the discussion was mentor led, and how much was items that you brought to discuss? How did these topics specifically prepare you to be a CSI principal?

7. Did you discuss or work through hypothetical problems, or scenarios designed to better you for your role? Did you discuss CSI specific issues, or scenarios? 
8. Will you describe your discussions about personnel management, labor relations, and evaluation of personnel? How did your mentor's guidance shape the way you approach personnel?

9. Will you discuss a time when you and your mentor disagreed on an approach? Were their instances where you had healthy debate about pedagogy, or leadership approach?

10. How did your mentoring experience contribute to your preparation as a novice principal, and did it influence your likelihood to remain in your role? 


\title{
Appendices B:
}

\author{
Informed Consent Document
}

\section{INFORMED CONSENT}

\author{
TITLE OF RESEARCH STUDY \\ PRINCIPAL MENTORING AS A RETENTION AND EFFECTIVENESS STRATEGY \\ IN COMPREHENSIVE IMPROVEMENT SCHOOLS
}

Introduction and Background Information

You (referred to as you in the rest of this document) are invited to take part in a research study because you have been identified as a current or former Comprehensive Support and Improvement (CSI) principal in the Jefferson County Kentucky school district. The study is being conducted under the direction of Dr. Brydon-Miller at the University of Louisville. About 15 local subjects will be invited to take part in this research. The total number of subjects across all sites will be 8 .

Purpose

The purpose of this study is to examine Comprehensive Improvement Schools (CSI) principals' experiences with mentoring programs and their perceptions of how such programs may mitigate administrative attrition. The lived experiences of the principals will be further analyzed for themes to increase understanding of what works and what does not work in administrative mentoring programs. This analysis will render a broader understanding of principal mentoring and how it can increase the effectiveness of novice principals and aid in their retention.

\section{Procedures}

Your participation in this study will last for one interview session, approximately one hour in length. During this interview you will be asked approximately 7 questions about your experience with principal mentoring. If any of the questions make you uncomfortable, you may choose not to answer. The interview will be recorded, and later 
transcribed. You, and your school will be given a pseudonym in the analysis of the study. The key to the pseudonym will be stored on an encrypted hard drive, accessible only by the research team, and institutional review board. The data generated will be deleted from the hard drive within five years. There will be a follow-up email with a transcript of your interview that you may review for accuracy, or request that it be struck from the record. If you consent to participate, you will have the following procedures while you are in this study. Your data will not be stored and shared for future research even if identifiable private information, such as your name and medical record number, are removed.

\section{Potential Risks}

The risks to human subjects associated with this study are minimal. There are no foreseeable risks other than possible discomfort in answering personal questions, or a potential report of a breach of ethics of a mentor. If such is reported, the investigator shall inform the proper authorities of the nature of the complaint. There may also be unforeseen risks. All participants are over the age of majority, do not demonstrate any impaired capacity, and meet the criteria of professionals outlined above. Further protections for their anonymity will be provided via pseudonyms and created school names. Participants will be given copy of their transcripts for approval before included in analysis of the study. No identifying information of the participants will be shared, as each participant will be given a pseudonym name and school, with the master copy secured on an encrypted hard drive. Study materials and transcripts will be retained on an encrypted hard drive, accessible by the research committee. All materials of the interviews, and the master interview list will be erased from the encrypted hard drive within five years' time from completion of the study, following final approval by the research committee.

\section{Benefits}

The possible benefits of this study include an increased understanding of principal mentoring as a retention strategy for novice principals, through better informed and crafted district policy. You may not benefit personally by participating in this study. The information collected may not benefit you directly; however, the information may be helpful to others.

\section{Alternatives}

Instead of taking part in this study, you could choose to not participate in the study. 


\section{Payment}

You will not be paid for your time, inconvenience, or expenses while you are in this study.

\section{Confidentiality}

Total privacy cannot be guaranteed. We will protect your privacy to the extent permitted by law. If the results from this study are published, your name will not be made public. Once your information leaves our institution, we cannot promise that others will keep it private.

Your information may be shared with the following:

The sponsor and others hired by the sponsor to oversee the research

Organizations that provide funding at any time for the conduct of the research.

The University of Louisville Institutional Review Board, Human Subjects Protection

Program Office, Privacy Office, others involved in research administration and research and legal compliance at the University, and others contracted by the University for ensuring human subjects safety or research and legal compliance

The local research team

Researchers at other sites participating in the study

People who are responsible for research, compliance and HIPAA/privacy oversight at the institutions where the research is conducted

People responsible for billing, sending and receiving payments related to your participation in the study

Applicable government agencies, such as:

Office for Human Research Protections

Others: JCPS Data and Research department.

Security 
The data collected about you will be kept private and secure by an encrypted, password protected computer.

\section{Voluntary Participation}

Taking part in this study is completely voluntary. You may choose not to take part at all. If you decide not to be in this study, you won't be penalized or lose any benefits for which you qualify. If you decide to be in this study, you may change your mind and stop taking part at any time. If you decide to stop taking part, you won't be penalized or lose any benefits for which you qualify. You will be told about any new information learned during the study that could affect your decision to continue in the study.

\section{Research Subject's Rights}

If you have any questions about your rights as a research subject, you may call the Human Subjects Protection Program Office at (502) 852-5188. You may discuss any questions about your rights as a research subject, in private, with a member of the Institutional Review Board (IRB). You may also call this number if you have other questions about the research, and you cannot reach the study doctor, or want to talk to someone else. The IRB is an independent committee made up of people from the University community, staff of the institutions, as well as people from the community not connected with these institutions. The IRB has approved the participation of human subjects in this research study.

\section{Questions, Concerns and Complaints}

If you have any questions about the research study, please contact Dr. Mary BrydonMiller 502-852-6411.

If you have concerns or complaints about the research or research staff and you do not wish to give your name, you may call the toll free number 1-877-852-1167. This is a 24 hour hot line answered by people who do not work at the University of Louisville.

\section{Acknowledgment and Signatures}

This document tells you what will happen during the study if you choose to take part. Your signature and date indicates that this study has been explained to you, that your 
questions have been answered, and that you agree to take part in the study. You are not giving up any legal rights to which you are entitled by signing this informed consent document though you are providing your authorization as outlined in this informed consent document. You will be given a copy of this consent form to keep for your records.

Printed Name of Legally

Authorized Representative (if applicable)
Signature of Legally

Date Signed

Authorized Representative

Authority of Legally Authorized Representative to act on behalf of Subject*

*Authority to act on behalf of another includes, but is not limited to parent, guardian, or durable power of attorney for health care.

\begin{tabular}{lccc}
\hline Printed Name of Person & Explaining Consent Form & Signature of Person Explaining & Date Signed \\
Consent Form (if other than the Investigator)
\end{tabular}




\section{CURRICULUM VITAE}

NAME: $\quad$ Robert Stephen Fulk

DOB: $\quad$ Louisville, Kentucky - July 24, 1980

EDUCATION \& TRAINING:

B.A., English

University of Louisville

M.Ed., Special Education

University of Louisville

Ed.S, Educational Administration

University of Louisville

Ed.D Education Leadership

University of Louisville

AWARDS:

Jefferson County Public Schools, Principal of the Year 2018

City of Louisville, Metro Council Citation for Excellence 2018

Kentucky Department of Education Best Practice Award 2018, 2019

Hilliard Lyons Excellence in Education, 2017

Pyramid Award, 2007, 2009

\section{PROFESSIONAL SOCIETIES:}

Kentucky Association of School Administrators (KASA)

Jefferson County Association of School Administrators (JCASA)

\section{PROFESSIONAL COMMITEES:}

NTI 2.0 Grading Committee (JCPS) 2020-present

AIS Principal Racial Equity Committee, Chair (JCPS) 2020-present

Principal Mentor (JCPS) 2018- current

Behavior Support Alternative School Task Force (JCPS) 2018- current

ECE Corrective Action Plan Principal Committee (JCPS) 2019-current

Principal Pipeline Advisory (JCPS)- 2018- current

District Substitute Teacher Task force (JCPS) 2017-current 
HS principals elected representative JCASA (JCPS) 2017- 2018

District Finance Advisory Committee (JCPS) 2017- current

Principal Communication Committee elected representative, area 3 (JCPS) 2017-2019

Committee for Certified Evaluation Plan (Bullitt) 2013-2016

Committee to restructure Alternative School program (Bullitt) 2011-12

Committee to design Discovery School (magnet) program (Bullitt) 2012-14

Pilot Principal, PGES Framework for KDE Year 1 and 2 (Bullitt) 2012-2013

District CDIP Committee Member (Bullitt) 2014

District Discipline Committee Member (Bullitt) 2013

District CIITS Administration Committee (Bullitt) 2012

State Certified SBDM Trainer 2013-2016

KASA Legislative Committee Member 2016-2018

\section{PROFESSIONAL PRESENTATIONS:}

JCPS Equity Summit 2018, 2019, 2020

High Tech High Deeper Learning Conference, San Diego (2 presentations) 2018

KASA Leadership Institute 2018

KYTalk KEA Conference 2018

JCPS Deeper Learning Symposium 2017, 2018

\#KyGoDigital Episode Digital Tools to Unite and Build Your School Culture 2018

\#KyGoDigital Northern KY Regional Conference

Google Derby City Summit 2018

UkNextgen 2018

LEAD Louisville 2017, 2018

\section{ADJUNCT WORK BELLARMINE UNIVERSITY:}

EDAD 707: Statistics \& Data Analysis for School Administrators

EDAD 710: Leading and Administering the Secondary School

EDAD 703: Human Resource Management 